\author{
Universidade de São Paulo \\ Instituto de Física
}

\title{
Potencial de Aplicação de Sílica Mesoporosa Ordenada em transporte, proteção e liberação de fármacos
}

\author{
Francisco Mariano Neto \\ Orientadora: Prof. ${ }^{a}$ Dr. ${ }^{\text {a }}$ Márcia Carvalho de Abreu Fantini \\ Co-orientador: Prof. Dr. Cristiano Luís Pinto Oliveira
}

São Paulo

2013 


\section{Resumo}

Este trabalho consistiu em uma investigação sobre a utilização da sílica mesoporosa ordenada tipo SBA-15 como veículo para a incorporação, proteção, transporte e liberação de substâncias biológicas de interesse imunológico e/ou terapêutico.

As técnicas principais utilizadas para a caracterização desses sistemas foram o espalhamento de raios $\mathrm{X}$ a baixo ângulo e isotermas de adsorção de nitrogênio, ambas discutidas em detalhe no capítulo 2. Um modelo teórico para ajuste aos dados de raios X é apresentado no capítulo 3. Os métodos experimentais, as técnicas de preparação de amostras e os procedimentos experimentais são descritos no capítulo 4.

O estudo preliminar da incorporação e do encapsulamento, por absorção e por pressão, de moléculas biológicas na matriz porosa da SBA-15 está reportado no capítulo ??.

Estudos in-situ de incorporação e liberação de moléculas foram executados e analisados através do modelo, de forma a verificar a utilidade da sílica SBA-15 para o transporte e a proteção de moléculas. Os resultados desses estudos estão apresentados no capítulo 5. 


\section{Abstract}

This work consisted of an investigation on the use of SBA-15-type ordered mesoporous silica as a vehicle for incorporation, protection, transport and release of biological substances for immunologic and/or terapeutic processes.

The main techniques used for characterization of these systems were small angle X-ray scattering and nitrogen adsorption isotherms, both discussed in detail in chapter 2. A theoretical model for simulation of the silica properties based on the X-ray data is presented in chapter 3. Experimental methods, sample preparation techniques and experimental procedures are described in chapter 4.

The preliminary study regarding incorporation of biological, interesting molecules through absorption and under pressure into the porous matrix of regular SBA-15 is reported in chapter ??

In-situ studies regarding incorporation and release of molecules were performed and analysed with the theoretical model, as to verify the usefulness of the SBA-15 silica for transport and protection of molecules. The results are presented in chapter 5 . 



\section{Sumário}

Resumo ii

Abstract iii

Notação e convenções vii

1 Introdução 1

2 Aspectos teóricos 5

2.1 Raios X ......................... 5

2.1.1 Ambiente experimental . . . . . . . . . . . 5

2.1.2 Espalhamento de raios X a baixo ângulo (SAXS) . . . . 8

2.1.3 Difração de Raios X (XRD) . . . . . . . . . . . . . . . 14

2.1.4 Intensidade espalhada de raios X . . . . . . . . . . 18

2.2 Adsorção de gases . . . . . . . . . . . . . . . . . . . . . . . 19

2.2.1 Determinação da área superficial . . . . . . . . . . . . . . 19

2.2.2 Microporosidade . . . . . . . . . . . . . 20

2.2.3 Distribuição de tamanho de poros . . . . . . . . . 21

3 Modelagem numérica de sílica mesoporosa ordenada 24

3.1 Modelo para a estrutura da SBA-15 . . . . . . . . . . . . 24

3.2 Implementação . . . . . . . . . . . . . . . . . . . 28

3.3 Perfil de densidade eletrônica . . . . . . . . . . . . . . . . 29

4 Métodos experimentais 30

4.1 Preparação de amostras . . . . . . . . . . . . . . . . . . . 30

4.1 .1 Síntese .................... 30

4.1.2 Ensaios de incorporação . . . . . . . . . . . . . . . 32

4.1.3 Preparação de amostras para os experimentos in-situ . . . 33

4.2 Espalhamento de raios X a baixo ângulo . . . . . . . . . . . . 35

4.2.1 Montagem experimental . . . . . . . . . . . 35 
4.2 .2 Medidas in-situ . . . . . . . . . . . . . . 36

4.3 Adsorção de gases . . . . . . . . . . . . . . . . . . . 37

4.3.1 Procedimento experimental . . . . . . . . . 38

5 Estudos in-situ $\quad \mathbf{4 0}$

5.1 Síntese e caracterização de material para utilização . . . . . . . . 40

5.2 Testes de recobrimento com o polímero Eudragit ${ }^{\circledR} \ldots \ldots . . .45$

5.3 Estabilidade estrutural da sílica SBA-15 . . . . . . . . . . . . 48

5.4 Liberação de BSA a partir da sílica SBA-15 . . . . . . . . . . 52

5.5 Liberação de Insulina a partir da sílica SBA-15 . . . . . . . . . . 56

5.5.1 Nova determinação estrutural da SBA-15 . . . . . . . . 57

5.5.2 Experimento in-situ de incorporação de insulina . . . . . . 58

5.5.3 Experimentos in-situ de liberação de insulina . . . . . . . 64

6 Conclusões $\quad 70$

$\begin{array}{ll}\text { Apêndices } & 73\end{array}$

A Curvas obtidas no LNLS $\quad 74$

$\begin{array}{lll}\text { B Raios X } & \mathbf{7 7}\end{array}$

B.1 Interação dos raios X com a matéria . . . . . . . . . . 78

B.2 Interferência . . . . . . . . . . . . . 80

$\begin{array}{lr}\text { Lista de Figuras } & 83\end{array}$

$\begin{array}{lr}\text { Lista de Tabelas } & 86\end{array}$

$\begin{array}{lr}\text { Referências Bibliográficas } & 87\end{array}$

$\begin{array}{lr}\text { Índice Remissivo } & 93\end{array}$ 


\section{Notação e convenções}

Ao contrário de outras áreas da Física, há poucos conflitos de notação e convenções entre diferentes abordagens na física aplicada. Neste texto faz-se uso do Sistema Internacional de Unidades ${ }^{[1]}$, com exceção para o caso de unidades de pressão na área de adsorção, onde tradicionalmente se usa milímetros de Hg. Além disso, temperaturas estão reportadas em Kelvin, com o valor correspondente em graus celsius entre parênteses. Devido a peculiaridades das subrotinas de ajuste, dimensões de poros e parâmetros de rede estão em $\AA\left(=10^{-1} \mathrm{~nm}\right)$.

Vetores estão indicados em negrito.

Termos em inglês e anglicismos são escritos em itálico.

As seguintes siglas (em ordem alfabética) são utilizadas no texto:

BET Brunauer-Emmett-Teller

BJH Barrett-Joyner-Halenda

BSA Bovine Serum Albumin

CCD Charge-Coupled Device

GDS Gibbs Dividing Surface

IUPAC International Union of Pure and Applied Chemistry

MCM Mobil Composition of Mater, instituição onde foram descobertas as sílicas mesoporosas ordenadas

NAI Nitrogen Adsorption Isotherm

NPH Neutral Protamine Hagedorn, uma forma de insulina de absorção lenta contendo um átomo de $\mathrm{Zn}$

OICM Organisation Intergouvernementable de la Convention du Mètre

PBS Phosphate Buffer Saline

PSD Pore Size Distribution

SAXS Small Angle X-ray Scattering 
SBA Santa Barbara, denotanto o lugar onde as sílicas tipo SBA (baseadas na família Pluronic ${ }^{\circledR}$ ) foram desenvolvidas

SMO Sílica Mesoporosa Ordenada 


\section{1}

\section{Introdução}

"The greatest challenge to any thinker is stating the problem in a way that will allow a solution."

\section{- Bertrand Russell}

Materiais mesoporosos ordenados contam com uma ampla gama de aplicações, de adsorção e catálise a áreas como microeletrônica e nanobiotecnologia. $\mathrm{O}$ primeiro material dessa classe a ser obtido com sucesso foi o MCM-41 ${ }^{[2 ; 3]}$, pertencente à família M41S, descoberta em 1992. O diâmetro médio de poros desse material, maior que $2 \mathrm{~nm}$, inaugurou a classificação de mesoporos da IUPAC ${ }^{[4]}$ (segundo a qual um material é denominado mesoporoso se apresenta poros com diâmetros entre $2 \mathrm{~nm}$ e $50 \mathrm{~nm}$ ).

O processo de síntese desses materiais é descrito como "Modelagem por Cristal Líquido" [3], em que uma fonte de sílica, por exemplo tetra-etil ortosilicato (TEOS), é hidrolizada em uma solução bifásica contendo estruturas micelares formadas por um direcionador de estrutura. Esse direcionador de estrutura pode ser um surfactante, como por exemplo o brometo de hexadecil trimetil amônio (CTABr) ou copolímeros di- ou tri-bloco, como por exemplo o Pluronic ${ }^{\circledR}$ P123, da BASF*.

Em particular, a síntese da sílica mesoporosa ordenada (SMO) tipo SBA-15, proposta em $1998^{[5]}$, foi estruturada de maneira a dar origem a um material com alta resistência térmica e mecânica e alto grau de ordenação, características

*Fórmula química nominal: $\mathrm{HO}\left(\mathrm{CH}_{2} \mathrm{CH}_{2} \mathrm{O}\right)_{20}\left(\mathrm{CH}_{2} \mathrm{CH}\left(\mathrm{CH}_{3}\right) \mathrm{O}\right)_{70}\left(\mathrm{CH}_{2} \mathrm{CH}_{2} \mathrm{O}\right)_{20} \mathrm{H}$. 
propiciadas pelo comportamento do molde polimérico (Pluronic ${ }^{\circledR} \mathrm{P} 123$ ) em meio ácido aliado à hidrólise da fonte de sílica (TEOS) seguida da agregação do $\mathrm{SiO}_{2}$ sobre a estrutura de micelas formada pelo P123. Essa estrutura se consolida após o tratamento hidrotérmico e a calcinação, que removem os resíduos da solução de síntese e o molde polimérico.

A concentração do molde polimérico na síntese da SBA-15 é tal que as micelas adquirem formato cilíndrico, de forma que durante o tratamento hidrotérmico elas se organizem numa estrutura hexagonal bidimensional. Variações nessa concentração levam a outras geometrias de poros. Entre as possibilidades de configuração estão a SBA-11 (cúbica), SBA-12 (hexagonal 3D) e a SBA-16 (cúbica em forma de gaiola), além da SBA-15 ${ }^{[5 ; 6]}$.

Entre as aplicações dessa classe de materiais pode-se citar o interesse original na área de catálise e adsorção ${ }^{[7]}$, remoção de substâncias contaminantes ${ }^{[8]}$, preparação de filamentos condutores de polianilina ${ }^{[9]}$ e carbono $^{[10]}$, fios semicondutores de germânio para aplicação em microeletrônica ${ }^{[11]}$ e imobilização de moléculas ${ }^{[12]}$.

Em particular é possível encontrar um grande número de aplicações biológicas de SMOs na literatura. Por exemplo, Lin et al. ${ }^{[13]}$ investigaram a utilização de partículas de sílica como marcadores celulares. Um composto formado de hemoglobina incorporada à SBA-15 foi utilizado na fabricação de um sensor de peróxido de hidrogênio ${ }^{[14]}$. Esses materiais também têm sido investigados em purificação de moléculas biológicas como aminoácidos ${ }^{[15]}$.

Um grande número de estudos tem focado as vantagens da utilização de materiais mesoporosos ordenados em sistemas de drug delivery. Esse tipo de aplicação em potencial varia desde a administração de Ibuprofeno ${ }^{[16]}$, que é um medicamento anti-inflamatório amplamente conhecido, até a incorporação de drogas anti-câncer hidrofóbicas ${ }^{[17]}$, proteínas impermeáveis à membrana celular ${ }^{[18]}$ e complexos híbridos de sílica e colágeno ${ }^{[19]}$.

A SBA-15 é especialmente efetiva como adjuvante ${ }^{\dagger}$ no que se refere à resposta imunológica. Mercuri et al. ${ }^{[21]}$ mostraram que, para diferentes grupos de camundongos (bons e maus respondedores à formação de anticorpos), essa sílica induz resposta imunológica similar ou superior à resposta do adjuvante tradicionalmente

\footnotetext{
†Uma substância que, em conjunto com um antígeno, é capaz de melhorar a resposta imunológica. ${ }^{[20]}$ 
utilizado em inoculação de animais, conhecido como Adjuvante de Freund Incompleto (IFA). Esse estudo indica que, ao inibir a ação enzimática dos macrófagos $M \Phi$, a sílica permite uma maior eficiência na produção de anticorpos. Trabalho mais recente confirma esse efeito modulador da sílica em camundongos ${ }^{[22]}$.

Avanços mais recentes na área ${ }^{[23]}$ incluem por exemplo estudos de liberação controlada de nimodipina ${ }^{[24]}$ (uma droga originalmente desenvolvida para o tratamento de hipertensão arterial e atualmente utilizada na prevenção de certos tipos de hemorragia cerebral), DNA ${ }^{[25]}, \alpha$-amilase ${ }^{[26]}$ (uma das enzimas componentes da pancreatina, envolvida no processamento de açúcares), e naproxeno ${ }^{\text {[27] }}$ (droga contra osteoporose). Há também estudos de funcionalização procurando aumentar a afinidade das partículas de sílica a células cancerígenas ${ }^{[28]}$. Outro ponto de interesse é a biocompatibilidade da sílica, investigada em sistema de drug delivery para terapia contra o câncer em animais ${ }^{[29]}$, além da biodistribuição in-vivo no organismo de camundongos ${ }^{[30]}$.

O objetivo deste trabalho é investigar, de um ponto de vista físico, não somente a aplicabilidade da sílica SBA-15 como adjuvante imunológico mas também a sua customização para um tipo específico de molécula de interesse biológico, expandindo o conceito apresentado em patente ${ }^{[31]}$ de 2007. Também se busca formas alternativas de administração de drogas sensíveis às condições adversas do trato digestivo, de forma a facilitar a sua utilização. O foco principal é a ação da pepsina. Essa enzima gastrintestinal é responsável pela primeira fase da digestão proteica, funcionando como catalisador do processo de hidrólise das ligações peptídicas entre os aminoácidos ${ }^{[32]}$. Uma vez que a droga passe pelo ambiente adverso, ela pode ser liberada num ambiente onde não vá sofrer degradação, sendo absorvida e posteriormente disponibilizada na corrente sangüínea.

Estudos preliminares de incorporação determinaram a capacidade da sílica SBA-15 de conter as moléculas dos compostos estudados, e estudos in-situ foram realizados de forma a se investigar a dinâmica de incorporação e de liberação. A técnica principal de análise foi SAXS ( espalhamento de raios X a baixo ângulo), com análises auxiliares realizadas através de NAI (isotermas de adsorção de nitrogênio).

Um modelo teórico ${ }^{[33]}$ foi adaptado a partir da literatura e ajustado às curvas de espalhamento das amostras de forma que novas informações sobre os processos 
de incorporação e liberação de moléculas na estrutura de poros da sílica SBA-15 pudessem ser obtidas. Com a fatoração das curvas de espalhamento em uma série de parâmetros foi possível identificar os efeitos da incorporação ou da liberação dessas moléculas. 


\section{2}

\section{Aspectos teóricos}

"If you are out to describe the truth, leave elegance to the tailor."

- Albert Einstein

\subsection{Raios X}

Uma introdução aos fundamentos das técnicas de raios $\mathrm{X}$ e à interação dos raios $\mathrm{X}$ com a matéria é apresentada no apêndice $\mathrm{B}$.

\subsubsection{Ambiente experimental}

Um experimento de espalhamento de raios $\mathrm{X}$ a baixo ângulo envolve a detecção de fótons provenientes de uma amostra exposta à radiação. Os raios $\mathrm{X}$ produzidos por uma fonte (usualmente um tubo ou um dipolo magnético) interagem com a amostra e são detectados por um sistema que pode ser composto por um imageplate que é lido em um equipamento especial, detectores filamentares sensíveis à posição ou detectores CCD. No caso de geometrias de transmissão um beamstopper é posicionado em frente ao detector para evitar danos provocados pela alta intensidade de radiação do feixe direto, formado pelos fótons não-interagentes.

As fontes de raios $\mathrm{X}$ mais comuns são tubos, que produzem a radiação através da excitação dos átomos de um alvo metálico por um feixe de elétrons emitidos por 


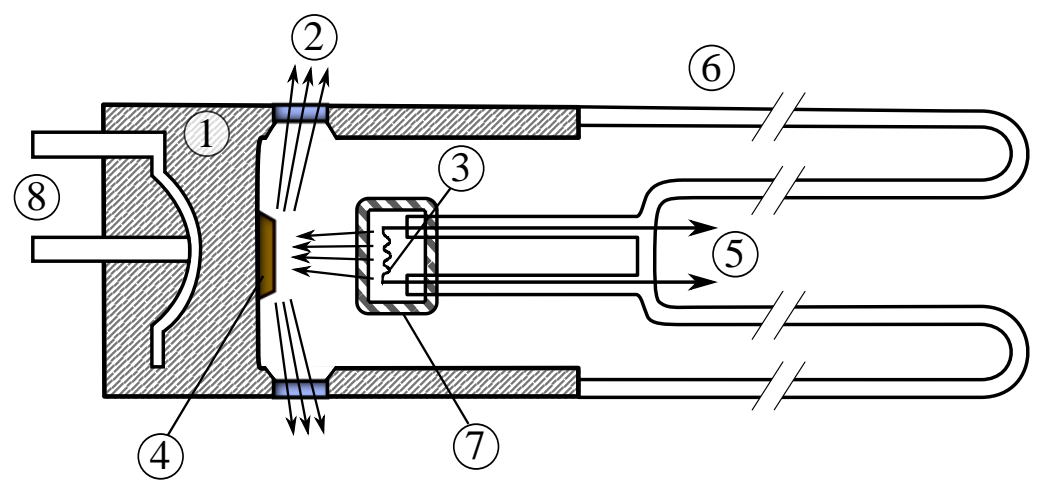

Figura 2.1: Esquema de produção de raios $\mathrm{X}$ em tubo de $\mathrm{Cu}$.

um filamento e acelerados por um campo elétrico. Os elementos mais comumente utilizados na construção de alvos são o Cobre $(\mathrm{Cu})$, Molibdênio (Mo) e Tungstênio (W). Um tubo está esquematizado na figura 2.1, onde tem-se:

1. Corpo metálico

2. Janela de berílio

3. Filamento de tungstênio

4. Ânodo $(\mathrm{Cu}, \mathrm{Mo}$ ou $\mathrm{W})$

5. Fonte de alta tensão

6. Cobertura de vidro

7. Lente focalizadora

8. Tubulação de refrigeração

Além disso, também são correntes geradores conhecido como ânodos rotatórios, em que o ânodo é um disco giratório, o que facilita a dissipação de calor e contribui com o aumento do fluxo.

O espectro de emissão desses dispositivos (v. figura 2.2) é composto por uma parte contínua, originada pela desaceleração dos elétrons ao atingirem o alvo, 


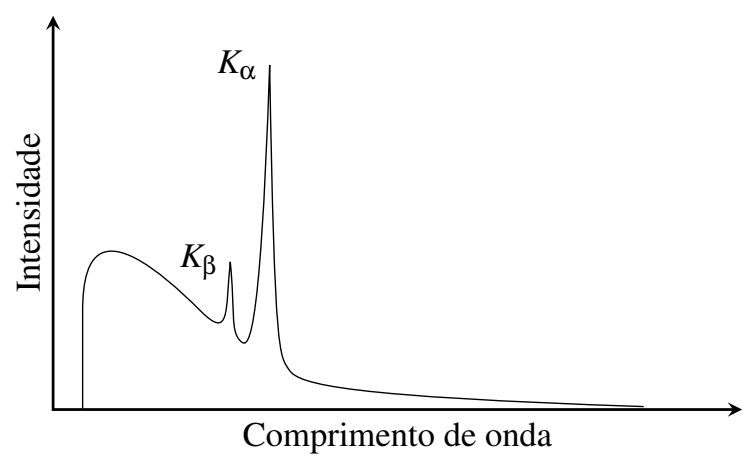

Figura 2.2: Exemplo de espectro contínuo e característico (fora de escala).

conhecida como radiação brehmstrahlung, e outra parte discreta, com comprimentos de onda bem definidos, originada pelo decaimento de elétrons das camadas mais internas dos átomos do alvo, excitados pela passagem dos elétrons vindos do filamento, denominada radiação característica. Essa segunda parte é a mais intensa e mais importante do espectro de emissão, uma vez que o seu comprimento de onda é fundamental nos cálculos envolvendo a interação dos raios X com a amostra. Usualmente o pico relacionado a uma das transições mais internas do átomo (por exemplo, a $\mathrm{Cu} K_{\alpha}$ ) é selecionado através de um filtro ou através de monocromadores. A energia desses picos de transição depende do alvo utilizado e desta forma tubos com alvos de diferentes materiais fornecerão radiação com diferentes comprimentos de onda. Um bom texto descrevendo essas características é o texto de Cullity ${ }^{[34]}$.

Medidas envolvendo raios $\mathrm{X}$ também podem ser executadas em aceleradores tipo síncrotron, onde a deflexão de um feixe de elétrons por um dipolo magnético causa a emissão de radiação. Há duas instalações desse tipo no hemisfério sul: o Australian Synchrotron, em operação em Melbourne, Austrália desde 2007, e o Laboratório Nacional de Luz Síncrotron (LNLS), em operação em Campinas desde 1997.

Em um acelerador, pacotes de elétrons são acelerados a velocidades próximas à velocidade da luz e submetidos à ação de dipolos magnéticos ou dispositivos de inserção como wigglers e onduladores. Esses dispositivos exercem forças sobre os pacotes de elétrons, ocasionando assim a emissão de radiação de alta intensidade. Boas descrições desse tipo de fonte podem ser encontradas nos textos 
de Jackson $^{[35]}$ (cap. 14) e Margaritondo ${ }^{[36]}$.

Há muitas vantagens na utilização desse tipo de fonte em relação a fontes mais tradicionais. Entre elas pode-se mencionar, por exemplo, a alta intensidade, colimação do feixe, facilidade na seleção de comprimento de onda e instalações especializadas e dedicadas, que possibilitam a realização de estudos que de outra forma seriam impraticáveis. Entre as desvantagens estão o alto custo de manutenção de um anel de armazenamento e a dificuldade na obtenção de tempo de máquina suficiente para estudos exploratórios.

\subsubsection{Espalhamento de raios $X$ a baixo ângulo (SAXS)}

O espalhamento de raios $\mathrm{X}$ a baixo ângulo sonda inomogeneidades da densidade eletrônica da amostra na região de nanometros a frações de micrometros em ângulos próximos a $0^{\circ}$.

A curva obtida num experimento de raios $\mathrm{X}$ pode ser descrita matematicamente utilizando o formalismo de espaço de Fourier, também conhecido como espaço recíproco. Designando como $\rho(\boldsymbol{r})$ a densidade eletrônica de um corpo, a sua transformada será dada pela equação B.10 (v. seção B.2):

$$
A(\boldsymbol{q})=\int \rho(\boldsymbol{r}) e^{-i \boldsymbol{q} \cdot \boldsymbol{r}} \mathrm{d} \boldsymbol{r}
$$

sendo $A(\boldsymbol{q})$ a amplitude da radiação espalhada e $\boldsymbol{q}$ o vetor de onda ou vetor troca de momento, que representa a diferença entre a direção do raio incidente e a direção do raio emergente da amostra, representadas por vetores unitários. A transformação inversa dessa equação,

$$
\rho(\boldsymbol{r})=\int A(\boldsymbol{q}) e^{i \boldsymbol{q} \cdot \boldsymbol{r}} \mathrm{d} \boldsymbol{q}
$$

Nessa faixa de ângulos, para um único centro espalhador (ou para um conjunto de centros espalhadores esparsamente distribuídos) o comportamento do feixe é análogo ao fenômeno de difração para luz visível, isto é, a interação entre o feixe e a amostra produz um "halo" em torno do feixe direto, gerado pela interferência entre as ondas espalhadas pela partícula. Dessa forma o primeiro "vale" na intensidade 
detectada é determinado pela diferença de fase entre os raios espalhados em diferentes pontos da partícula. A posição desse vale é da ordem de $2 \theta=\lambda / D$, onde $D$ é uma dimensão característica da partícula em questão.

É importante notar que, se $D$ é muito grande, esse vale estará em um ângulo demasiadamente pequeno para ser detectado (devido ao beam-stopper) e, se for muito pequeno, o espalhamento será fraco demais para ser observado.

Dada uma partícula com densidade eletrônica constante $\rho^{\prime}(\boldsymbol{r})$, definimos uma "função forma" [37] $s(\boldsymbol{r})$, igual a 1 para $\boldsymbol{r}$ dentro da partícula e nula caso contrário. A amplitude de radiação espalhada por essa partícula pode ser determinada por ${ }^{[38]}$

$$
A_{1}(\boldsymbol{q})=\int \rho^{\prime}(\boldsymbol{r}) s(\boldsymbol{r}) e^{-i \boldsymbol{q} \cdot \boldsymbol{r}} \mathrm{d} \boldsymbol{r}
$$

Sendo $A(\boldsymbol{q})$ e $S(\boldsymbol{q})$ as transformadas de Fourier de $\rho^{\prime}(\boldsymbol{r})$ e $s(\boldsymbol{r})$, respectivamente, podemos então escrever

$$
A_{1}(\boldsymbol{q})=\int A(\boldsymbol{y}) S(\boldsymbol{q}-\boldsymbol{y}) \mathrm{d} \boldsymbol{y}
$$

onde $y$ é uma variável de integração.

Se $s(\boldsymbol{r})$ é dado, $S(\boldsymbol{q})$ é completamente determinado e, se a partícula tem dimensões de nanometros a frações de micrometros, então $S(\boldsymbol{q})$ será diferente de zero somente para valores muito pequenos de $\boldsymbol{q}$.

$A(\boldsymbol{q})$, por sua vez, torna-se uma função Delta de Dirac para uma densidade eletrônica constante, sendo infinita para $\boldsymbol{q}=0$ e nula em qualquer outro ponto. Se, entretanto, a densidade eletrônica da partícula apresenta variações, estas se manifestarão como picos na sua transformada. Entretanto, todos eles estarão fora da região onde $S(\boldsymbol{q})$ tem valor não-nulo.

Em outras palavras, próximo à origem do espaço recíproco $A_{1}(\boldsymbol{q})$ é simplesmente proporcional a $S(\boldsymbol{q})$, sem influência de $\rho^{\prime}(\boldsymbol{r})$, isto é, o espalhamento de raios $\mathrm{X}$ a baixo ângulo é independente da estrutura interna da partícula espalhadora, sendo portanto relacionado diretamente à sua forma. 


\section{Intensidade espalhada}

A partir da equação B.10 é possível, conhecida a densidade eletrônica da amostra, obter teoricamente a intensidade espalhada com o uso do complexo conjugado de $A(\boldsymbol{q})$ :

$$
P(\boldsymbol{q})=\int_{V} \int_{V} \rho\left(\boldsymbol{r}_{1}\right) \rho\left(\boldsymbol{r}_{2}\right) e^{-i \boldsymbol{q} \cdot\left(\boldsymbol{r}_{1}-\boldsymbol{r}_{2}\right)} \mathrm{d} \boldsymbol{r}_{1} \mathrm{~d} \boldsymbol{r}_{2}
$$

A integral da equação 2.5 é uma transformada de Fourier envolvendo a distância relativa entre dois pontos do volume de integração. Dessa forma, torna-se conveniente proceder com a integração em dois passos distintos. Primeiramente faz-se a integração para todos os pares com a mesma distância relativa e, em seguida, conclui-se a integração sobre todas as distâncias possíveis.

O primeiro passo é a operação matemática de auto-correlação, escrita como

$$
\tilde{\rho}^{2}(\boldsymbol{r}) \equiv \int_{V} \rho\left(\boldsymbol{r}_{1}\right) \rho\left(\boldsymbol{r}_{2}\right) \mathrm{d} \boldsymbol{r}
$$

$\operatorname{com} \boldsymbol{r}=\boldsymbol{r}_{1}-\boldsymbol{r}_{2}$ constante. Essa equação é comumente conhecida como Função de Patterson e tem a propriedade de gerar um espaço onde cada par de elétrons com distância relativa $\boldsymbol{r}$ produz um ponto, e no qual a densidade de pontos é dada por $\tilde{\rho}(\boldsymbol{r})$. Cada par é contado duas vezes (para $\boldsymbol{r}$ e $-\boldsymbol{r}$ ) e por isso esse espaço tem um centro de simetria mesmo que este não seja o caso para o espaço "regular".

O segundo passo, então, consiste em uma integração no espaço de Patterson:

$$
P(\boldsymbol{q})=\int_{V} \tilde{\rho}^{2}(\boldsymbol{r}) e^{-i \boldsymbol{q} \cdot \boldsymbol{r}} \mathrm{d} \boldsymbol{r}
$$

com a transformada inversa sendo:

$$
\tilde{\boldsymbol{\rho}}(\boldsymbol{r})=\frac{1}{(2 \pi)^{3}} \int_{V} P(\boldsymbol{q}) e^{i \boldsymbol{q} \cdot \boldsymbol{r}} \mathrm{d} \boldsymbol{q}
$$

\section{Função de Correlação}

Para sistemas isotrópicos* o fator de fase pode ser substituído pela sua média,

*É indiferente se a característica isotrópica do sistema vem de uma característica estrutural ou de uma variação temporal. 


$$
\left\langle e^{-i q \cdot r}\right\rangle=\frac{\operatorname{sen} q r}{q r}
$$

de forma que a equação 2.7 se torna

$$
P(q)=4 \pi \int \tilde{\rho}^{2}(r) \frac{\operatorname{sen} q r}{q r} r^{2} \mathrm{~d} r
$$

Se o sistema é suficientemente diluído a distância entre as partículas torna-se grande o suficiente para que a densidade eletrônica seja entendida como um valor médio constante $\bar{\rho}(r)$ somado a um termo de desvio $\tilde{\eta}(r)$. Dessa forma a densidade eletrônica será $\rho(r)=\bar{\rho}+\eta(r)$. A função de Patterson, a menos das posições em que $\eta(r)$ é diferente de zero, deverá tender a um valor constante $V \bar{\rho}^{2}$, com valor inicial $\tilde{\rho}^{2}(0)=V \overline{\rho^{2}}$. Substituindo na equação 2.6 , temos

$$
\tilde{\rho}^{2}-V \bar{\rho}^{2}=\tilde{\eta}^{2}=V \cdot \gamma(r)
$$

onde $\gamma(r)$ é denominada função de correlação, introduzida por Debye ${ }^{[39]}$, que pode ser interpretada como a média no volume do produto entre dois desvios localizados a uma distância $r=\left|r_{1}-r_{2}\right|$ constante um do outro:

$$
\gamma(r)=\left\langle\eta\left(r_{1}\right) \eta\left(r_{2}\right)\right\rangle
$$

A equação 2.1.2 então fica

$$
P(q)=4 \pi V \int_{0}^{\infty} \gamma(r) \frac{\operatorname{sen} q r}{q r} r^{2} \mathrm{~d} r
$$

Cuja transformada inversa será

$$
\gamma(r)=\frac{1}{(2 \pi)^{3} V} \int_{0}^{\infty} q^{2} P(q) \frac{\operatorname{sen} q r}{q r} \mathrm{~d} q
$$

Para $q=0(r \rightarrow \infty)$, a equação 2.1.2 se torna 


$$
P(0)=4 \pi V \int_{0}^{\infty} \gamma(r) r^{2} \mathrm{~d} r
$$

$q=0$ significa que as ondas secundárias (espalhadas) estão todas em fase, de forma que é de se esperar que $P(0)$ seja igual ao total de elétrons dentro do volume $V$. Entretanto, isso não pode ser observado experimentalmente, e portanto deve ser considerado como um valor extrapolado ao invés de uma quantidade mensurada.

Para $r=0(q \rightarrow \infty)$ temos

$$
\lim _{r \rightarrow 0} \frac{\operatorname{sen} q r}{q r}=1
$$

e

$$
V \gamma(0)=\frac{1}{(2 \pi)^{3}} \int_{0}^{\infty} P(q) q^{2} \mathrm{~d} q=V \overline{\eta^{2}}
$$

Isto é, a integral da intensidade no espaço recíproco está diretamente relacionada à flutuação da densidade eletrônica, independentemente de fatores estruturais. Como ele deve permanecer o mesmo ainda que partes do sistema sejam deslocadas ou deformadas, o que alteraria o padrão de difração, recebe a denominação de Invariante.

$$
Q=\int_{0}^{\infty} P(q) q^{2} \mathrm{~d} q
$$

\section{Função Distribuição de Distâncias}

A partir da função de correlação é possível obter uma descrição da forma geométrica da partícula, conhecida como função distribuição de distâncias. Essa função descreve a probabilidade de um elemento de volume estar a uma distância $r$ de outro elemento de volume dentro da partícula, sendo dada por

$$
p(r)=r^{2} \cdot \gamma(r)
$$

A figura 2.3 apresenta a função $p(r)$ para alguns formatos de partícula mais comuns ${ }^{[40]}$. 


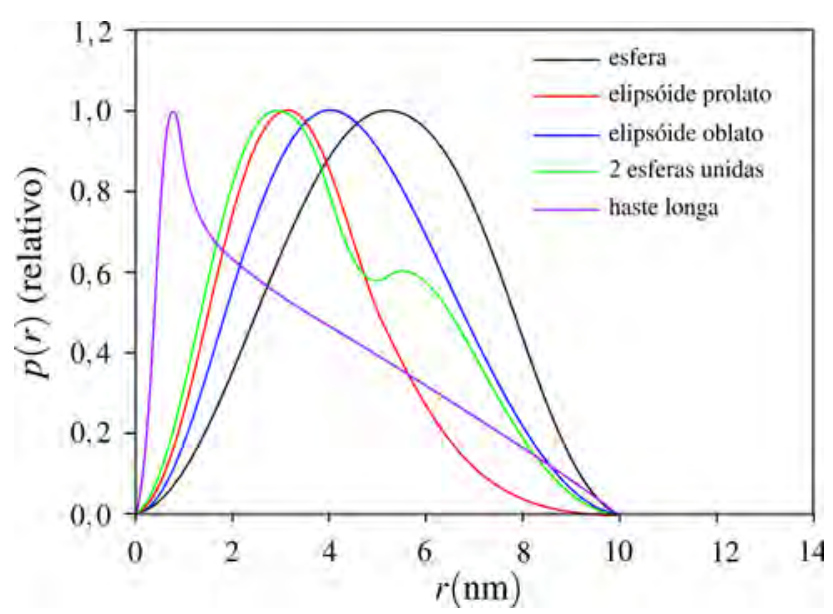

Figura 2.3: Função distribuição de distância para alguns formatos de partícula

\section{Lei de Guinier}

Na região onde $\boldsymbol{q}$ é suficientemente pequeno, o espalhamento de raios X é dominado por

$$
I(q)=N\langle I(\boldsymbol{q})\rangle
$$

onde $\langle I(\boldsymbol{q})\rangle$ é a média angular para todas as orientações possíveis e $N$ é o número de centros espalhadores. Guinier ${ }^{[41]}$ mostrou que, para $q$ pequeno, a intensidade é representada pela expressão

$$
I(q)=N \Delta n^{2} e^{-\frac{R_{g}^{2} q^{2}}{3}}
$$

onde o raio de giro $R_{g}$ é definido como

$$
R_{g}=\left[\frac{\int_{V_{l}} \rho(\boldsymbol{r}) r^{2} \mathrm{~d} v}{\int_{V_{l}} \rho(\boldsymbol{r}) \mathrm{d} v}\right]^{1 / 2}
$$

$V_{l}$ é o volume do centro espalhador e $\Delta n$ o excesso no número de elétrons.

O raio de giro é obtido a partir de um gráfico de $\ln I$ por $q^{2}$, no qual uma linha reta é esperada na região de baixo $q$, à qual uma função linear pode ser ajustada. A partir do coeficiente angular da reta ajustada, $\alpha_{g}$, calcula-se então o valor $R_{g}=\sqrt{3 \alpha_{g}}$, que pode então ser relacionado à partícula em questão através 
de relações geométricas. ${ }^{\dagger}$

\section{Lei de Porod}

Assim como a Lei de Guinier trata do comportamento assintótico da curva de espalhamento para $q \rightarrow 0$, a Lei de Porod é uma aproximação para o comportamento assintótico da curva de espalhamento a baixo ângulo. Como $q$ é inversamente proporcional a $\boldsymbol{r}$, é óbvio que objetos de grandes dimensões ocasionarão efeitos de espalhamento a ângulos menores, de forma que o início da curva de espalhamento pode ser influenciado pelo espalhamento a "alto ângulo" de objetos cuja dimensão coloca seus vetores de espalhamento atrás do beam-stopper. Ou seja, sendo a curva de espalhamento dada por

$$
I(q)=A e^{-4 \alpha}
$$

ela pode representar tanto o espalhamento a baixo ângulo dos objetos normalmente sondados pelo feixe de raios $\mathrm{X}$ bem como representar o espalhamento de objetos grandes que se apresenta no início da curva.

\subsubsection{Difração de Raios X (XRD)}

Até agora só foi tratado o problema de uma única partícula espalhadora, que é equivalente a um sistema suficientemente diluído, isto é, um sistema onde os centros espalhadores estão separados por grandes distâncias. Para amostras nas quais as inomogeneidades da distribuição de contraste eletrônico estão próximas umas das outras a correlação entre elas causa alterações na intensidade espalhada, de forma que esta não pode mais ser suposta como sendo exclusivamente composta pelo fator de forma.

No caso de sílicas mesoporosas ordenadas essa correlação advém do arranjo dos poros, que, sendo ordenado, pode ser entendido como um padrão de difração.

A difração de raios $\mathrm{X}$ a alto ângulo é usualmente utilizada na análise de amostras mono ou policristalinas, nas quais os átomos estão arranjados de forma a

\footnotetext{
†Para o caso particular de um cilindro de diâmetro $D$ e comprimento $L$, o raio de giro é dado por $R_{g}=\sqrt{D^{2} / 8+H^{2} / 12}$ com relação a seu centro de gravidade ou $R_{g, z}=\sqrt{2} D / 4$ com relação ao eixo longitudinal.
} 
produzir um padrão de interferência durante um experimento. Esse padrão pode ser utilizado para o cálculo de diversas propriedades do material, como distâncias entre os átomos, tamanho de cristalito e, em muitos casos, a composição da amostra.

No caso da SBA-15, amostras consideradas ordenadas apresentam poros organizados em uma rede hexagonal bidimensional de dimensões consideravelmente maiores que as tradicionalmente envolvidas nesse tipo de análise a alto ângulo. Para materiais como a SBA-15 a difração a alto ângulo produz apenas bandas largas, pois as paredes da sílica são compostas por $\mathrm{SiO}_{2}$ amorfo. Desta forma é possível distinguir apenas picos de interferência a baixos ângulos, que correspondem a alguns nanometros. Assim, pode-se então deduzir, com auxílio de outras técnicas, o tamanho dos poros, espessura das paredes e eventualmente uma medida qualitativa do grau de ordenação.

Esses picos surgem da interferência construtiva entre os feixes espalhados pela amostra. Essa interferência ocorre quando a diferença de caminho óptico entre os diversos fótons espalhados pela amostra é igual a um múltiplo inteiro do comprimento de onda incidente (v. fig. 2.4). Como trata-se de espalhamento coerente, em que não há mudança de frequiência e no qual existe uma relação bem definida entre a fase do fóton emitido e a fase do fóton incidente ${ }^{\ddagger}$, isso equivale a um múltiplo inteiro de $2 \pi$ na diferença de fase entre duas ondas ${ }^{[41]}$.

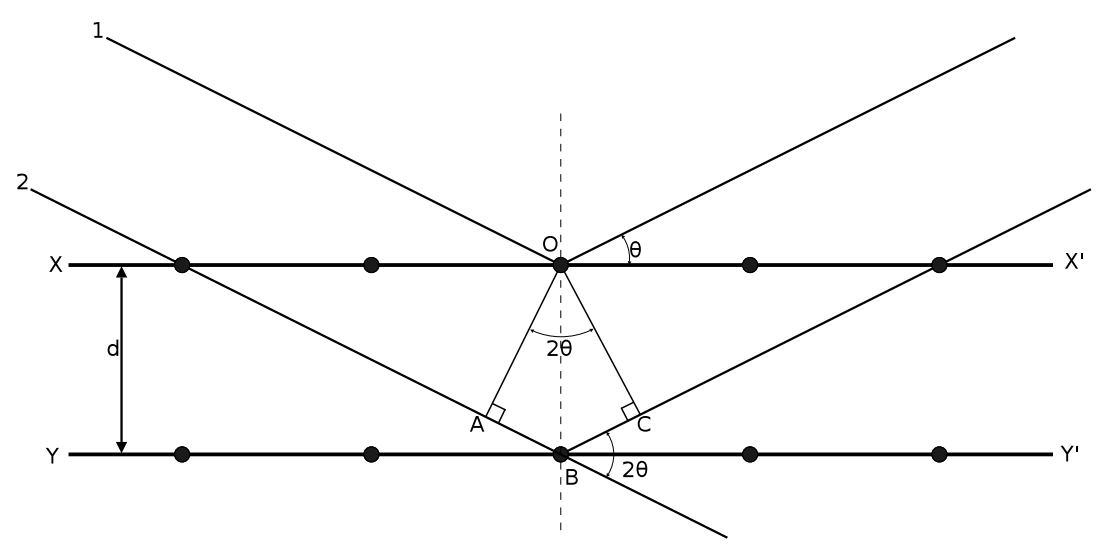

Figura 2.4: Ilustração da Lei de Bragg.

Sejam dois feixes paralelos e provenientes da mesma fonte (e, portanto, em

\footnotetext{
\$Para o espalhamento por um elétron essa diferença é igual a $\pi / 2$
} 
fase) incidentes sobre um conjunto de centros espalhadores (Fig. 2.4), separados por uma distância $d$, que corresponde à separação interplanar entre $X X^{\prime}$ e $Y Y^{\prime}$. A diferença de caminho óptico entre eles será dada pela distância $\overline{A B C}$ e o ângulo de espalhamento, ou seja, o ângulo entre o feixe incidente e o feixe espalhado, $\widehat{A B C}=2 \theta$ (v. seção B.1). Através da simetria da figura temos

$$
\begin{array}{r}
\overline{A B}=\overline{B C}=d \operatorname{sen}(\theta) \\
\overline{A B C}=\overline{A B}+\overline{B C}=2 d \operatorname{sen}(\theta)
\end{array}
$$

A condição para o surgimento de um pico é que a diferença de fase entre as duas ondas seja nula ou um múltiplo de $2 \pi$. Para isso, a diferença de caminho óptico entre as duas ondas deve ser um múltiplo inteiro do comprimento de onda, e portanto:

$$
n \lambda=2 d \operatorname{sen}(\theta)
$$

A equação 2.24 é conhecida como Lei de Bragg ${ }^{[42]}$, e expressa a condição de interferência construtiva segundo a qual surgem os picos de difração, prevendo em que ângulos com relação ao feixe incidente esses picos devem ser observados.

Cada pico de interferência produzido pelo arranjo de centros espalhadores da amostra está relacionado a uma condição semelhante à apresentada na figura 2.4. Assim, a cada pico corresponde uma família de planos cristalográficos, definidos a partir da simetria da amostra. A partir do conjunto de planos observados na amostra pode-se então "reconstruir" a cela unitária, obtendo-se assim a estrutura da amostra.

A cela unitária é definida por uma origem, três eixos $(x, y, \mathrm{e} z)$ e os três ângulos entre eles $(\alpha, \beta$ e $\gamma)$. As dimensões da cela em cada um dos eixos são $a$, $b$ e $c$, denominadas parâmetros de rede. Para uma determinada cela unitária os planos cristalográficos nela presentes são determinados pelos índices de Miller, que representam o ponto de cada eixo da cela unitária onde cruza cada plano. Dessa maneira, por exemplo, para uma dada cela unitária o plano (210) cruza o eixo $x \mathrm{em}$ 


\begin{tabular}{ccc}
$\mathrm{h}$ & $\mathrm{k}$ & $\mathrm{a} / \mathrm{d}_{\mathrm{hk}}$ \\
\hline \hline 1 & 0 & $2 / \sqrt{3}$ \\
1 & 1 & 2 \\
2 & 0 & $4 / \sqrt{3}$ \\
2 & 1 & $\sqrt{28 / 3}$ \\
3 & 0 & $6 / \sqrt{3}$ \\
2 & 2 & $\sqrt{48 / 3}$ \\
3 & 0 & $\sqrt{52 / 3}$
\end{tabular}

Tabela 2.1: Relação entre distância interplanar e o parâmetro de rede $a$ para as primeiras reflexões de uma rede hexagonal plana $(l=0)$.

$a / 2$, o eixo $y$ em $b / 1$ e é paralelo ao eixo $z^{\S}$.

A posição de cada pico e a distância interplanar a ele associada estão relacionadas por

$$
d=\frac{2 \pi n}{q}
$$

onde $q$ é o vetor de onda (v. eq. B.2).

A identificação de cada pico com uma família de planos é um procedimento conhecido como indexação e, a partir dos valores de distâncias interplanares obtidas, é possível determinar os parâmetros da cela unitária através de uma relação característica de cada tipo de estrutura.

A sílica SBA-15 apresenta estrutura hexagonal bidimensional, e a relação entre as distâncias interplanares $d_{h k l}$ e o parâmetro de rede é dada por

$$
\frac{1}{d_{h k l}^{2}}=\frac{4}{3}\left(\frac{h^{2}+h k+k^{2}}{a^{2}}\right)+\frac{l^{2}}{c^{2}}
$$

Numa estrutura hexagonal bidimensional (para a qual o parâmetro $l$ é considerado nulo) temos, para as sete primeiras reflexões em ordem de vetor de onda crescente, as relações entre a distância interplanar e o parâmetro de rede apresentadas na tabela 2.1 .

De forma coletiva a amplitude espalhada por uma célula unitária é dada em

\footnotetext{
${ }^{\S}$ Da divisão por zero resultaria um valor infinito para o ponto onde o plano cruzaria esse eixo, portanto eles são paralelos.
} 
termos de um fator de estrutura, que é a soma das ondas espalhadas por cada ponto da célula unitária. Escrevendo cada onda espalhada como uma função exponencial complexa

$$
A e^{i \phi}=f e^{2 \pi i(h u+k v+l w)}
$$

onde $A$ e $\phi$ são a amplitude e a fase de cada onda, o fator de estrutura para a reflexão (hkl) de uma célula unitária com $N$ pontos é escrito como

$$
F_{h k l}=\sum_{n=1}^{N} f_{n} e^{2 \pi i\left(h u_{n}+k v_{n}+l w_{n}\right)}
$$

Em geral $F$ é um número complexo, expressando tanto a amplitude quanto a fase da onda espalhada; seu valor absoluto é dado em termos da amplitude espalhada por um único elétron (v. eq. B.6):

$$
F=\frac{\text { amplitude da onda espalhada pela célula unitária }}{\text { amplitude espalhada por um elétron }}
$$

O fator de estrutura é expressado na intensidade espalhada através do quadrado do seu módulo, ou seja, através da expressão para $S(q)$ :

$$
S(q)=|F(q)|^{2}=\left\langle F(q) F^{*}(q)\right\rangle
$$

\subsubsection{Intensidade espalhada de raios $X$}

Isoladamente o fator de forma $P(q)$ descreve o espalhamento por uma partícula devido à sua forma e o fator de estrutura $S(q)$ descreve a organização espacial de um conjunto de partículas, respectivamente. Para uma amostra composta de partículas organizadas segundo uma estrutura descrita pelo fator de estrutura, a intensidade total espalhada é uma convolução desses dois fatores, dada por

$$
I_{t}(q)=\langle P(q) \cdot S(q)\rangle
$$

onde os chevrons indicam a média espacial sobre todas as orientações possíveis, efetivamente medida no caso de amostras em pó (isotrópicas) como as utilizadas neste trabalho. 
Ademais, a quantidade observada experimentalmente é composta pela intensidade total espalhada, convoluída com uma função de resolução $R(q,\langle q\rangle)^{[43]}$, que representa a sonda constituída das características do arranjo experimental (levando em conta parâmetros do equipamento e do feixe de raios X). Dessa forma a curva de espalhamento obtida num experimento será

$$
I(\langle q\rangle)=\int R(q,\langle q\rangle) I_{t}(q) \mathrm{d} q
$$

onde $\langle r\rangle$ é o valor médio do vetor de espalhamento do feixe.

\subsection{Adsorção de gases}

Uma introdução à interação entre gases e a superfície de sólidos, que é o fenômeno por trás da técnica de adsorção de gases, pode ser encontrada no apêndice ??.

\subsubsection{Determinação da área superficial}

Vários métodos são capazes de fornecer o valor da área superficial de uma amostra através de diferentes abordagens. Para este trabalho é utilizado o método BET, introduzido por Brunauer, Emmett e Teller em $1938^{[44]}$. Essa técnica é uma extensão da equação de Langmuir ${ }^{[45]}$, que descreve o comportamento de uma monocamada de adsorbato sobre a superfície (v. ??).

A equação BET é expressa por (v. ??):

$$
\frac{1}{v\left(p_{0} / p-1\right)}=\frac{c-1}{v_{m} c}\left(\frac{p}{p_{0}}\right)+\frac{1}{v_{m} c}
$$

onde $p$ é a pressão de equilíbrio e $p_{0}$ a pressão de saturação do adsorbato, $v$ a quantidade adsorvida e $v_{m}$ a quantidade adsorvida em uma monocamada.

A aplicação dessa equação é válida na região linear da isoterma, que no caso do nitrogênio está em $0,05<p / p_{0}<0,35$, de forma que, nessa região, a um gráfico com $1 / v\left[\left(p / p_{0}\right)-1\right]$ no eixo y e $\varphi=p / p_{0}$ no eixo x pode ser ajustada uma linha reta. Os coeficientes linear $l=1 / v_{m} c$ e angular $A=c-1 / v_{m} c$ dessa reta podem então ser utilizados na determinação de $v_{m}$ e $c$ : 


$$
\begin{aligned}
v_{m} & =\frac{1}{A+l} \\
c & =1+\frac{A}{l}
\end{aligned}
$$

Finalmente, pode-se calcular através desses valores a área total $\left(S_{\text {total }}\right)$ e a área específica $\left(S_{\mathrm{BET}}\right)$ da amostra:

$$
\begin{aligned}
S_{\text {total }} & =\frac{\left(v_{m} N s\right)}{V} \\
S_{\text {BET }} & =\frac{S_{\text {total }}}{a}
\end{aligned}
$$

onde $N$ é o número de Avogadro, $s$ a seção de choque de adsorção da espécie adsorvida, $V$ o volume molar de gás adsorvido e $a$ a massa da amostra.

\subsubsection{Microporosidade}

A microporosidade ${ }^{[4] \mathbb{I}}$ de um sólido é composta pelos orifícios com diâmetro inferior a $2 \mathrm{~nm}^{[4]}$.

Dois métodos podem ser utilizados para avaliação da área e volume dos microporos de uma amostra: t-plot e $\alpha_{s}$-plot.

Ambos os métodos, usados em conjunto com a determinação de área superficial (v. 2.2.1), podem servir para avaliar as características da microporosidade da amostra (como volume e área superficial dos microporos).

\section{t-plot}

Proposto por de Boer ${ }^{[46]}$, esse método supõe que, em uma dada região da isoterma, os microporos estão completamente preenchidos e a adsorção em poros maiores ocorre de acordo com alguma relação simples. Essa equação aproxima a adsorção em mesoporos, macroporos e na superfície externa em uma faixa de pressões relativas acima do preenchimento dos microporos mas abaixo da

\footnotetext{
"Poros com diâmetro inferior a $2 \mathrm{~nm}$.
} 
condensação capilar nos mesoporos. Para pequenos microporos e na ausência de sub-microporos ${ }^{\|}$, temos

$$
a(\varphi)=a_{\text {micro,max }}+k S_{\text {ext }} t_{c a m}(\varphi)
$$

onde $\varphi=p / p_{0}, a_{\text {micro,max }}$ é a adsorção nos microporos (coeficiente linear), $S_{\text {ext }}$ é a área superficial externa aos microporos, ou seja, área dos mesoporos, macroporos e área externa propriamente dita, e $t_{\mathrm{cam}}(\varphi)$ é a espessura estatística da camada adsorvida (v. eq. 2.43).

$\alpha_{s}-$ plot

Originalmente proposto por K. S. W. Sing ${ }^{[47]}$, esse método baseia-se na comparação da isoterma de adsorção obtida para a amostra com uma isoterma padrão obtida para um material semelhante, porém não-poroso. Aqui também se supõe que a adsorção em uma certa região pode ser descrita aproximadamente por uma reta, de forma que o coeficiente linear do ajuste representa a quantidade adsorvida nos microporos. A equação é

$$
a(\varphi)=a_{\text {micro, } \max }+k_{\text {std }} S_{\text {ext }} \alpha_{s}(\varphi)
$$

onde $\alpha_{s}(\varphi)=a_{s t d}(\varphi) / a_{s t d}(\varphi=0,4)$ e $k_{s t d}=a_{s t d}(\varphi=0,4) / S_{s t d}$ onde $S_{s t d}$ é a área superficial da amostra-padrão. $a_{s t d}$ é a adsorção obtida na isoterma padrão, como por exemplo a reportada no artigo de Jaroniec, Kruk e Olivier ${ }^{[48]}$.

\subsubsection{Distribuição de tamanho de poros}

A distribuição de tamanho de poros é um dos fatores decisivos na incorporação de moléculas de interesse biológico na estrutura porosa de materiais como a SBA15. Um tamanho adequado garante que essas moléculas sejam capazes de se alojar dentro dos poros, de forma que, sob o ponto de vista de aplicação, avaliar essa distribuição é importante.

O cálculo da distribuição de tamanho de poros a partir de dados de adsorção de gases é feito de maneira iterativa, através de métodos baseados na equação de

\footnotetext{
" Poros com diâmetros na mesma ordem de grandeza de moléculas, isto é, menores que $1 \mathrm{~nm}$.
} 
Kelvin (v. ??).

A parte plana de uma isoterma tipo IV (fig. ??) é o ponto inicial para o cálculo da distribuição de mesoporos, uma vez que nessa região os poros estão completamente preenchidos.

No primeiro passo da dessorção** o volume de gás liberado é correspondente à remoção de condensado capilar. Cada passo seguinte envolve a remoção do condensado capilar de um conjunto de poros gradualmente menores e a diminuição da camada adsorvida à superfície do material, que inclui os poros de tamanho maior (isto é, os poros onde já não há mais um condensado capilar). Nessa situação, $v_{k}$ é o volume da região central do poro, delimitada pela camada adsorvida, com raio $r_{k}$, e $v_{p}$ é o volume do poro, com raio $r_{p}$, conforme representado na figura 2.5 .

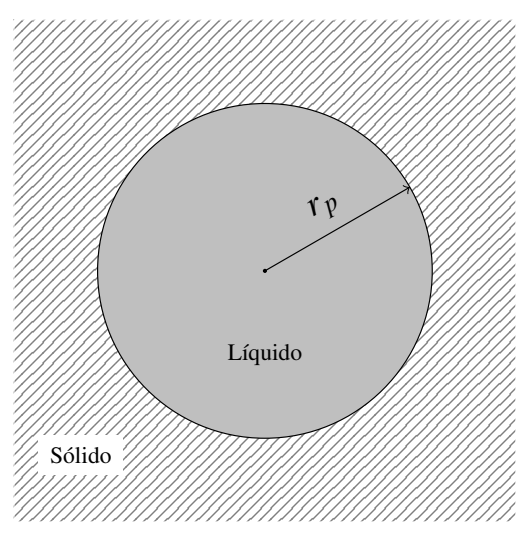

(a)

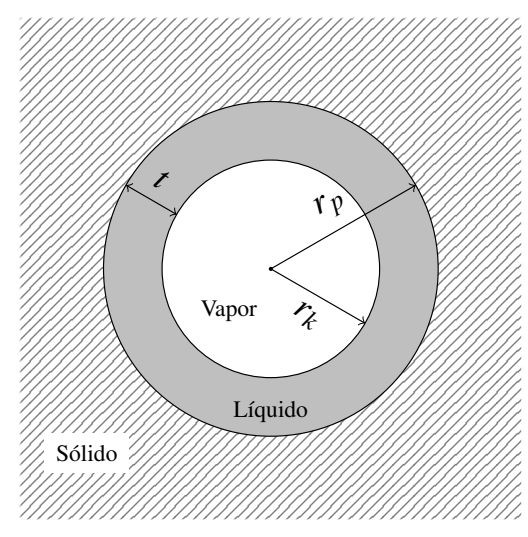

(b)

Figura 2.5: Poros durante a dessorção: (a) preenchido, (b) núcleo livre e camada adsorvida.

Supondo que $\delta v_{l}(j)$ seja o volume de nitrogênio líquido removido durante o j-ésimo passo, no primeiro passo da dessorção $(j=1)$ a remoção inicial de material resulta somente da evaporação capilar, de forma que o volume removido dos núcleos capilares é $\delta v_{k}(1)=\delta v_{l}(1)$. Então:

$$
v_{p}(1)=\frac{\bar{r}_{p}^{2}(1)}{\bar{r}_{k}^{2}(1)} v_{k}(1)
$$

onde $\bar{r}_{k}(1)$ e $\bar{r}_{p}(1)$ são os raios médios do núcleo e do poro, respectivamente.

\footnotetext{
${ }^{* *}$ No contexto do cálculo da PSD, entende-se por dessorção o caminho feito de valores maiores para valores menores de $p / p_{0}$, seja pelo ramo de dessorção ou de adsorção da isoterma.
} 
Com o andamento do processo $(j \neq 1)$ a contribuição da diminuição da camada adsorvida deve ser levada em conta, de forma que a expressão do volume removido da amostra torna-se, para o j-ésimo passo:

$$
\delta v(j)=\delta v_{k}(j)+\delta v_{t}(j)
$$

onde $\delta v_{k}()$ é o volume de núcleos esvaziado no j-ésimo passo e $\delta v_{t}(j)$ é o volume equivalente removido da camada adsorvida. O volume do conjunto de poros esvaziado no j-ésimo passo é, então, dado por

$$
\delta v(j)=\frac{\bar{r}_{p}^{2}(j)}{\left[\bar{r}_{p}(j)+\delta t(j)\right]^{2}} \times \delta v_{k}(j)
$$

onde $\bar{r}_{k}(j)$ e $\bar{r}_{p}(j)$ são os raios médios do núcleo e do poro, respectivamente, para o j-ésimo passo.

Através da utilização cíclica dessas equações (2.38, 2.39 e 2.40) pode-se então calcular as contribuições sucessivas de cada grupo de poros para cada passo da curva de dessorção. Para isso, entretanto, é necessário conhecer o valor de $\delta v_{t}(j)$. Considerando que a relação geométrica entre a área lateral de um cilindro e o seu volume é $a=2 \mathrm{~V} / r$, pode-se concluir que

$$
\begin{aligned}
\delta a_{k}(j) & =\delta a_{p}(j) \frac{\bar{r}_{p}(j)-\bar{t}(j)}{\bar{r}_{p}(j)} \\
& =\delta a_{p}(j) \times \rho(j)
\end{aligned}
$$

$\operatorname{com} \bar{r}_{p}(j)-\bar{t}(j)=\bar{r}_{k}(j)$, obviamente.

No método BJH original o fator $\rho(j)$ era suposto constante, correspondendo ao tamanho de poro mais comum, devido a dificuldades de cálculo. Atualmente, com a capacidade de processamento dos computadores atuais, esse valor é calculado a partir de uma expressão para a espessura estatística da camada adsorvida, dada por $^{[49]}$

$$
t\left(p / p_{0}\right)=0,1\left[\frac{60,65}{0,03071-\log \left(p / p_{0}\right)}\right]
$$




\title{
Modelagem numérica de sílica mesoporosa ordenada
}

\author{
"Infinite Diversity in Infinite Combinations."
}

- Axioma fundamental da filosofia Vulcana

\subsection{Modelo para a estrutura da SBA-15}

A sílica SBA-15 pode ser descrita como sendo um sistema consistindo de buracos polidispersos (fase " 1 ”) com densidade eletrônica $\rho_{1}$ e fração de volume $\phi_{1}$ inseridas em uma matriz (fase "2") de densidade eletrônica $\rho_{2}$ e fração de volume $\phi_{2}=1-\phi_{1}$, com interfaces nítidas. A intensidade espalhada pode então ser descrita como ${ }^{[33]}$

$$
I(q)=\left(\rho_{1}-\rho_{2}\right)^{2} n_{d}\left\langle F(q)^{2}\right\rangle(1+\beta(q)[\langle Z(q)\rangle-1] G(q))
$$

onde $\left\langle F(q)^{2}\right\rangle=P(r)$ é o fator de forma, $n_{d}$ é a densidade numérica de partículas e $(1+\beta(q)[\langle Z(q)\rangle>-1] G(q))=S(q)$ é o fator de estrutura, que descreve a distribuição espacial das partículas.

O tamanho e a distribuição espacial das partículas são supostos independentes um do outro, de forma que a intensidade espalhada pode ser decomposta em termos de $F(q)$ e $S(q)$ (eq. 3.1). 
$\mathrm{O}$ fator de forma, como visto anteriormente (eq. 2.5), está relacionado ao formato das partículas e pode ser expresso analiticamente para corpos simples ${ }^{[50]}$. Para um cilindro de raio $R$ e comprimento $L$ o fator de forma $P_{c i l}(q)$ é dado por

$$
P_{\text {cil }}=\int_{0}^{\pi / 2}\left[\frac{2 J_{1}(q R \operatorname{sen} \alpha)}{q R \operatorname{sen} \alpha} \frac{\operatorname{sen}(q L \cos \alpha / 2)}{q L \cos \alpha / 2}\right]^{2} \operatorname{sen} \alpha \mathrm{d} \alpha
$$

onde $J_{1}$ é a função de Bessel de primeira ordem. No caso de materiais como a SBA-15, em que o comprimento dos poros (cilindros) é muito maior que seu raio, esse fator pode ser aproximado por um termo longitudinal e um termo da seção transversal:

$$
P(q)=P_{\text {rod }}(q) P_{c s}(q)
$$

onde $P_{\text {rod }}(q)$ é tomado como o fator de forma de uma haste infinitamente longa ${ }^{[50]}$, enquanto $P_{c s}(q)=\left(F_{c s}(q)\right)^{2}$ e $F_{c s}(q)$ é dado por

$$
F_{c s}(q)=\frac{\Delta \rho_{\text {out }}}{\Delta \rho_{\text {in }}} R_{\text {out }}^{2} \frac{2 J_{1}(q R)}{q R} e^{-\frac{1}{2} q^{2} \sigma_{\text {int }}}-\left(\frac{\Delta \rho_{\text {out }}}{\Delta \rho_{\text {in }}}-1\right) R_{\text {in }}^{2} \frac{2 J_{2}(q R)}{q R}
$$

onde $\Delta \rho_{\text {out }} / \Delta \rho_{\text {in }}$ é a razão entre os contrastes de densidade eletrônica da parede e do interior do poro com relação ao meio em que o sistema se encontra, $R_{\text {out }}$ e $R_{\text {in }}$ são o raio externo e interno do poro, respectivamente, e $\sigma_{i n t}$ é a largura da interface Gaussiana entre $R_{\text {in }}$ e $R_{\text {out }}$. Uma representação esquemática está apresentada na figura 3.1. No cálculo do espalhamento, a composição dos perfis de densidade eletrônica dos vários poros resulta na densidade eletrônica da parede.

O fator de estrutura $S(q)$ contém o fator de rede $Z(q)$, expresso por ${ }^{[51 ; 33]}$

$$
Z(q)=c \frac{2}{\sqrt{3} a^{2} q} \sum_{\{h k\}} m_{h k} L_{h k}(q)
$$

onde $a$ é o parâmetro de rede, $m_{h k l}$ o fator de multiplicidade dos picos da rede hexagonal* e $L_{h k}$ é o formato (normalizado) dos picos, que estão localizados em $q_{h k}=(4 \pi / a \sqrt{3})\left(h^{2}+h k+k^{2}\right)^{1 / 2}$ e tem a forma

\footnotetext{
${ }^{*} m_{h 00}=m_{h h 0}=6, m_{h k 0}=12$ e $m_{0 k l}=0$.
} 


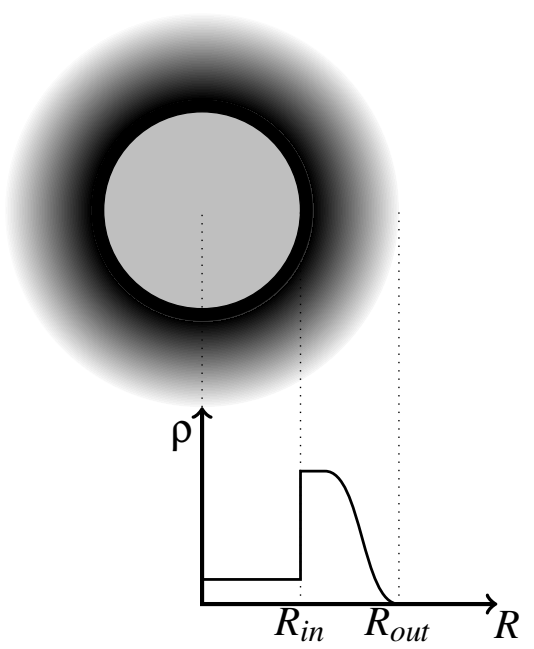

Figura 3.1: Representação esquemática do contraste de densidade eletrônica radial do poro.

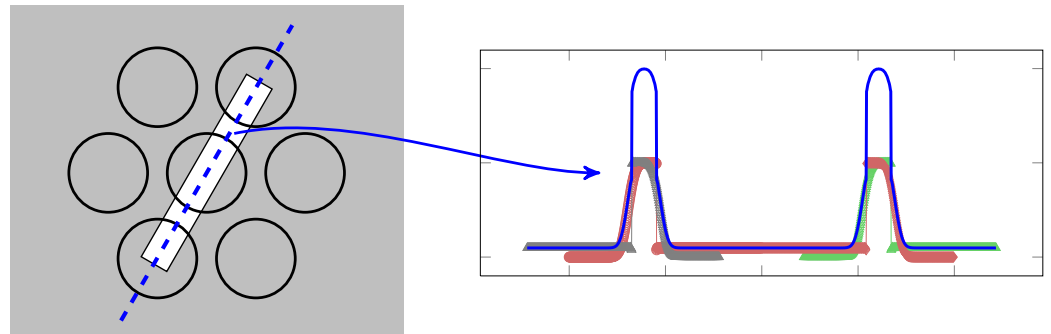

Figura 3.2: Diagrama demonstrando a relação entre o perfil de densidade eletrônica radial (fig. 3.1 e a rede hexagonal bidimensional dos poros.

$$
L_{h k}(q)=\frac{2}{\pi \delta}\left|\frac{\Gamma\left[v / 2+i \gamma_{v} 2\left(q-q_{h k}\right) /(\pi \delta)\right]}{\Gamma[v / 2]}\right|^{2}, \quad \int_{-\infty}^{\infty} L_{h k}(q) \mathrm{d} q=1
$$

onde $\Gamma[z]$ é a função Gama complexa. O parâmetro $v$ determina o formato do pico como Lorentziano, para $v \rightarrow 0$, ou Gaussiano, para $v \rightarrow \infty$. A largura do pico é controlada por $\delta$, relacionado ao tamanho do domínio $D$ pela equação de Debye-Scherrer:

$$
D=\frac{2 \pi}{\delta}
$$

O parâmetro $c$ é uma constante que serve para garantir a preservação do invariante de Porod (em particular nos casos de famílias de curvas obtidas em 
sequência), obtido através da eq. 2.1.2:

$$
Q=\int_{0}^{\infty} I(q) q^{2} \mathrm{~d} q=2 \pi^{2} \phi(1-\phi)\left(\rho_{1}-\rho_{2}\right)^{2}
$$

onde $\phi$ é a fração em volume de uma das fases. Na prática, este parâmetro funciona também como um "fator de escala" para o fator de estrutura.

A variação na posição de cada cilindro em torno de sua posição média é descrita como um deslocamento quadrático médio $\sigma_{a}^{2}$, sendo levada em conta com a adição de um parâmetro de desordem ${ }^{\dagger}$ :

$$
G(q)=e^{\sigma_{a}^{2} a^{2} q^{2}}
$$

A influência da polidispersão dos tamanhos dos cilindros é incluída com o fator $\beta(q)$ :

$$
\beta(q)=\frac{\left\langle F_{c s}(q)\right\rangle^{2}}{\left\langle F_{c s}^{2}(q)\right\rangle}
$$

onde $F_{c s}(q)$ é a amplitude de espalhamento da seção transversal do cilindro, e os chevrons indicam uma média sobre todos os possíveis diâmetros. Os termos da equação 3.10 são dados por

$$
\begin{aligned}
\left\langle F_{c s}(q)\right\rangle & =\frac{\int_{0}^{\infty} D(r) F_{c s}(q, r) \mathrm{d} r}{\int_{0}^{\infty} D(r) \mathrm{d} r} \\
\left\langle F_{c s}^{2}(q)\right\rangle & =\frac{\int_{0}^{\infty} D(r) F_{c s}^{2}(q, r) \mathrm{d} r}{\int_{0}^{\infty} D(r) \mathrm{d} r}
\end{aligned}
$$

Uma distribuição de Schulz-Zimm ${ }^{[52]}$ é utilizada para o cálculo das médias 3.11 e 3.12 :

$$
D(x)=\left(\frac{z+1}{x_{0}}\right)^{z+1} \frac{x^{z}}{\Gamma(z+1)} e^{-(z+1) \frac{x}{x_{0}}}
$$

onde $\Gamma(x)$ é a Função Gama real, $x_{0}$ é o centro da distribuição e $z$ está relacionado à polidispersidade $\sigma r / R$ dos raios através de

\footnotetext{
${ }^{\dagger}$ Similar ao fator de Debye-Waller que descreve vibrações térmicas em cristais.
} 


$$
z=\frac{1}{(\sigma r / R)^{2}}-1
$$

A microporosidade surge de cadeias de polímero soltas do lado de fora das micelas; a alto $q$ elas espalham como cadeias poliméricas ${ }^{[53 ; 54]}$, cuja intensidade pode ser descrita por um fator de forma de cadeia Gaussiana ${ }^{[55]}$ :

$$
I_{\text {chain }}(q)=\frac{2\left[e^{q^{2} R_{g}^{2}}-1+\left(q^{2} R_{g}^{2}\right)\right]}{\left(q^{2} R_{g}\right)^{2}}
$$

onde $R_{g}$ é o raio de giro de um microporo.

Finalmente, são adicionados um termo constante e um termo de espalhamento a baixo $q\left(\propto q^{-4}\right)$. A intensidade final fica então

$$
\begin{gathered}
I(q)=S c_{1} P_{\text {rod }}(q)\left\langle F_{c s}^{2}(q)\right\rangle(1+\beta(q)[\langle Z(q)\rangle-1] G(q))+ \\
S c_{2} I_{\text {chain }}(q)+S c_{\text {const }}+S c_{\text {linear }} \cdot q+ \\
S c_{\text {quad }} \cdot q^{2}+S c_{q^{-4}} \cdot q^{-4}
\end{gathered}
$$

\subsection{Implementação}

A subrotina de ajuste é escrita em FORTRAN, utilizando o método de mínimos quadrados não-linear para o ajuste ${ }^{[50]}$, implementando o algoritmo LevenbergMarquardt ${ }^{[56]}{ }^{\ddagger}$ Esse método também é conhecido como Método de Mínimos Quadrados Amortecido.

A curva ajustada aos dados experimentais é calculada a partir da equação 3.16 é

$$
\tilde{I}(\langle q\rangle)=\int R(\langle q\rangle, q) I(q) \mathrm{d} q
$$

onde $R(\langle q\rangle, q)$ é a função de resolução ${ }^{[43]}$ descrevendo a faixa de valores do vetor de espalhamento coberta pela "sonda" definida por $\langle q\rangle$. Os parâmetros de

\footnotetext{
$\ddagger$ Este algoritmo foi descoberto por Kenneth Levenberg ${ }^{[57]}$ em 1944 e redescoberto por Donald Marquardt $^{[58]}$ em 1963.
} 


\begin{tabular}{cc} 
Parâmetro & Significado \\
\hline \hline$S c_{1}$ & Fator de escala global \\
$S c_{\text {chain }}$ & Fator de escala para a microporosidade \\
$c$ & Parâmetro livre; Garante a conservação do invariante $Q$ \\
$a$ & Parâmetro de rede \\
$D$ & Tamanho do domínio ordenado de poros \\
$v$ & Formato do pico (Lorentziano/Gaussiano) \\
$\sigma_{a}$ & Desordem na rede hexagonal (posição dos poros) \\
$R_{\text {in }}$ & Raio interno dos poros \\
$\sigma_{R} / R$ & Dispersão relativa dos tamanhos dos poros \\
$L$ & Comprimento dos poros \\
$R_{\text {out }}$ & "Raio externo" dos poros. \\
$\Delta \rho_{\text {out }}$ & Contraste relativo de densidade eletrônica \\
$\Delta \rho_{\text {in }}$ & entre a parede e o interior do poro \\
$\sigma_{\text {int }}$ & Largura da interface entre $R_{\text {in }}$ e $R_{\text {out }}$ \\
$R_{g}$ & Raio de giro dos microporos \\
$S c_{\text {const }}$ & Background constante \\
$S c_{\text {linear }}$ & Background linear \\
$S c_{\text {quad }}$ & Background quadrático \\
$S c_{q^{-4}}$ & Fator de escala do espalhamento a baixo $q$
\end{tabular}

Tabela 3.1: Parâmetros utilizados na subrotina de ajuste e equivalência com os termos do modelo (seção 3.1).

entrada para essa função são estimados a partir da largura do feixe no detector.

A tabela 3.1 apresenta os parâmetros utilizados na rotina de ajuste e a sua relação com os termos embutidos na equação 3.1 .

\subsection{Perfil de densidade eletrônica}

O perfil de densidade eletrônica médio (como o exemplificado na figura 3.1) pode ser calculado a partir dos parâmetros obtidos no ajuste. Isso é feito com o uso de uma transformada de Hankel:

$$
\rho_{t}(r)=2 \pi \int_{0}^{\infty} F_{c s}(q) J_{0}(q r) \mathrm{d} q
$$

onde $F_{c s}(q)$ é a amplitude de espalhamento para a seção transversal do cilindro e $J_{0}(x)$ é a função de Bessel do primeiro tipo de zerésima ordem.

Os perfis assim calculados são normalizados pelo valor de $\Delta \rho_{\text {out }}$ na análise dos dados (como, por exemplo, na figura 5.9). 


\section{Métodos experimentais}

"Vou atirar uma bomba ao destino."

- Álvaro de Campos

\subsection{Preparação de amostras}

\subsubsection{Síntese}

A rota de síntese utilizada, descrita a seguir, é a original proposta para a SBA-15 ${ }^{[59]}$.

Em uma síntese típica da SBA-15 são utilizadas as proporções em massa apresentadas na tabela 4.1 .

\begin{tabular}{|cc|}
\hline TEOS & $8,6 \mathrm{~g}$ \\
$\mathrm{HCl} 2 \mathrm{M}$ & $122 \mathrm{~g}$ \\
$\mathrm{P} 123$ & $4 \mathrm{~g}$ \\
$\mathrm{H}_{2} \mathrm{O}$ & $28 \mathrm{~g}$ \\
\hline
\end{tabular}

Tabela 4.1: Proporções em massa empregadas na síntese da sílica SBA-15.

O Pluronic P123 $\left(\mathrm{PEO}_{20} \mathrm{PPO}_{70} \mathrm{PEO}_{20}\right.$, fig. 4.1) é solubilizado em meio ácido ( $\mathrm{HCl}$ a $2 \mathrm{M}$ ) e submetido a agitação por 2 horas. Nesse ponto, as moléculas do copolímero se organizam em agregados micelares cujo formato depende da sua 


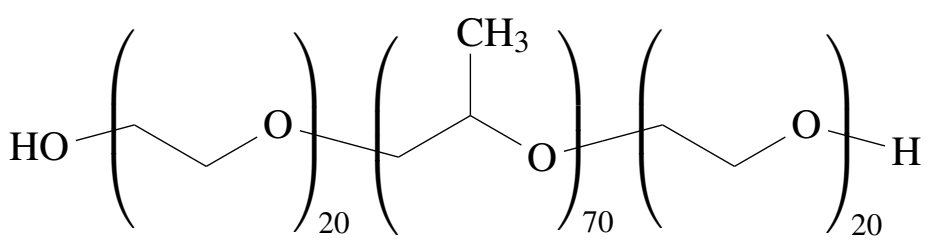

Figura 4.1: Estrutura do copolímero tribloco Pluronic ${ }^{\circledR}$ P123

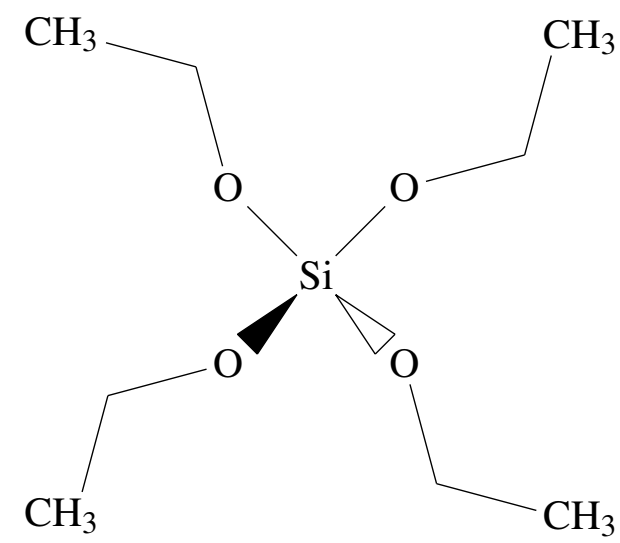

Figura 4.2: Estrutura da fonte de sílica (TEOS)

concentração $^{[5]}$. Na concentração utilizada formam-se micelas cilíndricas cujo raio está diretamente relacionado às proporções geométricas da molécula do copolímero. Em seguida é adicionado o TEOS $\left(\mathrm{SiC}_{8} \mathrm{H}_{20} \mathrm{O}_{4}\right.$, fig. 4.2) e mantém-se a mistura sob agitação por 24 horas em temperatura controlada de $313 \mathrm{~K}\left(40^{\circ} \mathrm{C}\right)$. Durante esse período o TEOS é incorporado à porção hidrofóbica das micelas, onde passa por um processo de hidrólise, que gera $\mathrm{SiO}_{2}$ e etanol:

$$
\mathrm{SiC}_{8} \mathrm{H}_{20} \mathrm{O}_{4}+2 \mathrm{H}_{2} \mathrm{O} \longrightarrow \mathrm{SiO}_{2}+4 \mathrm{C}_{2} \mathrm{H}_{5} \mathrm{OH}
$$

$\mathrm{O} \mathrm{SiO}_{2}$ se aloja na porção hidrofílica das micelas, onde vai dar origem às paredes do material. Após esse processo de agitação a mistura é transferida para um auto-clave e submetida a tratamento hidrotérmico por 48 horas a $383 \mathrm{~K}\left(100^{\circ} \mathrm{C}\right)$, sendo em seguida lavada abundantemente com água destilada e seca ao ar livre à temperatura ambiente. $\mathrm{O}$ processo em auto-clave proporciona a organização final da estrutura hexagonal das micelas, bem como a densificação das paredes. Finalmente, o pó resultante é submetido a calcinação para remoção do molde polimérico sob atmosfera de $\mathrm{N}_{2}$ por 2 horas e ar por 4 horas, com rampa de aquecimento de 
$2 \mathrm{Kmin}^{-1}$ até $813 \mathrm{~K}\left(540^{\circ} \mathrm{C}\right)$ sob $\mathrm{N}_{2}$. Uma representação esquemática do processo de síntese está apresentada na figura 4.3.

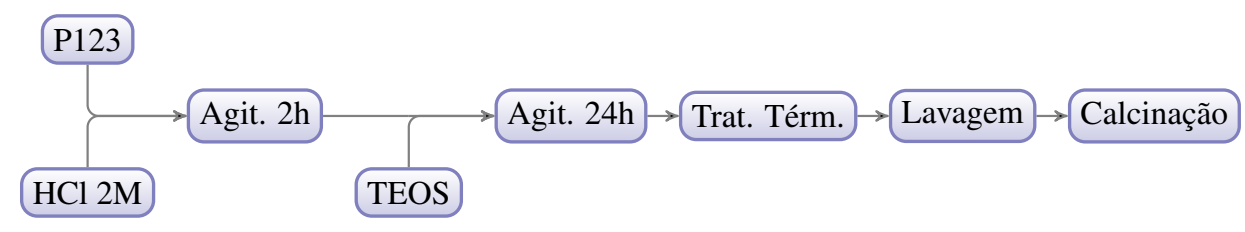

Figura 4.3: Esquema representando o processo de síntese da sílica mesoporosa SBA-15.

\subsubsection{Ensaios de incorporação}

Ensaios de incorporação de moléculas de interesse biológico foram realizados com a SBA-15. Esses estudos foram realizados através da mistura da substância à sílica em solução aquosa com pH controlado.

Foram executados experimentos com vacina contra Hepatite B, insulina e albumina bovina (BSA). O pH foi controlado com uso de uma solução tampão salina de fosfato (PBS), preparada segundo as quantidades apresentadas na tabela 4.2 .

\begin{tabular}{|cc|}
\hline $\mathrm{H}_{2} \mathrm{O}$ & $500 \mathrm{~g}$ \\
$\mathrm{NaCl}$ & $4 \mathrm{~g}$ \\
$\mathrm{KCl}$ & $0,1 \mathrm{~g}$ \\
$\mathrm{Na}_{2} \mathrm{HPO}_{4}$ & $0,575 \mathrm{~g}$ \\
$\mathrm{KH}_{2} \mathrm{PO}_{4}$ & $0,1 \mathrm{~g}$ \\
\hline
\end{tabular}

Tabela 4.2: Quantidades utilizadas na preparação do PBS.

Foram utilizados dois tipos de insulina: regular ${ }^{[60]}$, produzida pela Eli Lilly, e NPH ${ }^{[61]}$, produzida pela Novo Nordisk, marcada com um átomo de Zn, ambas adquiridas diretamente em farmácia. Além disso foi utilizada a vacina contra Hepatite $\mathrm{B}^{[62]}$ (proteína de DNA recombinante HBsAg), fornecida pela Cristália.

As misturas foram feitas em béquer de vidro, utilizando água destilada. Os componentes eram misturados com agitação magnética e depois submetidos a um período de repouso ou agitação, conforme o estudo sendo executado. As secagens foram realizadas em estufa a temperaturas de até $313 \mathrm{~K}\left(40^{\circ} \mathrm{C}\right)$, de forma a evitar a degradação tanto da insulina quanto das proteínas presentes na vacina. 


\subsubsection{Preparação de amostras para os experimentos in-situ}

Para estudo da liberação de fármacos a partir da sílica SBA-15 foram executados experimentos com BSA e com insulina. A BSA é uma molécula tradicionalmente utilizada como antígeno experimental e, por isso, é a candidata ideal para os experimentos preliminares. A insulina, por sua vez, tem importância estratégica no tratamento de diabetes e por isso foi utilizada nesses experimentos.

Para simular as condições ambientais do organismo às quais os complexos formados por essas moléculas com a SBA-15 foram utilizadas duas soluções que mimetizam as condições por onde vão passar os elementos que entram no trato gastrointestinal: suco gástrico e suco intestinal.

O suco gástrico, presente no estômago, é um meio altamente ácido composto fundamentalmente por ácido clorídrico, $(\mathrm{HCl})$, cloreto de potássio e cloreto de sódio ( $\mathrm{KCl}$ e $\mathrm{NaCl}$, respectivamente). Ele também contém enzimas digestivas, em particular a pepsina, cuja função é desenovelar as proteínas ingeridas, cujas cadeias de aminoácidos serão quebradas posteriormente no trato gastrointestinal.

O suco intestinal (também conhecido como suco entérico) propriamente dito é uma solução de $\mathrm{pH}$ relativamente neutro cuja função é ativar as enzimas fornecidas pelo suco pancreático, coletivamente conhecidas como pancreatina, para que o processo de digestão possa prosseguir com a quebra das cadeias de aminoácidos chegando do estômago. Além disso, o suco intestinal também contém uma coleção de outras substâncias como hormônios, muco e substâncias que neutralizam o ácido clorídrico. É neste processo que açúcares, proteínas e gorduras são reduzidos a seus elementos mais básicos e absorvidos pelo organismo.

Ambos os sucos foram mimetizados segundo padrões internacionais estabelecidos pela United States Pharmacopeia ${ }^{[63]}$.

O suco gástrico foi preparado dissolvendo-se $0,2 \mathrm{~g}$ de $\mathrm{NaCl}$ e $0,32 \mathrm{~g}$ de pepsina purificada, derivada de mucosa estomacal suína, em $0,7 \mathrm{~mL}$ de $\mathrm{HCl}$ previamente diluído. Em seguida o volume foi completado a $100 \mathrm{~mL}$ com água, resultando em uma solução com pH 1,2.

$\mathrm{O}$ suco intestinal foi preparado dissolvendo-se $0,68 \mathrm{~g}$ de $\mathrm{KH}_{2} \mathrm{PO}_{4}$ em $25 \mathrm{~mL}$ de água, seguido de 7,7 mL de solução $0,2 \mathrm{~N}$ de $\mathrm{NaOH}$ e $50 \mathrm{~mL}$ de água. Foi adicionado $1 \mathrm{~g}$ de pancreatina e o volume foi completado com água até $100 \mathrm{~mL}$. O 
pH desta solução era 6,8.

As amostras utilizadas nos experimentos de liberação foram preparadas conforme a seguir.

\section{BSA}

O lote de albumina utilizado em todos os experimentos foi adquirido junto à empresa Sigma-Aldrich*.

Amostras de BSA incorporada à sílica SBA-15 foram misturadas numa proporção em massa de 0,4:1 (BSA:SBA-15) em solução PBS. A albumina foi previamente solubilizada na solução, sendo em seguida adicionada a sílica SBA-15. Essa mistura foi mantida em repouso por 2 horas e seca por evaporação em estufa a $T=313 \mathrm{~K}\left(40^{\circ} \mathrm{C}\right)$. Metade do pó resultante desse processo foi separada e misturada ao polímero Eudragit ${ }^{\circledR}$, na proporção e massa de 1:1 (Eudragit:SBA-15), e submetida a novo processo de secagem.

\section{Insulina}

A insulina utilizada nos experimentos foi adquirida comercialmente, fornecida pela Eli Lilly, derivada de DNA recombinante, modelo Humulin ${ }^{\circledR}$ R, adquirida em frascos contendo $10 \mathrm{ml}$.

A preparação das amostras com insulina partiu da diluição da insulina como recebida numa proporção volumétrica de 1:3 em 50ml PBS. Em seguida, a cada ml dessa solução foram misturados $1,25 \mathrm{mg}$ de SBA-15, resultando numa proporção de 20000 UI:1 g (Insulina:SBA-15).

Essa solução foi então mantida em repouso por $2 \mathrm{~h}$ e seca por evaporação em estufa a $313 \mathrm{~K}\left(40^{\circ} \mathrm{C}\right)$. Da mesma forma que com a BSA, metade do pó resultante foi separado e misturado ao Eudragit para recobrimento, na mesma proporção em massa de 1:1 (Eudragit:SBA-15) e seca novamente.

*Product\# 12345-234. 


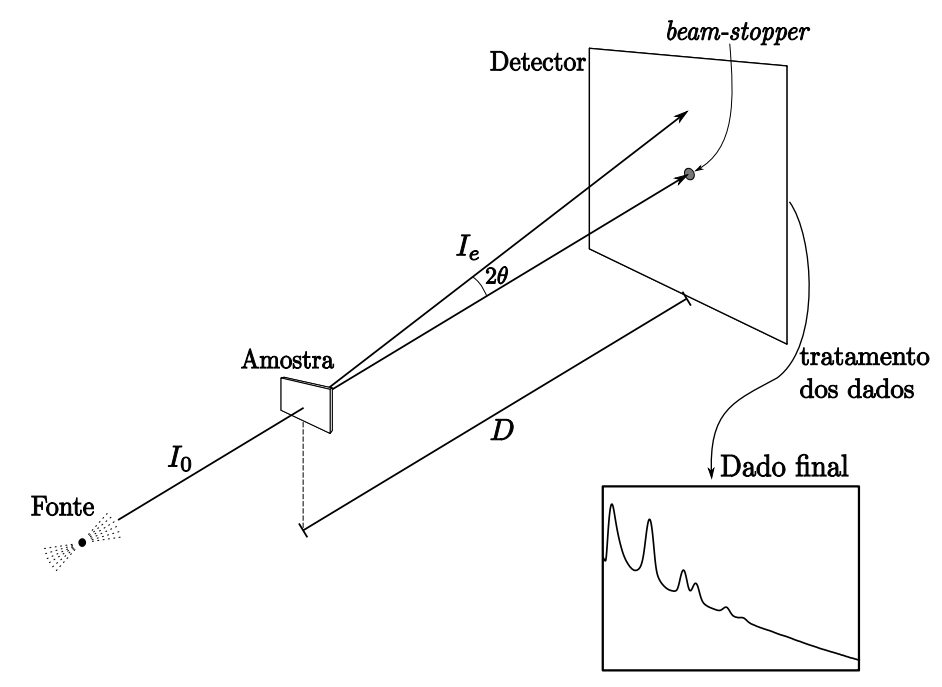

Figura 4.4: Geometria experimental de um experimento de SAXS/SAXRD.

\subsection{Espalhamento de raios $X$ a baixo ângulo}

\subsubsection{Montagem experimental}

Neste trabalho as amostras possuem poros com dimensões da ordem de nanometros a dezenas de nanometros, ou seja, o espalhamento ocorre na região de baixos ângulos, próxima ao feixe direto (composto de fótons não-interagentes).

Nessa condição fatores como alinhamento do feixe, tamanho do beam-stopper e distância amostra-detetor tornam-se mais importantes, uma vez que quanto menor o ângulo mínimo atingido maior é a dimensão observada no espaço direto.

Neste trabalho os experimentos de espalhamento/difração de raios $\mathrm{X}$ a baixo ângulo foram realizados com o arranjo experimental apresentado na figura 4.4, com geometria de transmissão. Fótons provenientes da fonte são selecionados e colimados, incidem sobre a amostra, acondicionada em porta-amostra próprio, e atingem o detetor, protegido do feixe direto por um beam-stopper, a uma distância D.

O gráfico tipicamente obtido é composto pelo espalhamento de raios $\mathrm{X}$ de inomogeneidades eletrônicas não correlacionadas (fator de forma) e por um padrão de interferência proveniente do arranjo espacial dessas inomogeneidades (fator de 
estrutura) ${ }^{[41]}$.

No Laboratório de Cristalografia do IF-USP o equipamento utilizado foi um Bruker Nanostar, com feixe ponto gerado por um tubo de cobre com corrente $I=30 \mathrm{~mA}$ e tensão aceleradora $V=40 \mathrm{kV}$ e monocromatizado por um espelho de Göbbel. As amostras foram acondicionadas em porta-amostra específico do equipamento ou especialmente projetado para medidas em condições sob pressão. Esse equipamento conta com um detector filamentar HiStar bidimensional.

Também foram feitas medidas no Laboratório Nacional de Luz Síncrotron, localizado no CNPEM, em Campinas/SP. Naquele laboratório as medidas foram executadas na linha SAXS2, onde o feixe de raios X se origina em um dipolo magnético com campo de 1,67 T, e é focalizado verticalmente por um espelho curvo cilíndrico e horizontalmente por um monocromador side-bounce de $\mathrm{Si}(111)$ com um corte assimétrido de 8 graus. Essa linha é equipada com um detector CCD fabricado pela MAR (model\# MAR-165). Todo o caminho é mantido sob vácuo, incluindo a região onde se localiza a amostra.

\subsubsection{Medidas in-situ}

A incorporação e liberação de moléculas de interesse biológico foram estudadas através de medidas in-situ de SAXS de soluções contendo a sílica SBA-15 e BSA ou insulina regular.

Nas medidas realizadas no Nanostar o arranjo experimental consistia de um conjunto de tubos de polietileno interligando os elementos do circuito, que incluíam

- Erlenmeyer contendo a solução, posicionado sobre um agitador magnético;

- Bomba peristáltica modelo SVP4 100 psi;

- Flange da câmara de raios X;

- Porta-amostras contendo um capilar de quartzo (no interior do qual a solução era exposta aos raios $\mathrm{X}$ )

Os experimentos foram realizados durante períodos de até 48 horas, com frames de 6 horas cada.

Nas medidas realizadas no LNLS o arranjo experimental incluía:

- Proveta contendo a solução, posicionada sobre um agitador magnético; 
- Bomba peristáltica Provitec DM-5900 (pertencente à linha de luz);

- Tubos flexíveis conduzindo a solução ao porta-amostras;

- Porta-amostras adaptado ao arranjo da linha de luz expondo um capilar de quartzo com a solução ao feixe de raios $\mathrm{X}$

Os experimentos foram realizados com frames de 5 minutos, durante 12 horas no caso dos experimentos de liberação e durante 1 hora durante o experimento de incorporação.

\subsection{Adsorção de gases}

Isotermas de adsorção podem ser determinadas através da medida da quantidade de gás removida da fase gasosa (p. ex. métodos volumétricos) ou através da medida da quantidade incorporada pela amostra (p. ex. métodos gravimétricos). Neste trabalho apenas métodos volumétricos foram utilizados.

Nos métodos volumétricos uma quantidade conhecida de gás é inserida no sistema onde está a amostra. A quantidade de gás adsorvido à sua superfície será igual à diferença entre a quantidade injetada e a quantidade necessária para preencher o espaço em torno da amostra (espaço livre) do sistema, dada a pressão de equilíbrio atingida.

O espaço livre é definido como a diferença entre o volume do porta-amostras vazio e o volume da amostra. O volume total do porta-amostras é um valor conhecido, e é mantido como referência. O seu volume com a amostra é medido através do preenchimento do sistema com um gás completamente inerte (usualmente $\mathrm{He}$ ), com pequeno potencial de adsorção. Dessa forma, a partir da quantidade de gás utilizada e da pressão final dentro do porta-amostra, calcula-se o volume disponível para a fase gasosa do adsorbato, que é o espaço livre.

O tamanho da dose de gás utilizada em cada passo da isoterma é determinado com o auxílio de um volume de dosagem, onde pressão e temperatura são medidas antes da abertura da válvula do porta-amostras.

A isoterma assim obtida é uma curva de quantidade adsorvida em função da pressão relativa (razão entre a pressão de equilíbrio e a pressão de saturação do adsorvente à temperatura da análise). 


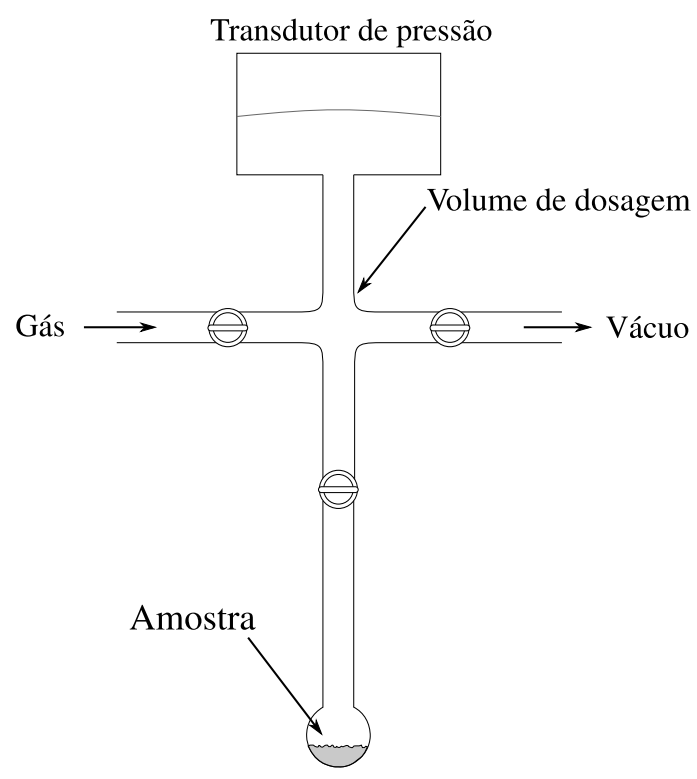

Figura 4.5: Arranjo para medida de isotermas de adsorção.

\subsubsection{Procedimento experimental}

A obtenção de uma isoterma de adsorção consiste em duas fases: degaseificação e medida.

A degaseificação é um tratamento térmico sob vácuo com o objetivo de retirar da amostra quaisquer substâncias que estejam adsorvidas à superfície, bem como minimizar a umidade e remover eventuais impurezas da amostra.

O porta-amostra é pesado enquanto vazio, assim como a amostra. Em seguida esta é colocada dentro do porta-amostra e nova pesagem é efetuada, determinandose assim um valor inicial para a massa de amostra. A pesagem da amostra isolada serve como guia para a separação da quantidade desejada a ser medida.

O conjunto é em seguida ligado ao equipamento de adsorção, onde a amostra é degaseificada num processo de duas partes: (a) aquecimento até a temperatura adequada e (b) tratamento por um período suficiente para que a taxa de liberação dessa amostra seja satisfatória (p. ex. $10 \mu \mathrm{mHg} / \mathrm{min}$ ). Simultaneamente a amostra é submetida a evacuação controlada até um determinado valor de pressão (p. ex. $1 \mathrm{mmHg}$ ), a partir do qual a evacuação é irrestrita, isto é, a taxa de evacuação não é mais limitada.

Para o processo de medida o conjunto porta-amostra+amostra é pesado nova- 
mente, e o valor de massa de amostra obtido é o que será utilizado nos cálculos de análise. O conjunto é posicionado no equipamento e o procedimento de medida é iniciado, com a determinação do espaço livre da amostra seguida da medida da isoterma segundo protocolo pré-estabelecido.

Neste trabalho todas as medidas de adsorção gasosa foram executadas num equipamento Micromeritics ASAP 2020, equipado com duas estações de degaseificação e uma de análise, com cold-trap de $\mathrm{N}_{2}$. Durante as medidas o sistema foi mantido à temperatura de $77 \mathrm{~K}$ em banho de $\mathrm{N}_{2} \ell$.

Amostras sem componentes degradáveis foram degaseificadas a $473 \mathrm{~K}\left(200^{\circ} \mathrm{C}\right)$ por 24 horas, enquanto amostras com componentes biológicos foram degaseificadas a $313 \mathrm{~K}\left(40^{\circ} \mathrm{C}\right)$ por 72 horas. Todas foram submetidas ao mesmo protocolo de medida. 


\section{5}

\section{Estudos in-situ}

"These heavy sands are language time and wind have silted here."

- James Joyce, Ulysses

\subsection{Síntese e caracterização de material para utiliza- ção}

Para utilização nos estudos in-situ de incorporação e liberação de moléculas na estrutura de poros da sílica SBA-15 uma grande quantidade de material foi sintetizada, para garantir a uniformidade das características estruturais da sílica pura e garantir a confiabilidade de comparações entre amostras.

Para tanto vários processos de síntese idênticos ao descrito na seção 4.1 foram executados, com as proporções entre reagentes apresentadas na tabela 4.1.

As sínteses foram realizadas em um banho térmico de óleo de silicone com temperatura previamente estabilizada a $313(5) \mathrm{K} 40(5){ }^{\circ} \mathrm{C}$, em uma chapa agitadora Nalgon Hotlab II. O tratamento hidrotérmico foi feito em auto-clave de teflon.

Em seguida o material foi caracterizado e separado para utilização. A figura 5.1 apresenta a isoterma de adsorção obtida para uma alíquota desse material, com a distribuição de tamanho de poros apresentada na figura 5.2, calculada a partir da curva de dessorção. 
A área superficial obtida para esse material é de $840(3) \mathrm{m}^{2} \mathrm{~g}^{-1}$, dos quais $259(3) \mathrm{m}^{2} \mathrm{~g}^{-1}$ respondem pela microporosidade das paredes. O volume total de poros, calculado a partir da quantidade adsorvida à pressão relativa $p / p_{0}=$ 0,994 , é de $1,22 \mathrm{~cm}^{3} \mathrm{~g}^{-1} \mathrm{~nm}^{-1}$, dos quais $0,1104(27) \mathrm{cm}^{3} \mathrm{~g}^{-1} \mathrm{~nm}^{-1}$ são advindos da microporosidade.

A distribuição de tamanho de poros apresenta um pico bem definido, com $\bar{D}=79,4(16) \AA$, representando uma dispersão nos diâmetros de aproximadamente $2 \%$.

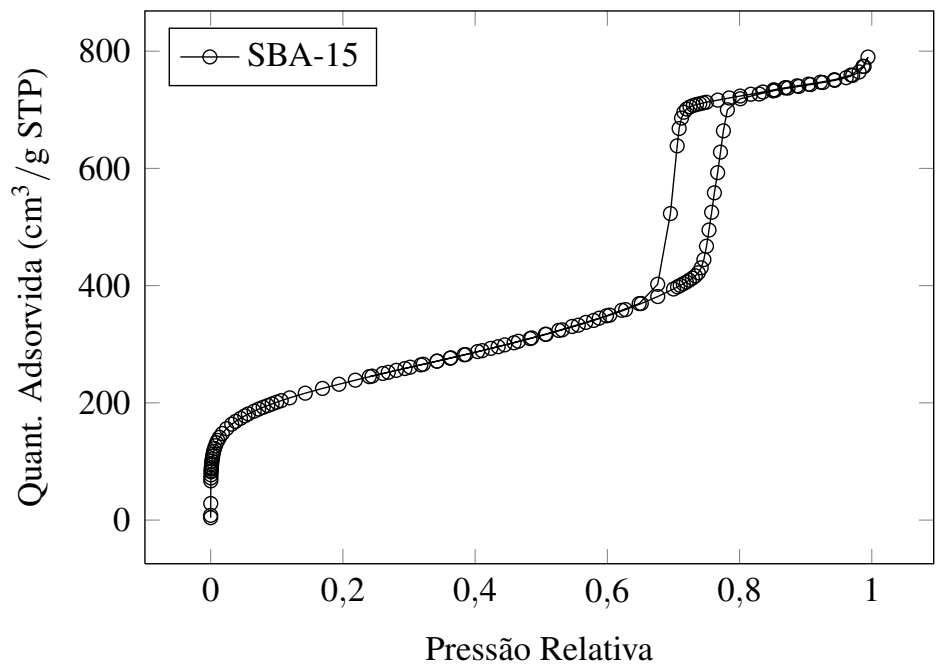

Figura 5.1: Isoterma de adsorção de uma amostra de SBA-15 sintetizada para os estudos in-situ. 


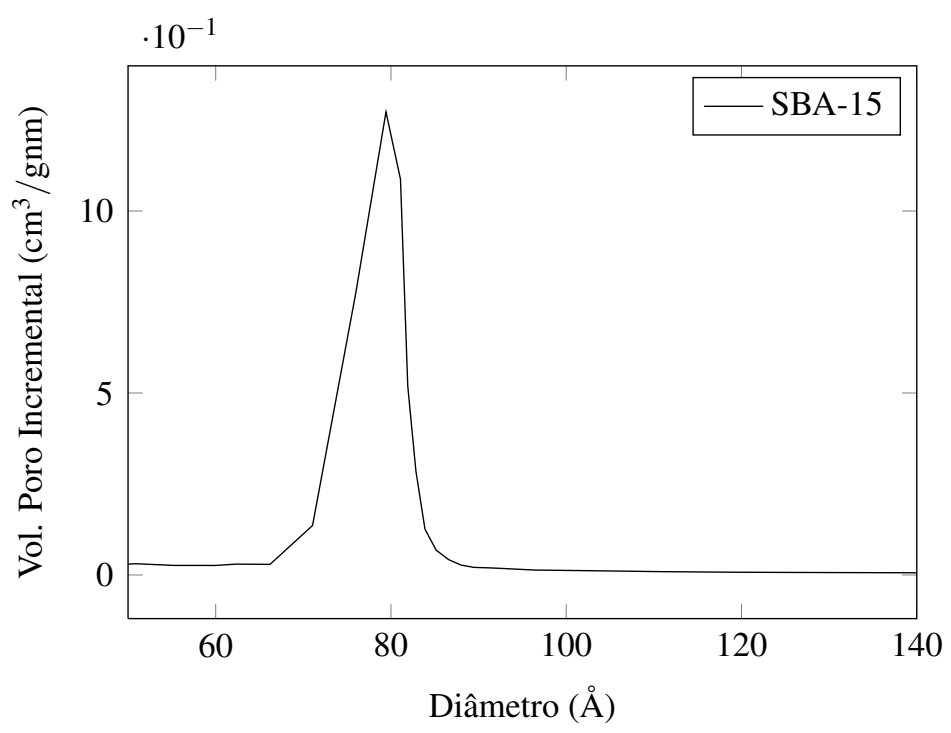

Figura 5.2: Distribuição de tamanho de poros de uma amostra de SBA-15 sintetizada para os estudos in-situ.

A caracterização por espalhamento de raios $X$ a baixo ângulo está apresentada no gráfico da figura 5.3, onde está representado também o ajuste do modelo teórico (linha azul). Esse ajuste resultou em um valor de $\chi^{2}=1,53$, com parâmetro de rede $a=121,74(6) \AA$ e raio médio dos poros $r=55,4(1) \AA$ e dispersão relativa dos raios de $12 \%$. O valor para o contraste de densidade eletrônica relativo entre a parede do poro e seu interior é $\Delta \rho_{\text {out }} / \Delta \rho_{\text {in }}=9,7(1)$.

A aparente discrepância entre os valores obtidos para o tamanho do poro a partir dos dados de SAXS e NAI é atribuída a alguns fatores.

A parede do poro não é perfeitamente plana, possuindo rugosidade e imperfeições, além de radicais hidroxila, aos quais as moléculas de $\mathrm{N}_{2}$ são mais sensíveis no que se refere à adsorção. Por outro lado, ao supor que a parede interna do poro seja lisa e abrupta, o modelo teórico apresentado no cap. 3 calcula um valor efetivo, o que resulta em um valor maior para o raio do poro.

A figura 5.5 apresenta imagens de SEM da sílica SBA-15, obtidas em um equipamento JEOL JSM-7401F. Essas imagens apresentam o formato dos feixes de poros da sílica, com alguns $\mu \mathrm{m}$ de comprimento e aproximadamente $0,3 \mu \mathrm{m}$ de diâmetro, o que possibilita uma estimativa de que cada feixe possui da ordem de 1000 poros. 
5.1 | síntese e caracterização de material para utilização

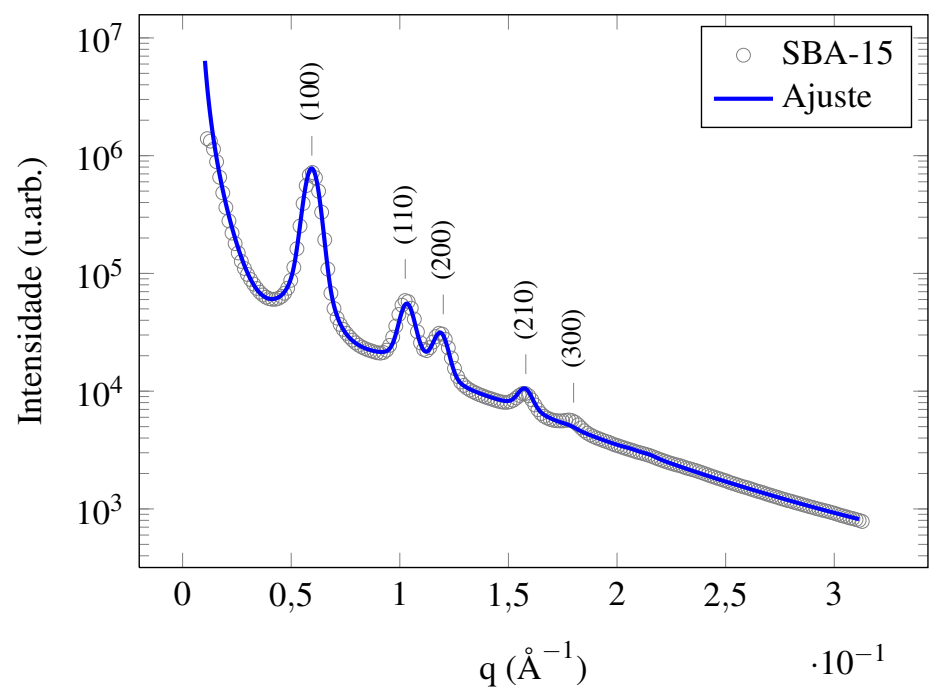

Figura 5.3: Curva de SAXS de uma amostra de SBA-15 sintetizada para os estudos in-situ.

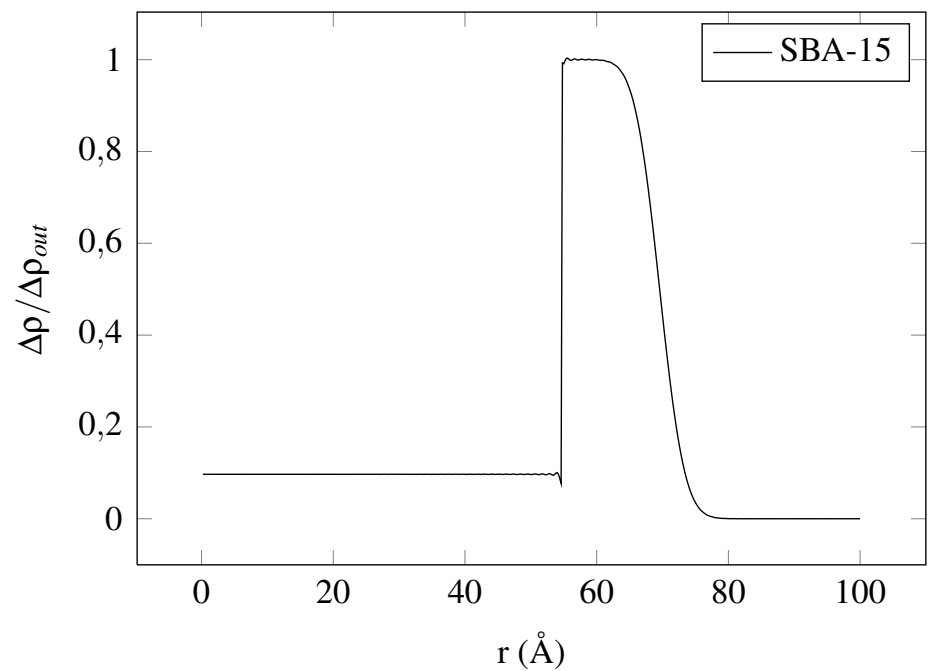

Figura 5.4: Perfil de densidade eletrônica calculado a partir do ajuste da figura 5.3. 


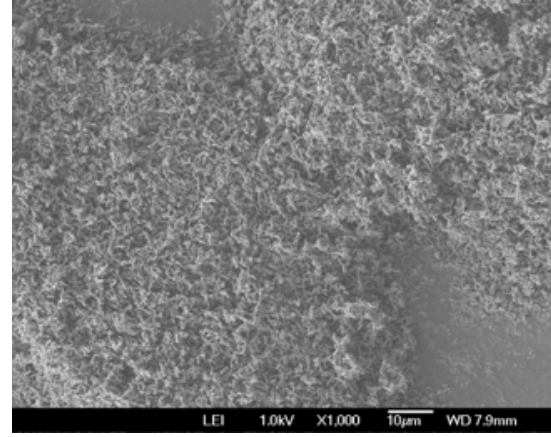

(a) $1000 x$

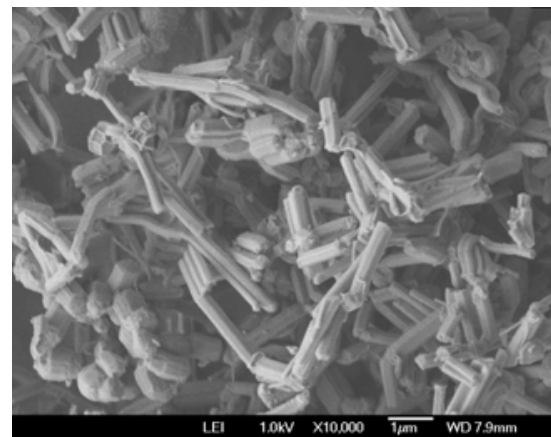

(c) $10000 \mathrm{x}$

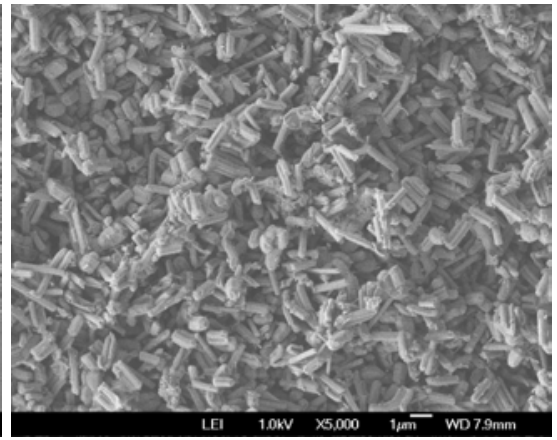

(b) $5000 \mathrm{x}$

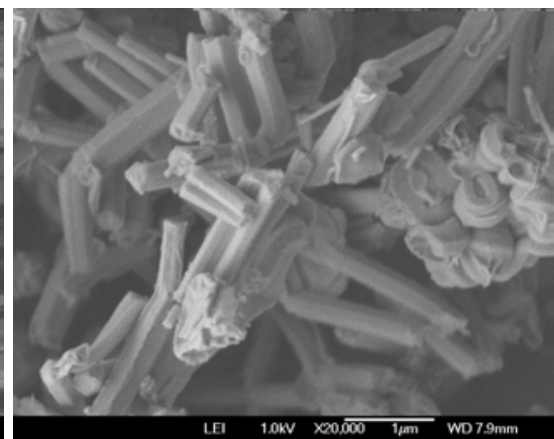

(d) $20000 \mathrm{x}$

Figura 5.5: Imagens de SEM das amostras de SBA-15 preparada para os estudos in-situ. 


\subsection{Testes de recobrimento com o polímero Eudragit ${ }^{\circledR}$}

O polímero comercial Eudragit ${ }^{\circledR}$, fabricado e comercializado pela Evonik Industries, é uma dispersão de copolímero etil-acrilato e ácido metacrílico em água que, depois de seco, forma uma camada protetora sensível a variações de $\mathrm{pH}$. Dessa forma o conteúdo protegido por essa camada pode ser liberado em um meio mais propício à sua função. A especificação técnica desse polímero, fornecida pela própria empresa, está no apêndice ??.

Dessa maneira, um conteúdo que necessite atravessar o trato digestivo para ser absorvido na parede intestinal poderá fazê-lo sem sofrer degradação no ambiente ácido do estômago. Esse objetivo pode ser alcançado pela combinação da sílica SBA-15 com o Eudragit ${ }^{\circledR}$.

Testes preliminares de combinação da sílica com esse polímero foram realizados misturando-se sílica e polímero numa proporção em massa de 1:1. Após secagem em estufa o material resultante foi caracterizado por NAI e SAXS.

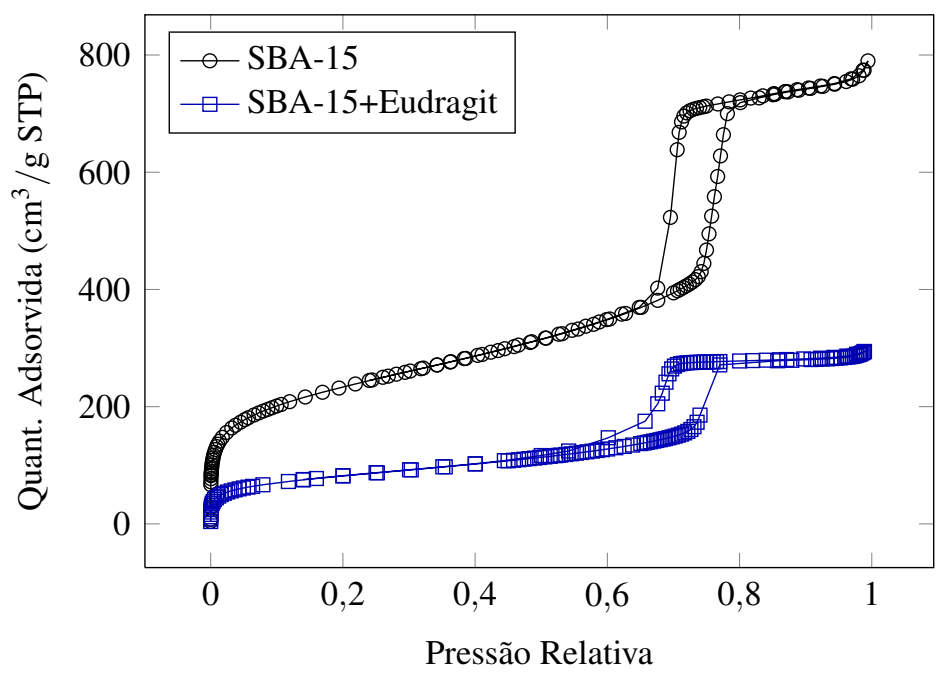

Figura 5.6: Isoterma de adsorção de uma amostra de SBA-15 pura e com Eudragit.

As isotermas apresentadas na figura 5.6 mostram a capacidade de adsorção severamente reduzida da amostra de SBA-15 com Eudragit devida à presença desse polímero. Esse fato também fica evidente na PSD, apresentada na figura 
5.7. Essa amostra apresenta área superficial de 284(5) $\mathrm{m}^{2} \mathrm{~g}^{-1}$, expressivamente inferior à obtida para a SBA-15 pura (v. figs. 5.1 e 5.2). O volume de poros, $0,47 \mathrm{~cm}^{3} \mathrm{~g}^{-1} \mathrm{~nm}^{-1}$, também é expressivamente inferior ao valor da SBA-15 pura, indicando uma alta taxa de preenchimento dos poros. A PSD é muito menor que a da amostra pura, demonstrando o preenchimento dos poros pelo Eudragit.

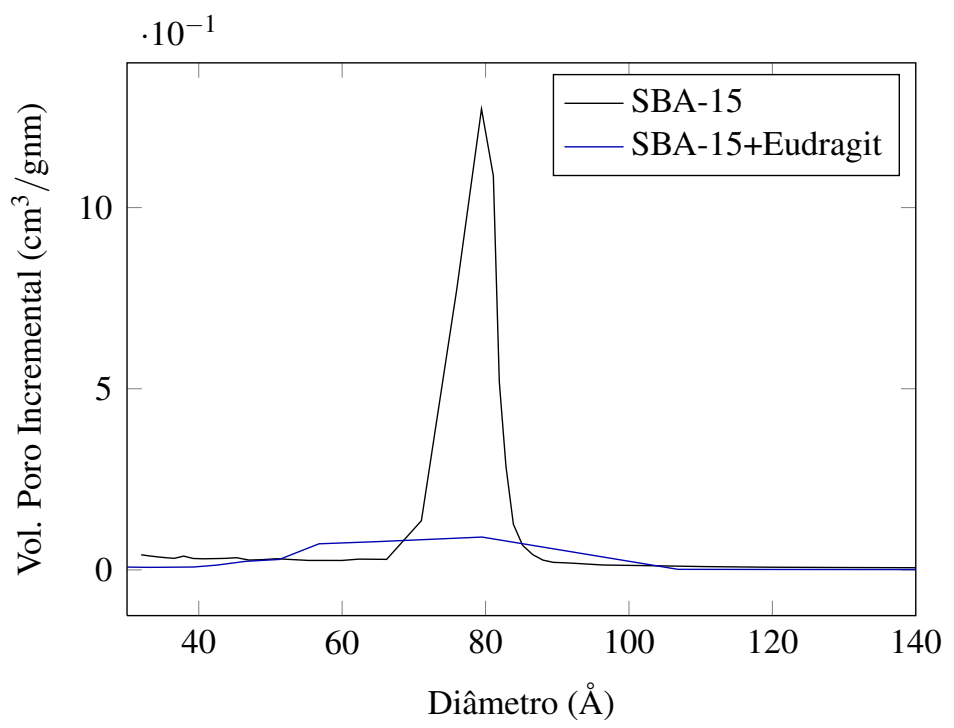

Figura 5.7: Distribuição de tamanho de poros de SBA-15 pura e com Eudragit.

As curvas de SAXS, apresentadas na figura 5.8, também demonstram o efeito do Eudragit sobre a distribuição de densidade eletrônica da sílica, conforme evidenciado pelas intensidades reduzidas de espalhamento em toda a curva e, em particular, das reflexões planares da rede hexagonal bidimensional.

$\mathrm{O}$ valor de $\Delta \rho_{\text {out }} / \Delta \rho_{\text {in }}$ também é significativamente menor, $4,0(4)$. Além disso, o raio obtido para o poro também é menor, $r=49,8(5) \AA ̊$, embora a dispersão seja de $11 \%$, semelhante à obtida para a amostra pura. 


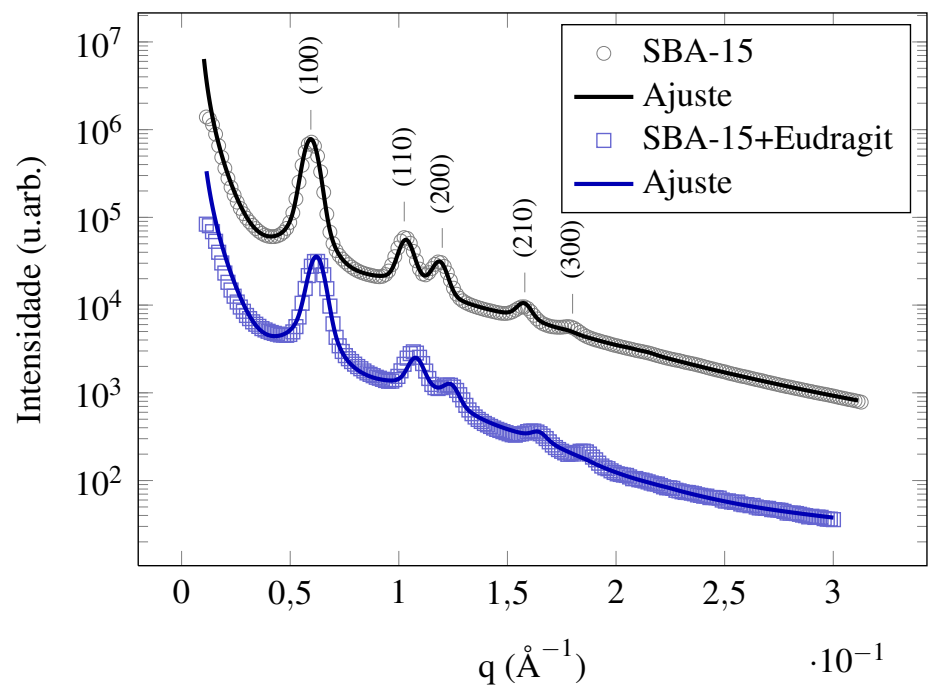

Figura 5.8: Curva de SAXS de uma amostra de SBA-15 sintetizada para os estudos in-situ.

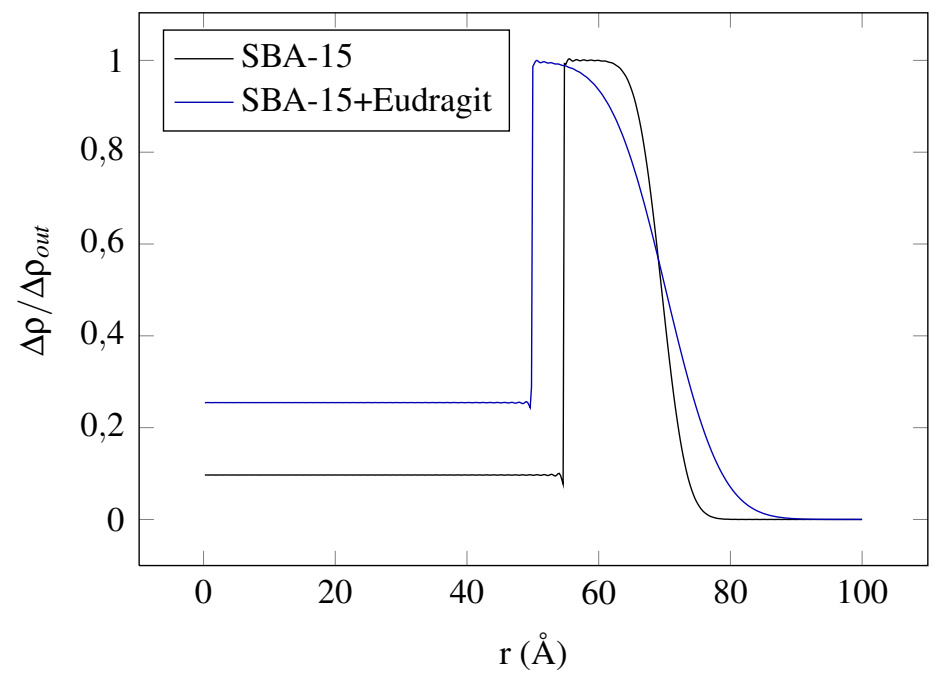

Figura 5.9: Perfis de densidade eletrônica calculados a partir dos ajustes da figura 5.8. 


\subsection{Estabilidade estrutural da sílica SBA-15 em meios corporais mimetizados}

A viabilidade da sílica SBA-15 como meio de transporte de moléculas de interesse biológico passa pela sua estabilidade estrutural nos diferentes meios a que ela será exposta em seu caminho através do organismo.

Essa estabilidade foi avaliada através de experimentos in-situ de SAXS durante a exposição da sílica a soluções mimetizando o suco gástrico e o suco intestinal, além de uma solução PBS e água.

Foram utilizados frames de 1 hora cada no arranjo descrito na seção 4.2.2.

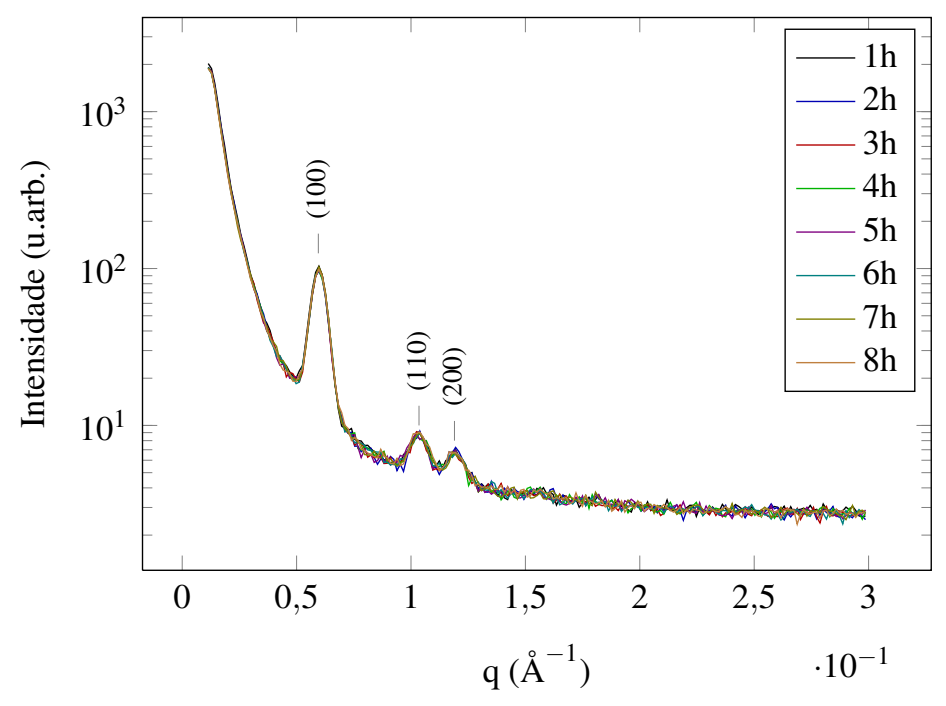

Figura 5.10: Curvas de SAXS de amostras de SBA-15 em água.

As curvas de SAXS da SBA-15 em água (fig. 5.10) não mostram nenhuma variação, sendo praticamente coincidentes. Isso demonstra a alta estabilidade da sílica em meio aquoso, sem ocorrência de perda estrutural ou qualquer efeito que afete sensivelmente a distribuição de densidade eletrônica do material. As curvas de SAXS para a SBA-15 em PBS (fig. 5.11) mostram pequena variação abaixo de $q=0,05 \AA^{-1}$, conforme detalhe mostrado no plot Guinier da figura 5.12. A aplicação da Lei de Guinier (eq. 2.21) mostra que o valor obtido para $R_{g}$, inicialmente em 54,6(19) $\mathrm{A}$, se estabiliza em torno de 46,5(8) A. Esse valor é quase $20 \%$ superior ao raio de giro em torno do eixo longitudinal calculado para um 
cilindro com raio igual ao raio obtido para os poros da SBA-15 $\left(R_{g}=r / \sqrt{2} \approx 39 \AA\right)$, o que indica que esse valor não advém do espalhamento pelos poros. Além disso, o valor inicial obtido para $R_{g}$ é correspondente a um raio $r \approx 66 \AA$, também muito superior ao raio do poro vazio $(\approx 20 \%)$.

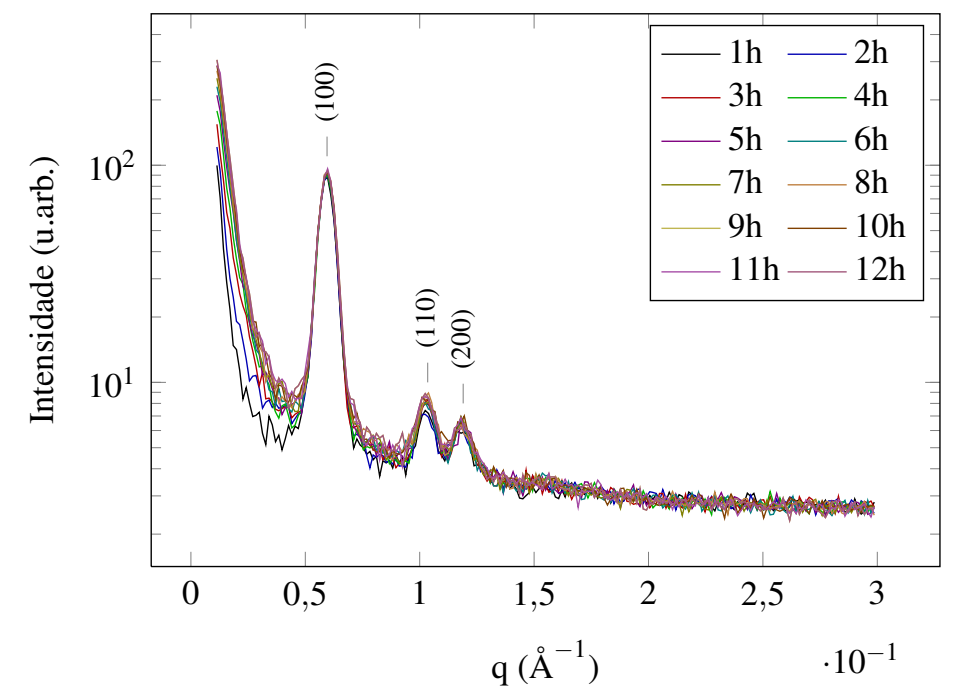

Figura 5.11: Curvas de SAXS de amostras de SBA-15 em PBS.

Essa variação é atribuída, então, à desaglomeração da sílica no início do experimento, uma vez que ela é adicionada à solução em forma de pó. Dessa forma, tanto a desaglomeração do material quanto a sua permeação pela solução ocasionam essa mudança nas curvas de SAXS, que se estabilizam após o período inicial de 2 horas.

Nas curvas da SBA-15 em suco gástrico e suco intestinal (figs. 5.13 e 5.14, respectivamente) não foi observada nenhuma variação nas intensidades ou nas posições dos picos. Em comparação com a curva para o PBS (5.11) a mudança a baixo q no início do experimento não se manifesta. Esse efeito é atribuído às características desses meios corporais mimetizados, cujo $\mathrm{pH}$ parece não ter efeito sobre as paredes, afastando assim a hipótese de lichiviação de $\mathrm{SiO}_{2}$. Além disso, tanto a pepsina quanto as moléculas componentes da pancreatina tampouco têm efeito sobre os poros, visto que as intensidades dos picos também permanecem constantes. 


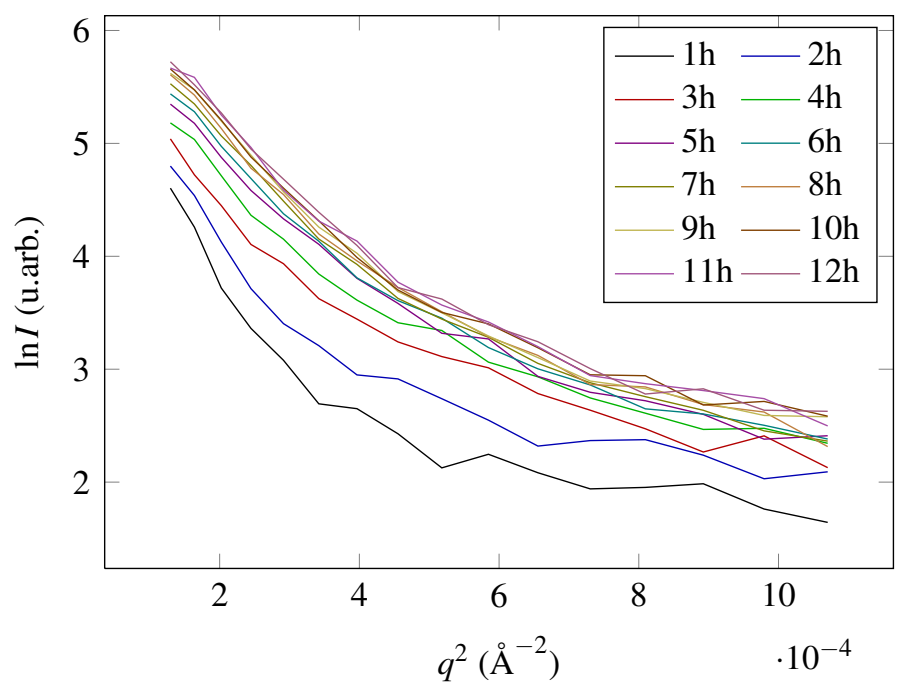

Figura 5.12: Região de Guinier das curvas de SAXS da figura 5.11.

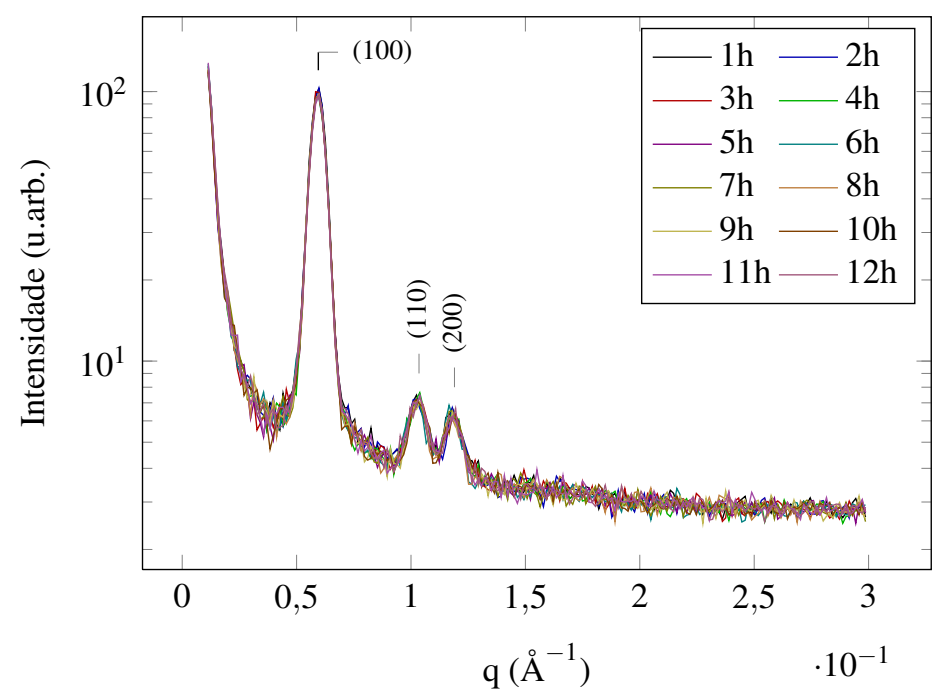

Figura 5.13: Curvas de SAXS de amostras de SBA-15 em suco gástrico. 
5.3 | estabilidade estrutural da sílica sba-15

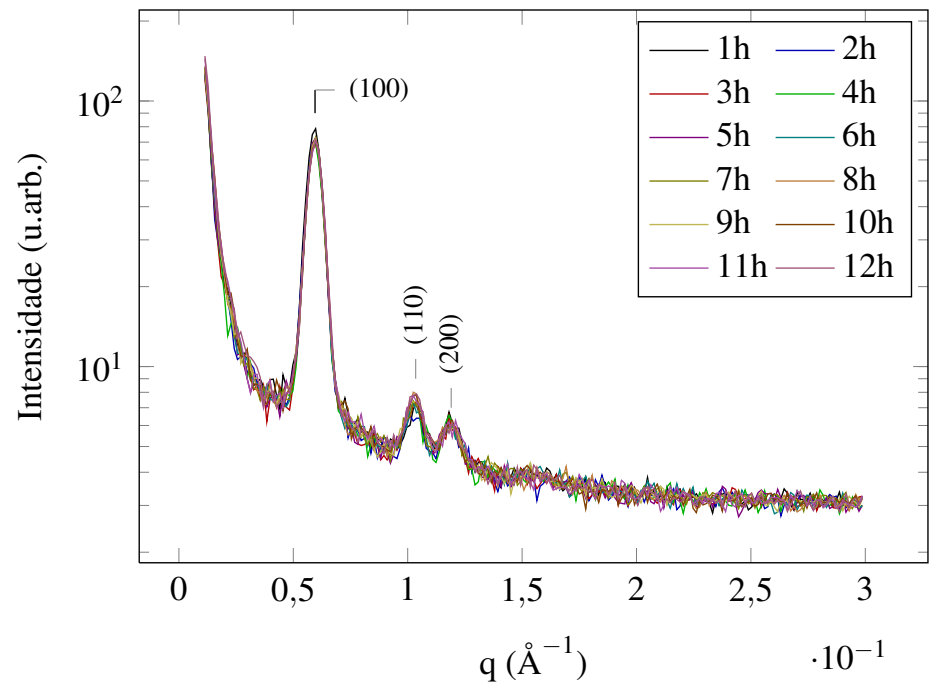

Figura 5.14: Curvas de SAXS de amostras de SBA-15 em suco intestinal. 


\subsection{Liberação de BSA a partir da sílica SBA-15}

Os estudos in-situ preliminares de liberação de substâncias foram executados com albumina bovina (BSA). As amostras foram preparadas segundo o protocolo descrito na subseção 4.1.3. Os pós resultantes do processo de mistura foram previamente processados em almofariz de ágata e adicionados à solução PBS, ao suco gástrico e ao suco intestinal no momento da medida, com um pequeno período de desaglomeração das partículas que os compunham.

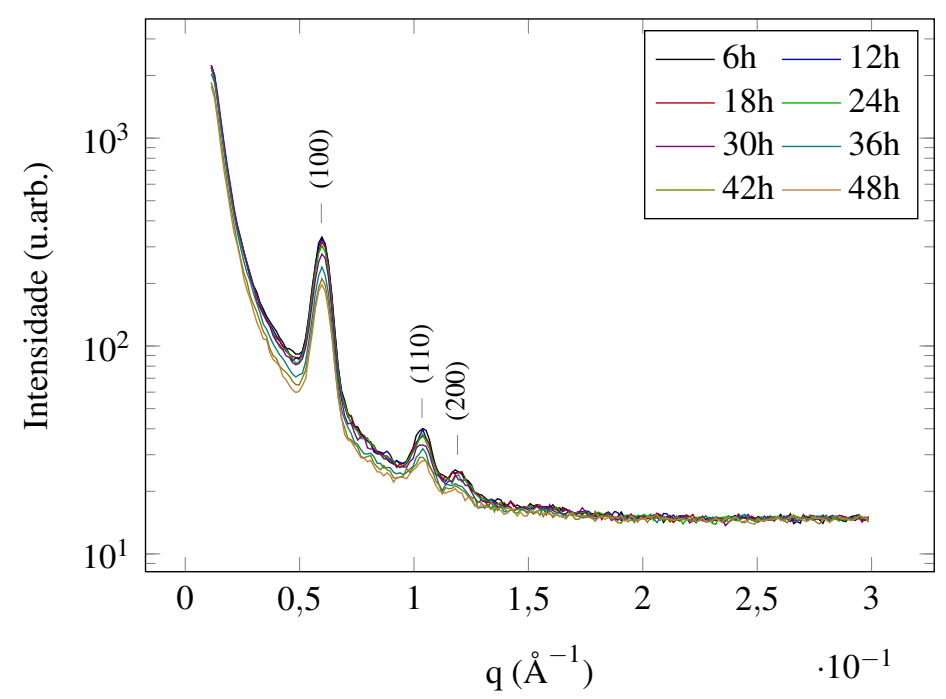

Figura 5.15: Curvas de SAXS de amostras de SBA-15 com BSA em PBS.

A figura 5.15 apresenta os dados obtidos para o experimento de liberação em PBS. Observa-se uma evolução sistemática na intensidade espalhada com o tempo, o que indica uma variação das condições da amostra com o passar do tempo.

Nos dados para o suco gástrico (fig. 5.16) é possível observar uma transição entre $12 \mathrm{~h}$ e $24 \mathrm{~h}$, na qual a intensidade da curva de espalhamento aumenta sensivelmente, permanecendo estável dali em diante até o final do experimento. Além disso, as intensidades dos picos também foram afetadas durante essa transição, permanecendo sem maiores alterações em seguida.

Os dados para as amostras com Eudragit em suco gástrico mostram uma transição da mesma natureza, porém em um intervalo de tempo deslocado. Ela ocorre entre $30 \mathrm{~h}$ e $42 \mathrm{~h}$. Isso sugere que a presença do polímero tem um efeito 


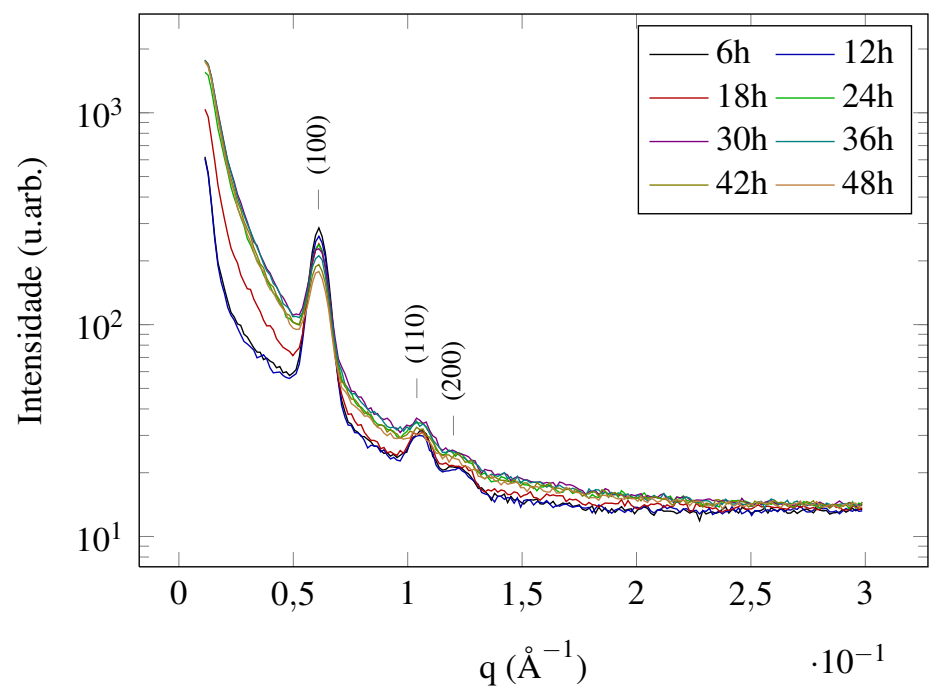

Figura 5.16: Curvas de SAXS de amostras de SBA-15 com BSA em suco gástrico.

decisivo sobre o momento em que essa transição ocorre ao influenciar a ação do suco gástrico sobre o complexo SBA-15+BSA.

As curvas de SAXS para as amostras em suco intestinal não apresentam alterações de intensidade ou posição dos picos, exceto por uma ligeira diferença na curva de $6 \mathrm{~h}$, na qual a intensidade na região onde aparecem os picos está um pouco acima das demais. Esse efeito sugere que a liberação da BSA e consequente alteração da densidade eletrônica deve ocorrer num período de tempo inferior a $6 \mathrm{~h}$, levando à necessidade de obtenção de curvas com um tempo de exposição menor (v. seção 5.5).

No caso da amostra com Eudragit uma sutil diminuição da intensidade da curva como um todo foi observada com o passar do tempo, em particular na região do pico (100), onde há melhor estatística dos dados devido a contagens maiores. Isso confirma a natureza do Eudragit ${ }^{\circledR}$, que proporciona um mecanismo de liberação lenta em meios com pH acima de 6, como é o caso do suco intestinal.

Embora as curvas obtidas com o Nanostar forneçam informações de alta relevância para esta avaliação do potencial da sílica SBA-15 como veículo, fica clara a necessidade de obtenção de curvas in-situ com um tempo de aquisição muito menor para que seja possível avaliar o período inicial da liberação de moléculas a partir da SBA-15. Entretanto, os limites técnicos impostos pelo equipamento disponível 


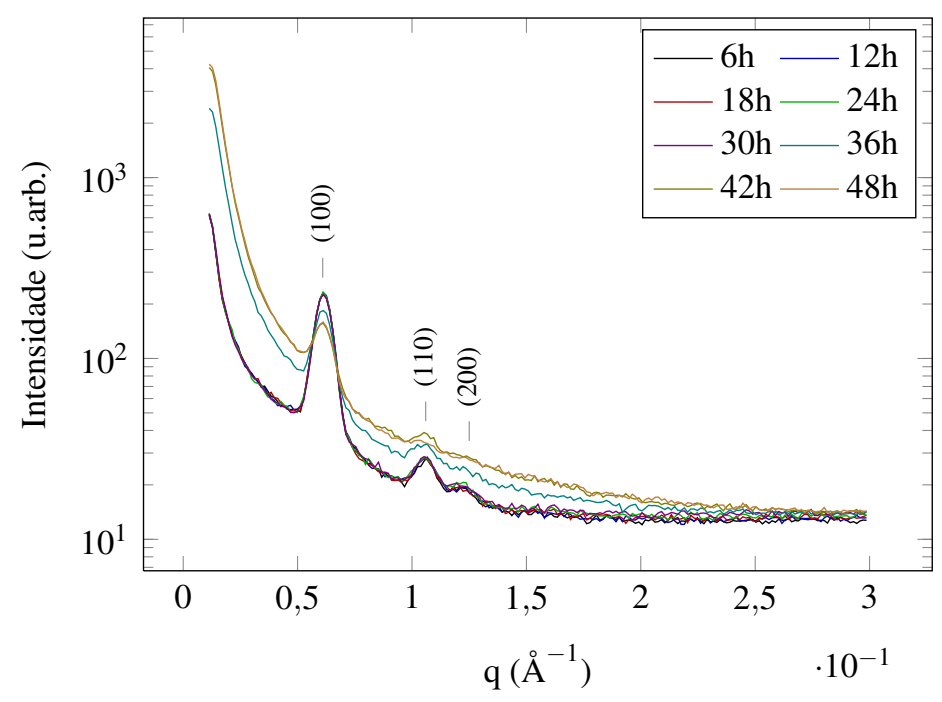

Figura 5.17: Curvas de SAXS de amostras de SBA-15 com BSA e Eudragit em suco gástrico.

levam a limitações no tempo necessário para obtenção de curvas de SAXS com estatística de contagens apreciável, que possam ser utilizadas de forma confiável em uma análise deste tipo. Esta necessidade justifica, portanto, a utilização de radiação síncrotron para a obtenção de curvas mais "rápidas", isto é, experimentos com períodos de aquisição menores. 


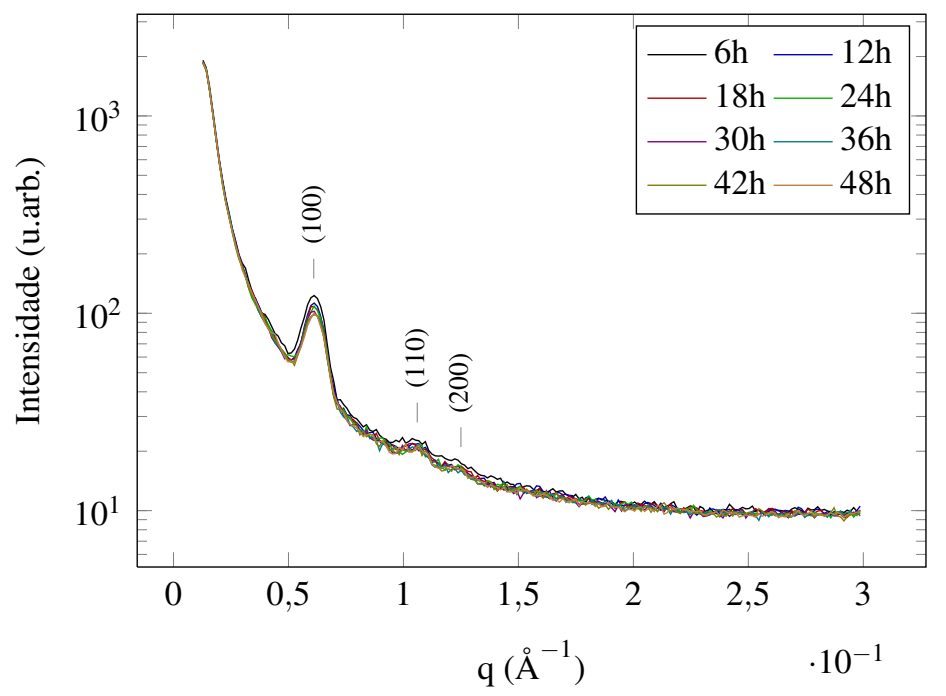

Figura 5.18: Curvas de SAXS de amostras de SBA-15 com BSA em suco intestinal.

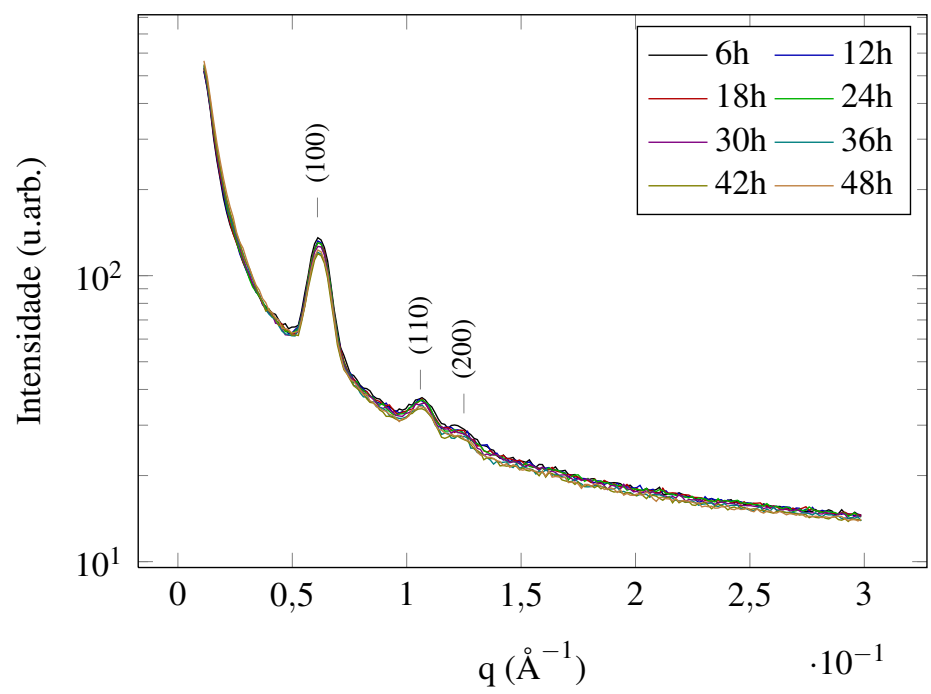

Figura 5.19: Curvas de SAXS de amostras de SBA-15 com BSA e Eudragit em suco intestinal. 


\subsection{Liberação de Insulina a partir da sílica SBA-15}

Para os experimentos com radiação síncrotron procedeu-se à utilização de insulina, uma molécula de grande importância terapêutica, para a qual o potencial de aplicação da sílica SBA-15 torna-se evidente quando se considera que o meio inóspito oferecido pelo estômago constitui uma barreira à terapia de reposição via oral. Isso leva a formulações que são, via de regra, administradas pela via intra-muscular.

Somente o potencial de se desenvolver um método de entrega de insulina que tenha alta capacidade, liberação lenta, e que possa transportá-la incólume às regiões que irão absorvê-la, disponibilizando-a na corrente sangüínea, já seria suficiente para justificar o investimento de tempo e dinheiro na sua viabilização; não obstante, as demais aplicações em potencial desse método são de uma variedade ainda inexplorada. Inúmeros tipos de antígenos e fármacos podem ser melhor aproveitados se forem apresentados ao organismo de maneira mais eficiente.

Os experimentos de liberação de insulina a partir da estrutura de poros da SBA-15 foram executados no arranjo experimental da linha SAXS2, no LNLS (v. pág. 36), cuja alta intensidade proporciona a possibilidade de obtenção de frames de curta duração.

Os procedimentos foram executados com uma série de amostras de controle. Essas amostras serviram para avaliações preliminares do comportamento das soluções em que os dados finais seriam obtidos. A cada um dos experimentos de liberação correspondeu uma curva obtida para a solução "pura", isto é o suco gástrico ou o suco intestinal mimetizados ou PBS. Nos experimentos de incorporação e liberação a quantidade de amostra a ser misturada na solução foi determinada a partir da proporção de 0,1 g de SBA-15 (descontando a massa de moléculas agregadas a ela) para $20 \mathrm{~mL}$ da solução em questão.

Os dados adquiridos com o detector da linha de luz foram integrados em torno do ângulo azimutal, normalizados pela transmitância e em seguida corrigidos pela da remoção da curva de background correspondente. 


\subsubsection{Nova determinação estrutural da SBA-15}

Para fins de comparação a sílica SBA-15 pura foi novamente examinada através de um experimento de SAXS executado no LNLS. A figura 5.20 apresenta a curva obtida e a curva ajustada a ela.

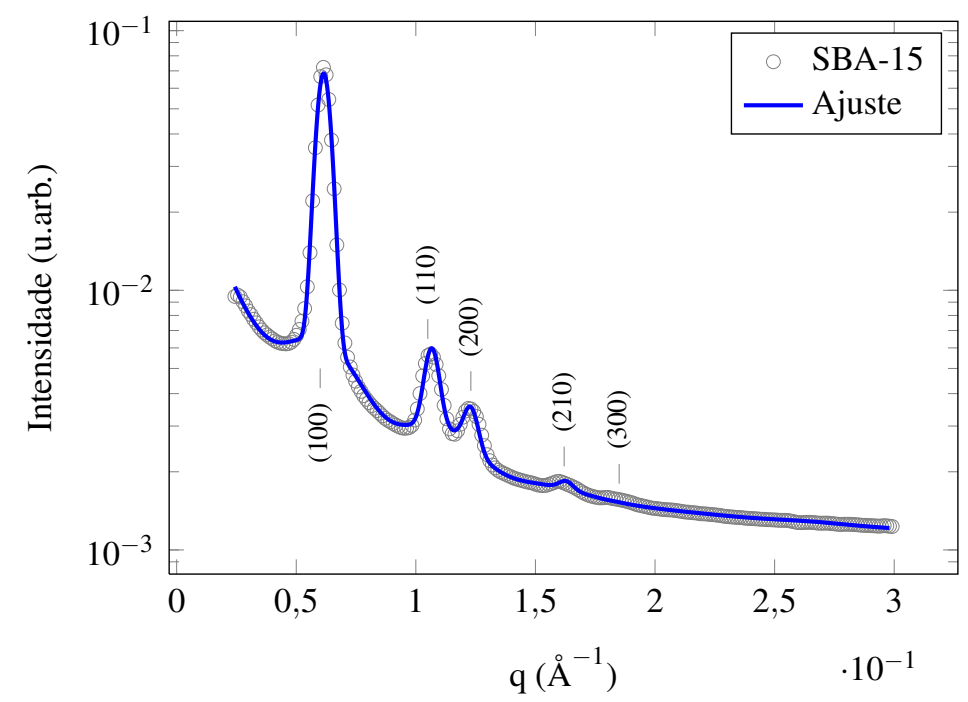

Figura 5.20: Curva de SAXS de uma amostra de SBA-15 obtida na linha SAXS2.

Para este ajuste, o valor obtido para o parâmetro de rede foi $a=117,8(4) \AA$, ligeiramente inferior ao obtido com os dados da figura 5.3. Este resultado entretanto é mais confiável devido à qualidade dos dados obtidos no LNLS, bem como a um valor de $\chi^{2}$ menor $(0,76)$. Para esse mesmo ajuste o valor do raio dos cilindros foi $r=45,7(9) \AA$, mais próximo de estar de acordo com os resultados obtidos a partir dos dados de NAI. Variações nos arranjos experimentais, como condições de vácuo, geometria do porta-amostras, entre outras, podem interferir na quantidade de resíduos atmosféricos presentes na amostra, especialmente água adsorvida.

\section{Nota sobre os parâmetros de ajuste das curvas obtidas no LNLS}

Nos ajustes de curvas obtidas no arranjo experimental do LNLS a subrotina de ajuste mostrou ser insensível a variações no contraste relativo de densidade eletrônica acima de determinado valor. Isto se deve ao fato de o modelo ter sido originalmente desenvolvido para descrever a formação e auto-organização das 
micelas do copolímero P123 em solução, e a subseqüente formação das paredes de sílica até o passo do tratamento hidrotérmico segundo a sequência de síntese (fig. 32, pág. 32). De fato, naquele trabalho, esse parâmetro foi fixado devido à sua pequena influência sobre os resultados ${ }^{[33]}$. Devido à densificação das paredes, que ocorre durante o tratamento hidrotérmico, e à calcinação, esse contraste é muito maior e, por isso, foi fixado em $\Delta \rho_{\text {out }} / \Delta \rho_{\text {in }}=20$, valor determinado nos ajustes prévios da SBA-15 pura.

A incorporação e liberação de material na estrutura da sílica foram rastreadas com o auxílio de outros parâmetros, como por exemplo o background constante $\left(S c_{\text {const }}\right)$ e o espalhamento a baixo $q\left(S c_{q^{-4}}\right)$.

Além disso, outros parâmetros que apresentaram esse tipo de comportamento foram igualmente fixados durante os procedimentos de ajuste. Entre estes estão o tamanho do domínio $(D)$, formato do pico $(v)$ e a largura da interface entre $R_{\text {in }}$ e $R_{\text {out }}\left(\sigma_{\text {int }}\right)$.

\subsubsection{Experimento in-situ de incorporação de insulina}

A incorporação de insulina, conforme determinada em experimentos anteriores (v. seções ?? e ??), é o processo pelo qual as moléculas desse hormônio se alojam dentro dos poros da SBA-15.

Uma determinação com experimentos in-situ foi executada de forma a se estabelecer a velocidade do processo de incorporação, bem como seus efeitos sobre os parâmetros de ajuste.

Uma versão adaptada do procedimento presente na subseção 4.1 .3 foi executada, na qual o volume total de solução PBS foi dividido. Em uma parte foi colocada a insulina, e em outra parte foi colocada a SBA-15. Dessa forma, a influência da permeação da sílica pela solução PBS sobre as curvas de SAXS foi contornada.

Os parâmetros $S c_{1}, S c_{\text {chain }}$ e $S c_{\text {const }}$ todos têm uma variação brusca entre o primeiro e o segundo pontos (v. figuras 5.21, 5.22 e 5.23, respectivamente) permanecendo estáveis dali em diante. Esse comportamento reflete o final do processo de permeação da estrutura de poros da sílica com a solução PBS. Em particular, no caso dos microporos, o seu preenchimento ocasiona uma mudança no contraste de densidade eletrônica levando, assim, a uma queda no seu parâmetro de escala. 


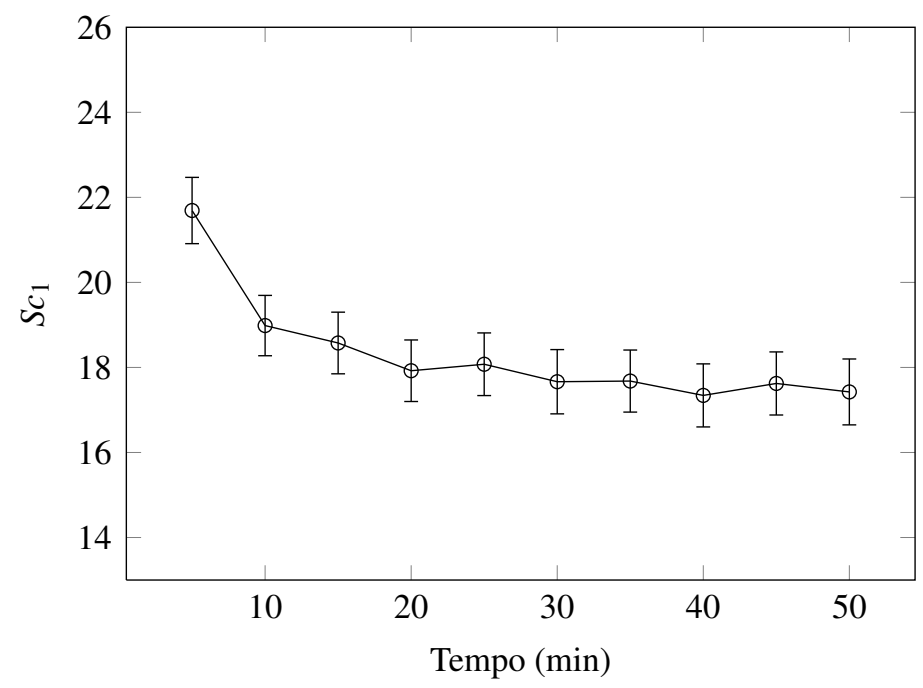

Figura 5.21: Parâmetro de escala obtido dos ajustes das curvas experimentais de incorporação de insulina.

A mudança no fator de escala global, por sua vez, indica um aumento na absorção do feixe de raios $\mathrm{X}$ pela amostra. Isso pode ser considerado como evidência indireta do carregamento da insulina pela estrutura de poros da sílica, uma vez que, sendo presentes em toda a solução, uma vez incorporadas aos poros as moléculas de insulina são carregadas pela sílica. Dessa forma, ao circular pelo sistema, essas partículas vão coletando a insulina, e ao passar novamente pelo capilar de quartzo exposto ao feixe, apresentam maior absorção. A variação de

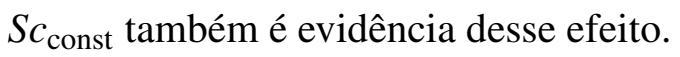

O parâmetro $c$ (fig. 5.24), ao aumentar logo no início da medida, pode indicar o aumento do contraste eletrônico na região espalhadora, corroborando a hipótese de que a insulina é incorporada logo no início do processo. A substituição do ar presente nos poros pela solução e pelas moléculas de insulina acarreta um crescimento do volume total de espalhamento, levando ao aumento desse parâmetro.

Os parâmetros relacionados à geometria dos poros, $R_{\mathrm{in}},{ }_{R} / R$ e $R_{\text {outer }}$ (figs. 5.25, 5.26 e 5.27, respectivamente) comportam-se como esperado, dada a estabilidade da estrutura da SBA-15, permanecendo estáveis em valores compatíveis com os resultados da sílica pura (vazia). Em particular, o valor do raio interno dos poros se estabiliza em $R_{\text {in }} \approx 46 \AA$, um valor muito próximo do obtido na determinação da SBA-15 pura, obtido previamente. 


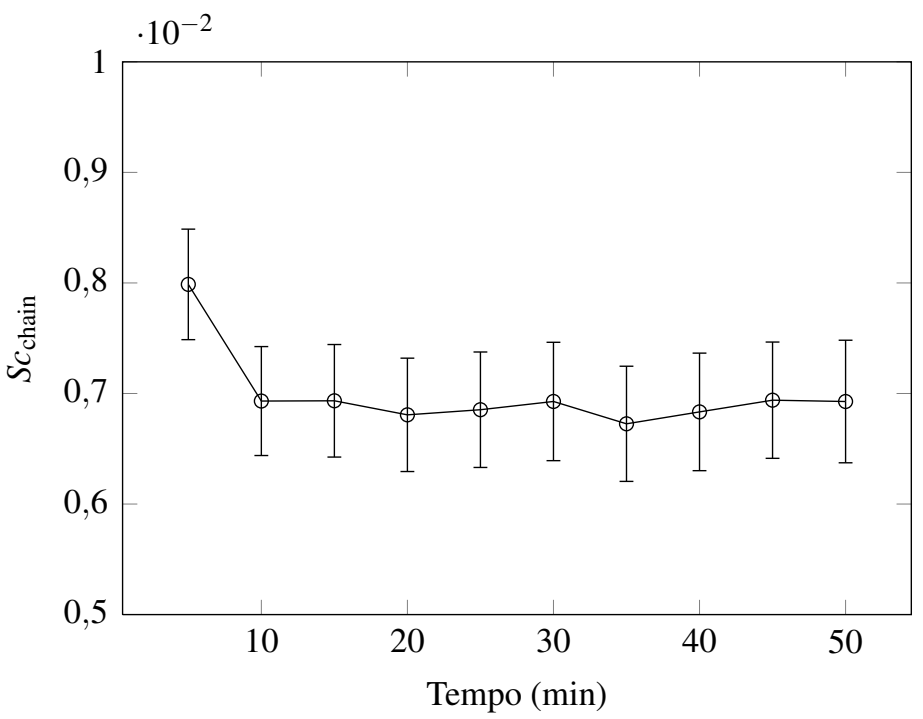

Figura 5.22: Parâmetro de escala obtido dos ajustes das curvas experimentais de incorporação de insulina.

$\mathrm{O}$ valor de $S c_{q^{-4}}$ tem uma ligeira tendência de aumento, porém mantém-se com valores virtualnente nulos, pois os valores de incerteza são muito grandes, dando indicação de que, neste experimento, esse parâmetro torna-se irrelevante. De fato, no caso desta solução, não há partículas cuja dimensão propicie um espalhamento próximo de $q_{\min }$. 


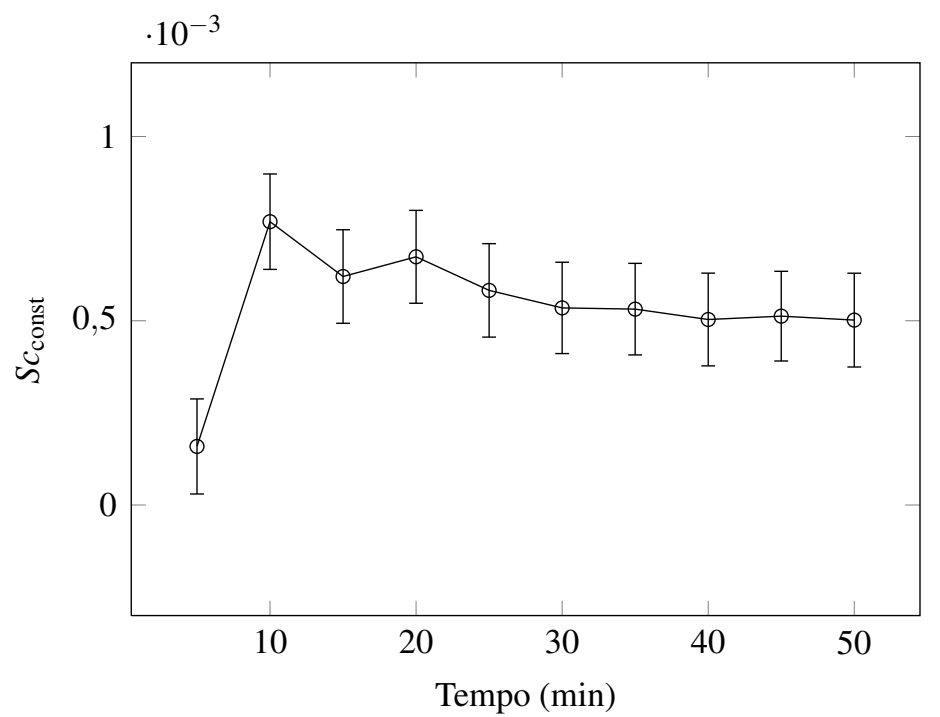

Figura 5.23: Background constante obtido dos ajustes das curvas experimentais de incorporação de insulina.

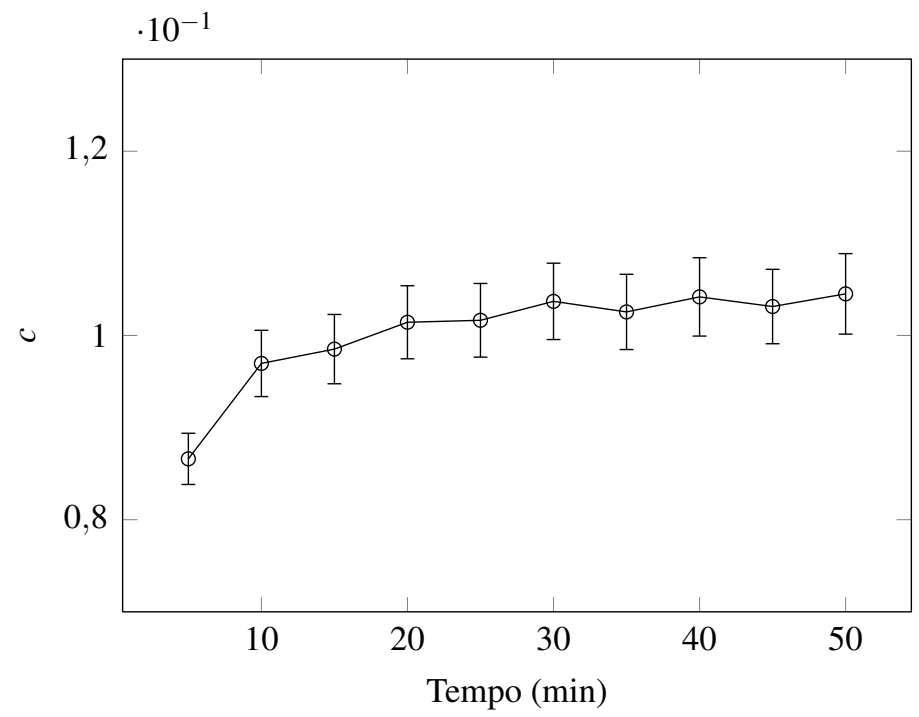

Figura 5.24: Parâmetro $c$ obtido dos ajustes das curvas experimentais de incorporação de insulina. 


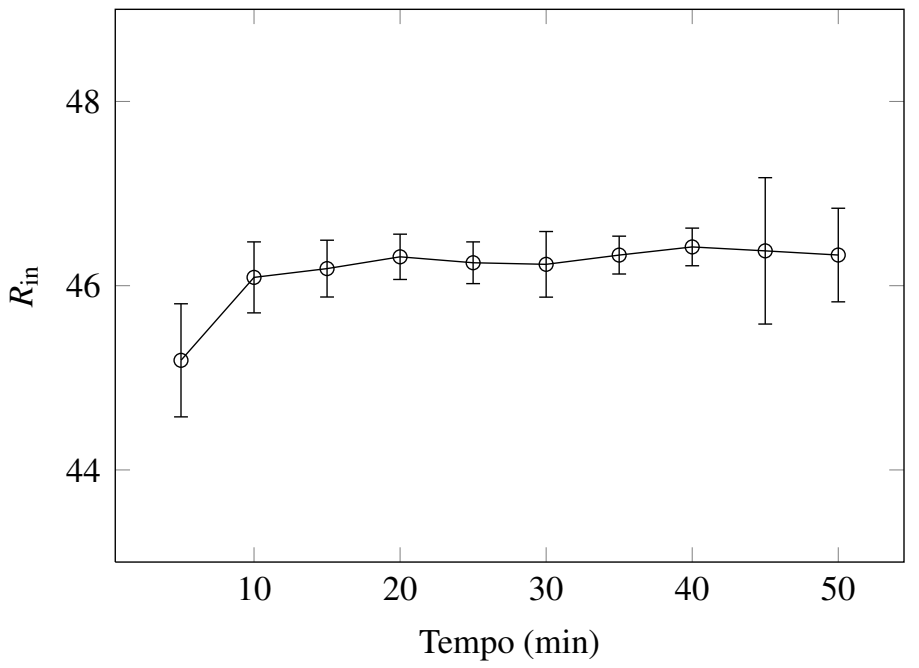

Figura 5.25: Raio interno dos poros obtido dos ajustes das curvas experimentais de incorporação de insulina.

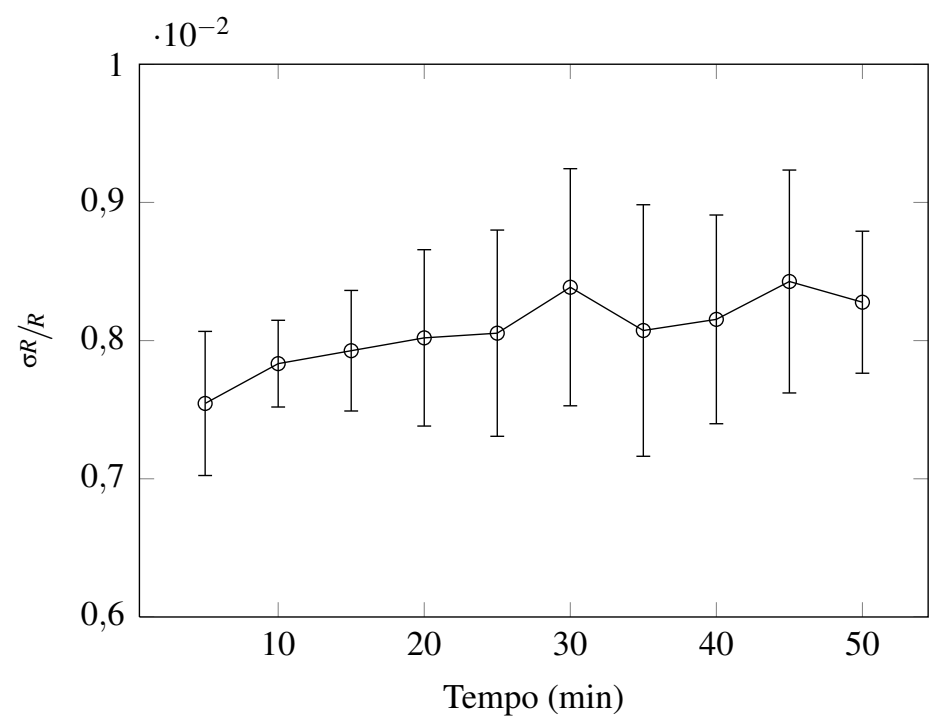

Figura 5.26: Dispersão relativa do tamanho dos poros obtida dos ajustes das curvas experimentais de incorporação de insulina. 


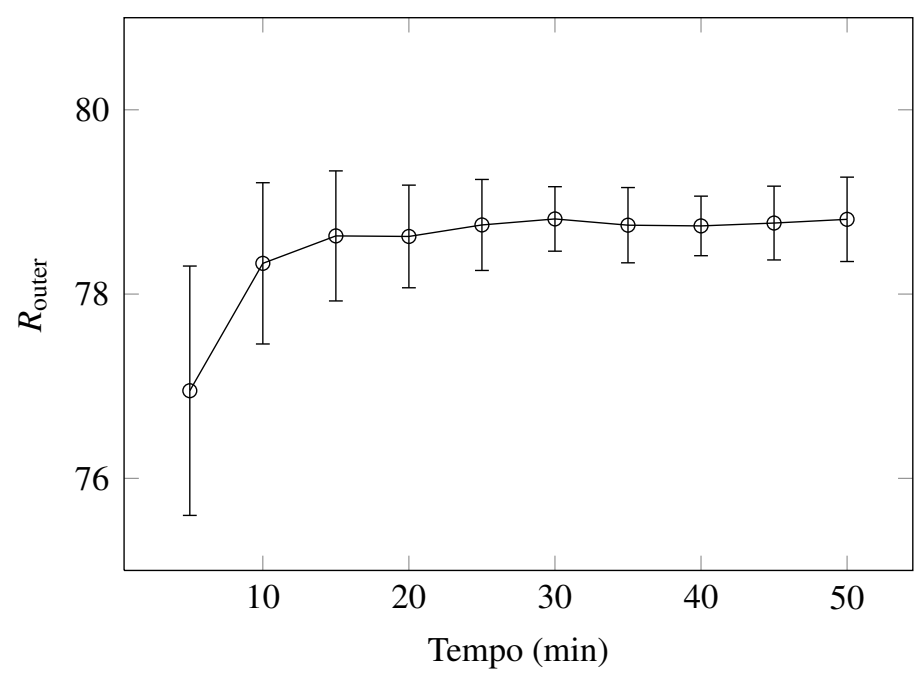

Figura 5.27: Raio externo dos ajustes das curvas experimentais de incorporação de insulina.

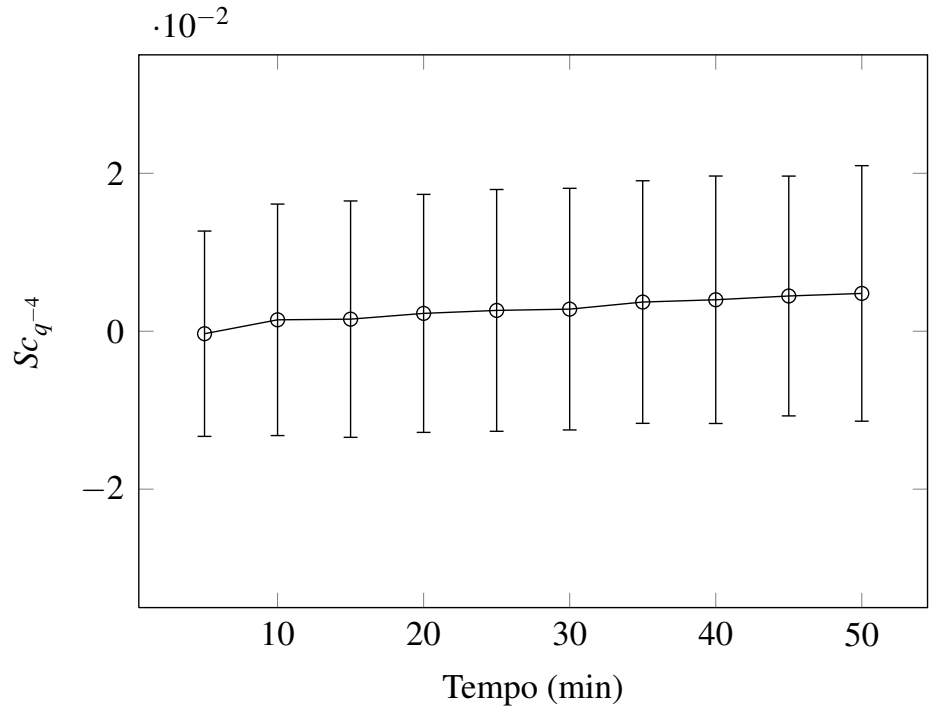

Figura 5.28: Parâmetro de escala do espalhamento a baixo $q$ obtido dos ajustes das curvas experimentais de incorporação de insulina. 


\subsubsection{Experimentos in-situ de liberação de insulina}

No interesse da brevidade, as curvas de espalhamento obtidas após integração azimutal e correção por transmissão e background estão apresentadas no apêndice A. As figuras 5.29 a 5.33 apresentam os parâmetros obtidos após os procedimentos de ajuste (v. tab. 3.1).

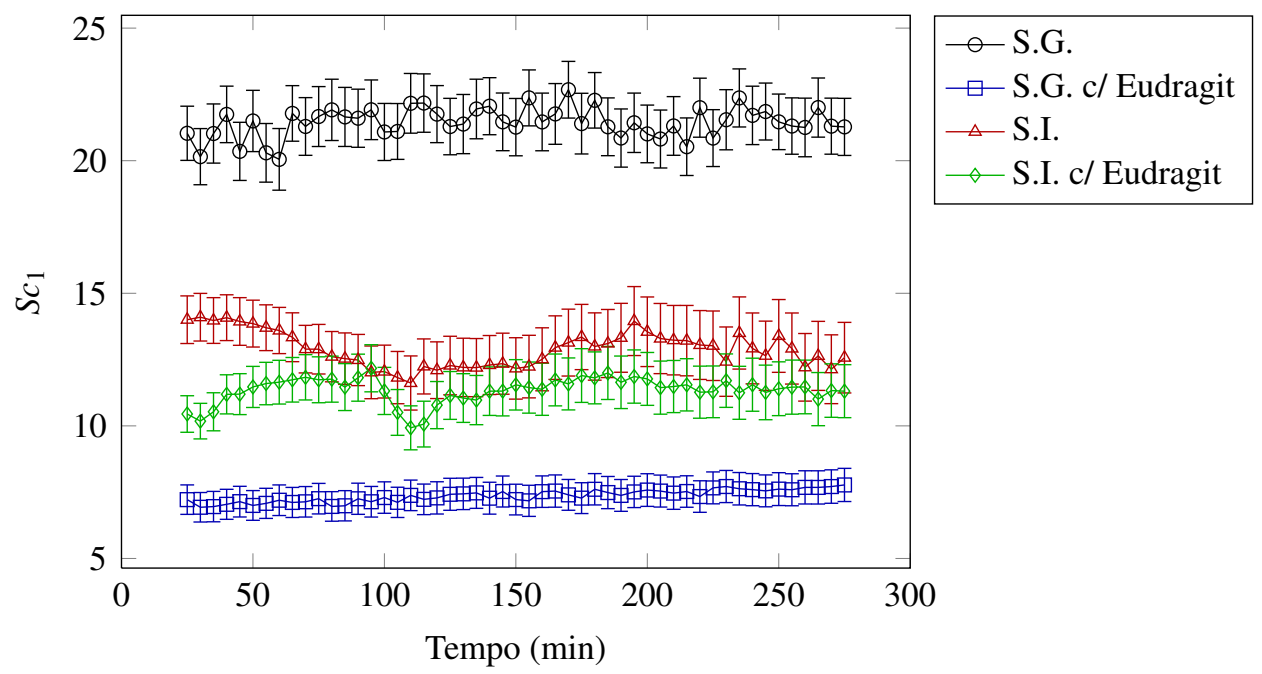

Figura 5.29: Parâmetro de escala obtido dos ajustes das curvas experimentais de liberação de insulina.

O parâmetro $S c_{1}$ (fig. 5.29) apresenta ligeira tendência de subida durante os experimentos com sugo gástrico. No caso dos experimentos com suco intestinal nota-se comportamento distinto no início do experimento (até aproximadamente 100 minutos) seguido de um comportamento semelhante a partir desse ponto.

O parâmetro $S c_{\text {chain }}$ (fig. 5.30), por sua vez, apresenta comportamento estável para a maioria dos experimentos, com exceção da amostra em suco intestinal. Essa amostra apresenta queda no valor desse parâmetro no início do experimento, seguido de estabilização a partir desse ponto.

O parâmetro $c$ (fig. 5.31) permanece estável durante os quatro experimentos, demonstrando a estabilidade da rede hexagonal bidimensional de poros e, ao mesmo tempo, a constância do invariante durante os experimentos, isto é, a conservação do volume total de espalhamento.

Os valores dos parâmetros geométricos dos poros, representados pelos parâ- 


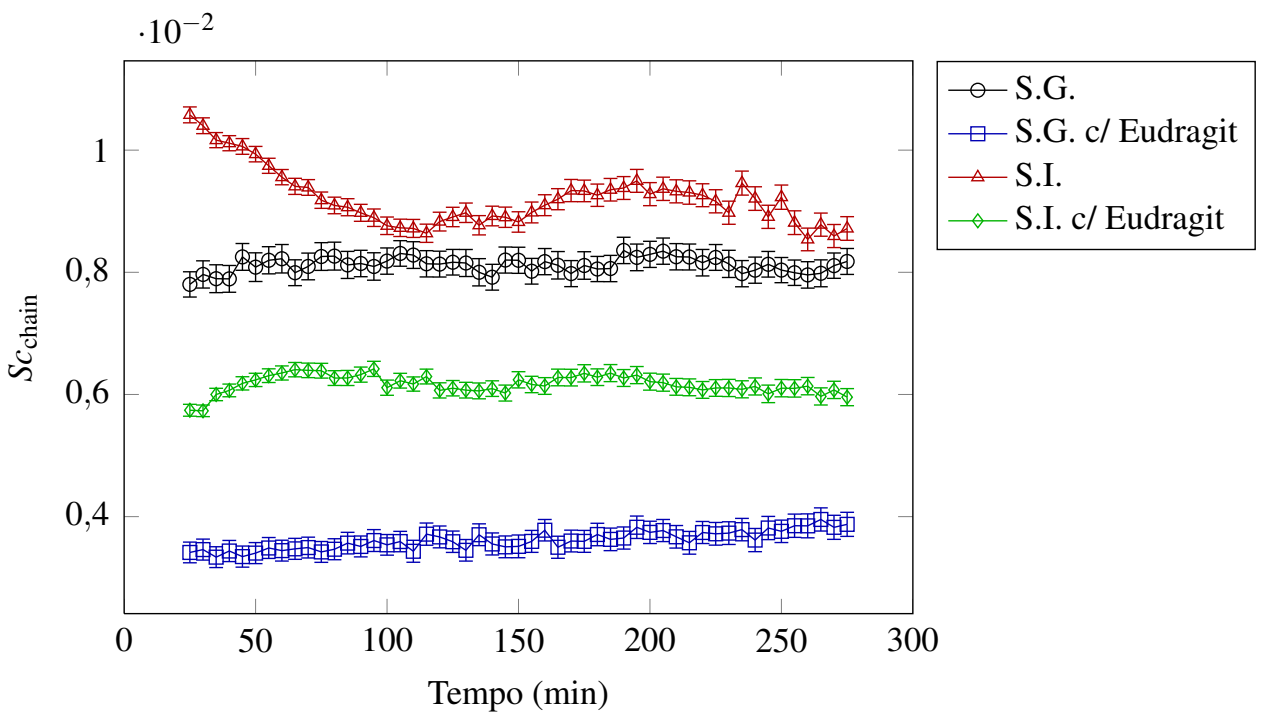

Figura 5.30: Parâmetro de escala dos microporos obtido dos ajustes das curvas experimentais de liberação de insulina.

metros $R_{\text {in }}, R_{\text {outer }}$ e $\sigma_{R} / R$, permaneceram constantes durante todos os ajustes. De fato, eles apresentaram alto grau de correlação com outros parâmetros de ajuste e, quando variados isoladamente, mostraram não ter variação apreciável, de forma que, por motivos de tempo computacional e complexidade do modelo, eles foram fixados em um valor determinado com base no ajuste da SBA-15 pura e foram mantidos constantes durante os procedimentos de ajuste, sendo $R_{\text {in }}=46,6 \AA$, $R_{\text {outer }}=77,3 \AA$ e $\sigma_{R} / R=0,01$.

O parâmetro $S c_{\text {const }}$ (fig. 5.32) apresenta tendência de subida para todas as amostras com suco intestinal. Esse efeito foi avaliado através de ajustes lineares $\left(S c_{\text {const }}=\mathrm{a} \cdot q+\mathrm{b}\right)$ às curvas da figura 5.32 , cujos resultados estão apresentados na tabela 5.1.

As amostras com suco gástrico mostram um valor para o parâmetro $a$ cerca de $40 \%$ superior para a amostra sem Eudragit em relação à amostra recoberta com esse polímero. Essa diferença chega a $60 \%$ quando essa comparação é feita entre as amostras em suco intestinal. Ademais, a amostra sem Eudragit em suco intestinal mostra o maior valor para esse ritmo de aumento de $S c_{\text {const }}$, o que condiz com a hipótese de que essa situação é a mais favorável à liberação de insulina.

Coeficientes angulares $a$ positivos indicam diminuição da absorção pela amos- 


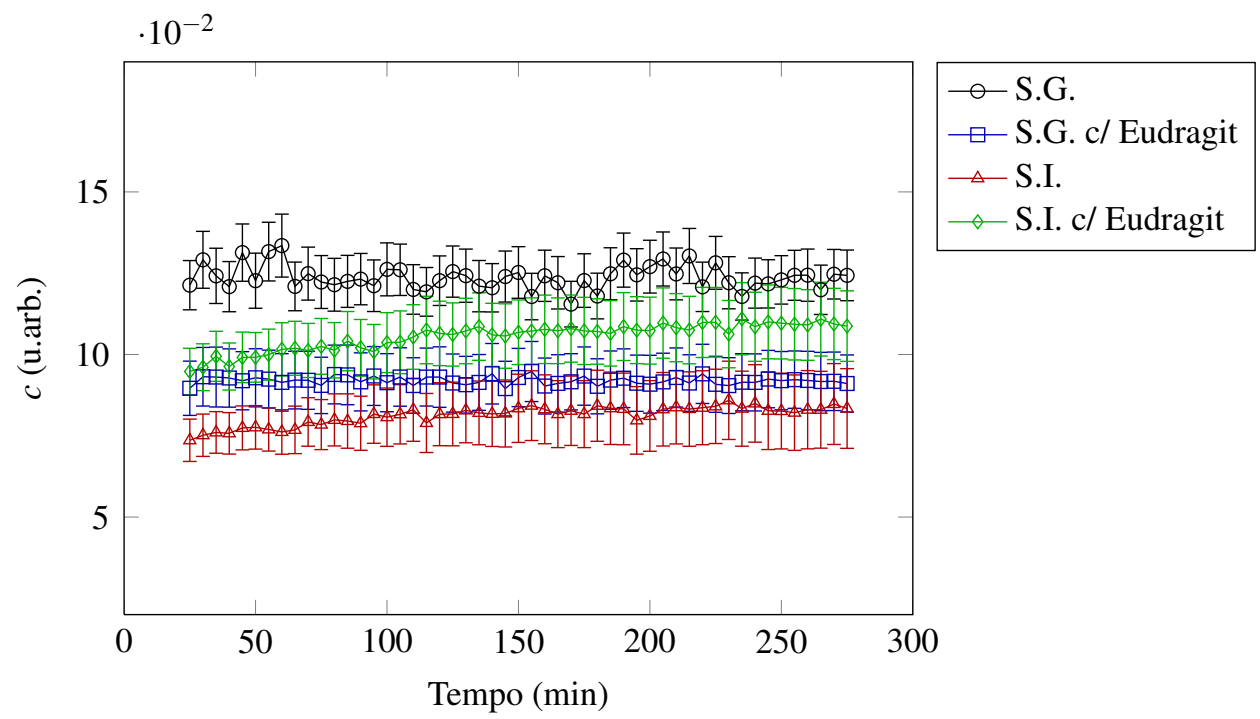

Figura 5.31: Parâmetro $c$ obtido dos ajustes das curvas experimentais de liberação de insulina.

tra, o que indica que há menos material sendo exposto ao feixe. No caso da amostra em suco gástrico, isso está ligado à degradação dos componentes da solução, entre eles a própria pepsina. Os subprodutos desse processo, ocupando volume maior, ocasionam uma diminuição da concentração aparente da amostra.

No caso das amostras em suco intestinal, essa diminuição da absorção está relacionada à fibrilação de amilase, lipase e protease (componentes da pancreatina) em torno das moléculas de insulina, que não são capazes de processar, o que produz um material filamentar que se enovela e se deposita no fundo da proveta onde a solução é mantida, tendo dificuldade em voltar a circular pelo sistema por ser mais denso. Esse fato foi verificado diretamente no porta-amostra.

\begin{tabular}{ccc} 
Amostra & $a\left(\times 10^{-7}\right)$ & $b\left(\times 10^{-4}\right)$ \\
\hline S.G. & $3,1(4)$ & $-13,68(14)$ \\
S.G. c/ Eudragit & $1,8(3)$ & $1,26(6)$ \\
S.I. & $5,2(21)$ & $0,72(3)$ \\
S.I. c/ Eudragit & $2,20(17)$ & $1,619(27)$
\end{tabular}

Tabela 5.1: Ajustes lineares feitos às curvas da fig. 5.32.

O parâmetro $S c_{q^{-4}}$ (fig. 5.33), representando o espalhamento a mais baixo ângulo, comporta-se de maneira semelhante nos dois experimentos com suco 


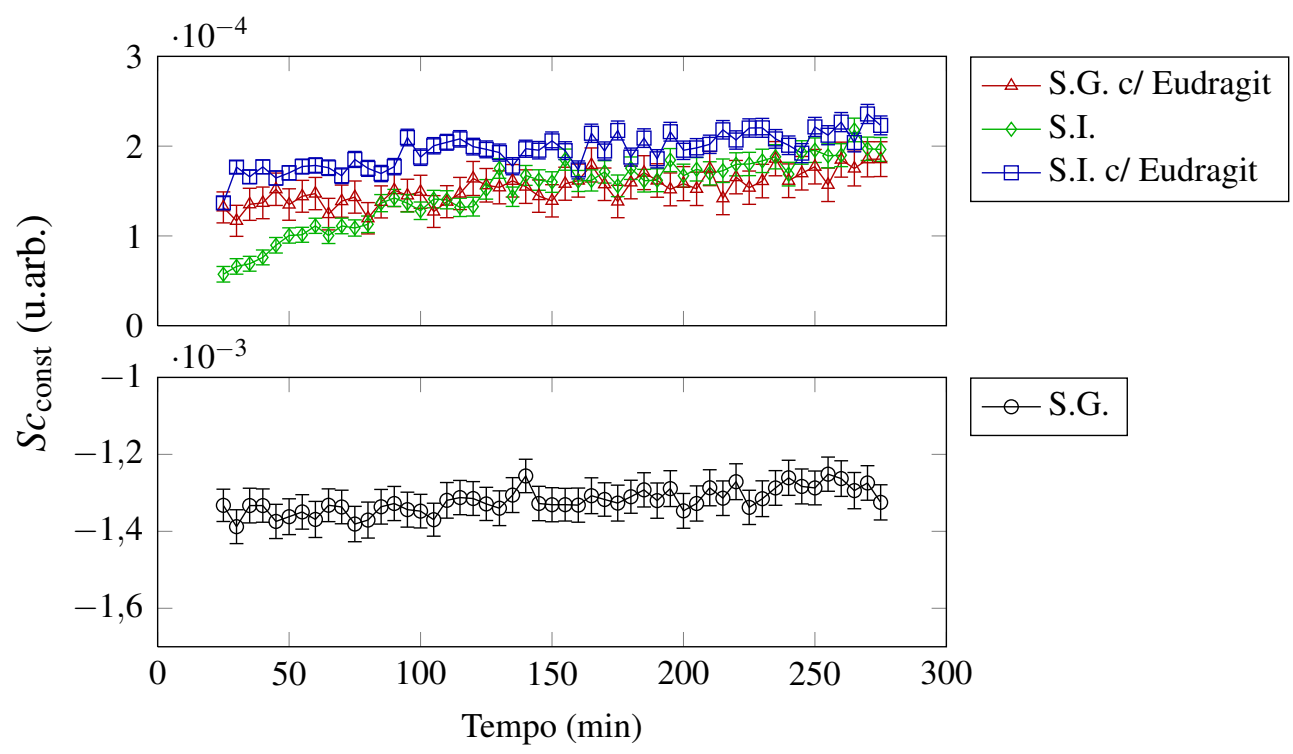

Figura 5.32: Background constante obtido dos ajustes das curvas experimentais de liberação de insulina.

gástrico, com um crescimento linear e constante. Para a amostra sem Eudragit em suco intestinal ele mostra um crescimento linear similar ao apresentado para o suco gástrico, com um coeficiente angular $a$ obtido em ajustes lineares (v. tabela 5.2) ligeiramente maior, podendo indicar um maior ritmo de liberação de insulina. No caso da amostra com Eudragit em suco intestinal nota-se uma estabilidade desse parâmetro até 60 minutos, ponto a partir do qual ele começa a subir num ritmo muito superior ao das outras três amostras. Isso pode ser uma evidência de possíveis efeitos do Eudragit sobre o próprio suco intestinal, que limitariam o fenômeno de fibrilação dos componentes da solução, permitindo assim que eles permaneçam circulando pelo sistema, ocasionando assim esse crescimento do parâmetro.

\begin{tabular}{ccc} 
Amostra & $a\left(\times 10^{-4}\right)$ & $b\left(\times 10^{-2}\right)$ \\
\hline \hline S.G. & $1,2(3)$ & $3,6(5)$ \\
S.G. c/ Eudragit & $1,22(9)$ & $10,53(15)$ \\
S.I. & $1,63(16)$ & $4,3(3)$ \\
S.I. c/ Eudragit & $5,65(3)$ & $8,4(4)$
\end{tabular}

Tabela 5.2: Ajustes lineares feitos às curvas da fig. 5.33. O valor para a amostra S.I. c/ Eudragit foi calculado a partir do ponto $t=60 \mathrm{~min}$. 


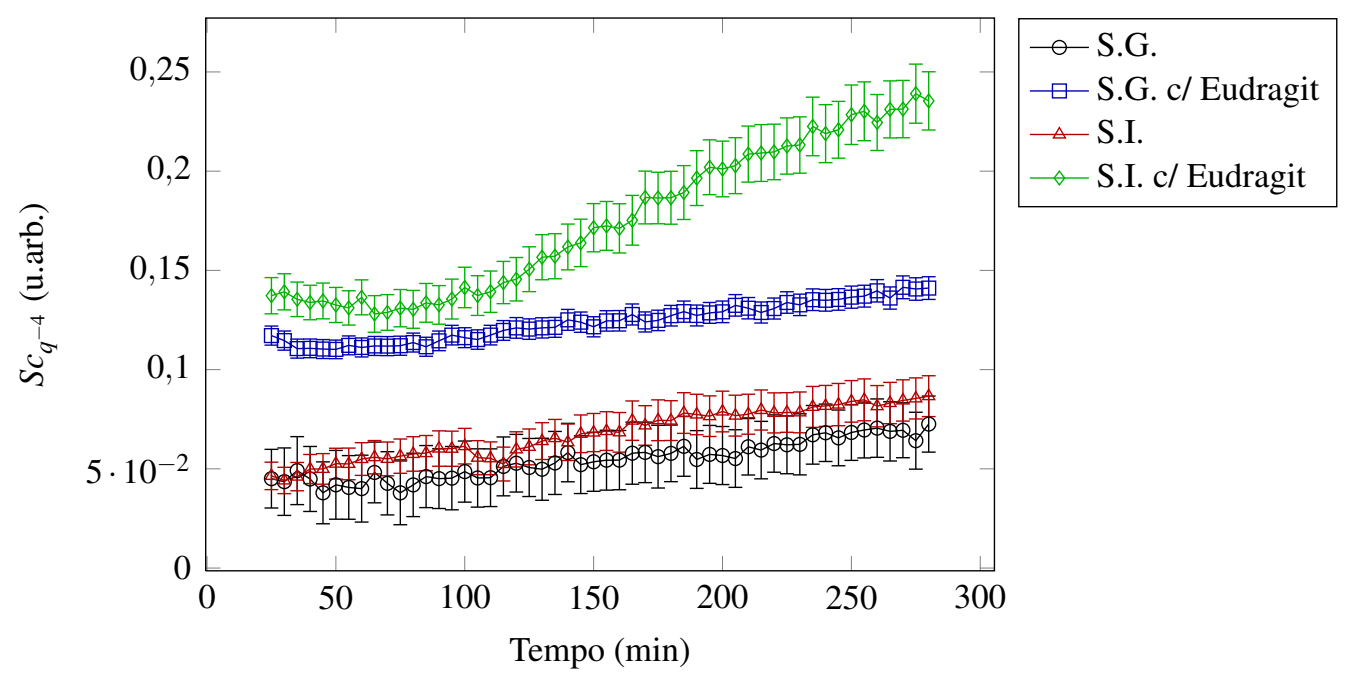

Figura 5.33: Fator de escala para baixo $q$ obtido dos ajustes das curvas experimentais de liberação de insulina.

Não há evidência de diferenças significativas entre as amostras em suco gástrico, no que se refere a este parâmetro. A saída de insulina dos poros poderia ocasionar um aumento desse parâmetro, o que não ocorre.

Experimentos anteriores (v. seção ??) demonstraram que a insulina se encontra dentro dos poros da sílica após o processo de incorporação. Portanto, o comportamento semelhante das duas amostras submetidas à ação do suco gástrico pode representar que, num ambiente ácido, o equilíbrio dinâmico da liberação da insulina está distintamente deslocado em favor da permanência dessas moléculas dentro dos poros. Em outras palavras é termodinamicamente favorável para a insulina ficar dentro dos poros. A pepsina, apesar de possuir tamanho compatível com os poros (aprox. 40x40x60 Å), não é capaz de executar o desenovelamento da insulina nessa situação. Dessa forma, a insulina é protegida da ação degradante da pepsina já pelo fato de estar encapsulada na estrutura de poros da SBA-15. Além disso, esse desenovelamento poderia ser detectado por um aumento do fator de escala $S c_{\text {chain }}$, uma vez que ele responde justamente pelas inomogeneidades da densidade eletrônica que tenham formato filamentar (esse mesmo parâmetro, entretando, não refletiu o surgimento do material formado pela fibrilação no suco intestinal porque as fibras formadas por esse material se enovelaram, formando um material filamentar que foi observado visualmente no arranjo). O que se observa, 
entretanto, é que esse parâmetro permanece estável (fig. 5.30).

Resultados similares, no que se refere à proteção de material pela sílica SBA-15, já foram observados em trabalhos anteriormente encontrados na literatura. ${ }^{[21]}$ 


\section{6}

Conclusões

"Ob-la-di ob-la-da, life goes on, bra”

- The Beatles, Ob-la-di, ob-la-da

Os estudos iniciais com incorporação de moléculas biológicas mostraram que mesmo a SBA-15 normal tem potencial para incorporar grandes quantidades de material biológico. Em particular o resultado obtido no experimento inicial com insulina possibilitou que a proporção de insulina para sílica utilizada fosse multiplicada por 20 para os experimentos seguintes. Mesmo com a proporção baixa foi observada uma mudança significativa nas intensidades relativas dos picos de difração, em particular no caso dos picos de mais alta ordem, ao ponto de os picos (220) e (300) surgirem para as amostras misturadas sob pressão. Os resultados obtidos através das medidas de adsorção mostraram mudança significativa na distribuição de tamanho de poros, indicando assim o seu preenchimento pelas moléculas, especialmente no caso da insulina.

Diversos processos de síntese resultaram numa grande quantidade de sílica SBA-15, que foi utilizada em todos os estudos subsequentes. O estudo preliminar com Eudragit ${ }^{\circledR}$ mostrou que esse composto é capaz de recobrir completamente a sílica, incluindo as partes internas dos poros. Esse indicativo mostrou que moléculas incorporadas à sílica seriam protegidas no caso de soluções com baixo $\mathrm{pH}$, de acordo com a natureza desse polímero. 
Os estudos de estabilidade da sílica SBA-15 obtiveram resultados positivos, mostrando que esse material é resistente às condições ambientais encontradas no percurso do trato gastrintestinal. Dessa forma, é de se esperar que esse material possa ser capaz de proteger a sua carga das condições ambientais que esses meios oferecem.

Os estudos posteriores, de liberação de BSA, mostraram a influência decisiva do Eudragit sobre a velocidade da liberação dessa molécula a partir da estrutura de poros, atrasando esse processo em cerca de 24 horas no caso do suco gástrico. Os dados obtidos para o suco intestinal, por outro lado, não apresentaram diferenças. Isso leva à conclusão de que, embora não esteja incorporada dentro dos poros (como sugerem os dados para o suco intestinal), a BSA é protegida da ação desenovelante do suco gástrico pela película de Eudragit que envolve o complexo sílica+BSA.

A incorporação de insulina à estrutura de poros da SBA-15, já detectada nos experimentos anteriores, foi explicada de maneira um pouco mais detalhada pelos resultados do estudo in-situ de incorporação, que mostrou que esse processo acontece rapidamente, logo nos primeiros minutos de interação entre a SBA-15 e a insulina. Depois disso, o material permanece dentro dos poros.

Os experimentos de liberação de insulina, realizados in-situ, mostraram novamente a diferença de comportamento do Eudragit nos diferentes meios. Mais ainda, no caso da insulina, mesmo amostras sem Eudragit mostraram evidências de que, estando inserida nos poros, a insulina está numa situação termodinamicamente favorável, de forma que a pepsina não é capaz de proceder com a desenovelação. Dessa forma, a proteção do Eudragit torna-se, de certa forma, opcional para moléculas que se localizem dentro dos poros.

As tentativas iniciais de se aplicar um modelo numérico à SBA-15 mostraram que seria necessário modelar a estrutura completa da sílica, incluindo o espalhamento desordenado, e a partir disso efetuar adaptações ao modelo estrutural de forma a levar em conta a presença da densidade eletrônica de diferentes moléculas dentro e fora dos poros. O modelo utilizado, adaptado de estudos a respeito da síntese da sílica SBA-15, foi capaz de fornecer outros parâmetros que serviram como guia na análise das curvas de SAXS que foram obtidas e na elaboração de conclusões a respeito do comportamento do complexo sílica+molécula incorporada.

A aplicação da sílica SBA-15 já foi amplamente estudada no que se refere a 
moléculas menores, como fármacos em geral. Entretanto um estudo sistemático envolvendo moléculas mais complexas, que poderiam ser utilizadas em novas formulações para administração de hormônios e vacinas, tem caráter inédito. Parte da escassez de estudos envolvendo esse tipo de molécula envolve a dificuldade em tratar o sistema poro+molécula, problema que procuramos sanar neste trabalho. Não obstante, utilizou-se uma metodologia heterodoxa, envolvendo a análise das intensidades espalhadas de raios $\mathrm{X}$ pelo material, o que possibilitou a análise do complexo formado pela sílica e pela molécula diretamente em solução. A instrumentação para a execução deste tipo de experimento, bem como os procedimentos para a análise e interpretação dos dados, foram desenvolvidos e ficam à disposição para estudos futuros.

Embora tenha foco em métodos físicos, este trabalho teve um aspecto largamente interdisciplinar, uma vez que envolveu conceitos e aplicações importados da área biológica, especificamente da área de imunologia, onde o projeto de estudo de mestrado foi originado. Ademais, este trabalho não se limitou às situações típicas de laboratório, em que soluções padrão contendo elementos experimentais são comuns e correntes, mas seguiu adiante, ousando buscar ambientes tão próximos dos reais quanto possível, no que se refere às soluções que mimetizavam o trato digestivo.

Naturalmente, as perspectivas para estudos futuros são amplas. Estudos mais detalhados e sistemáticos das soluções de trabalho (suco gástrico, suco intestinal) são necessários, não somente para entender melhor o seu comportamento através do longo tempo de experimento, mas também para uma melhor compreensão do mecanismo de interação entre o Eudragit e os diversos componentes dessas soluções. Mais ainda, torna-se interessante um refinamento do modelo teórico de forma a se obter ajustes mais precisos das curvas experimentais, com o menor número possível de parâmetros, adaptando-o às condições específicas dos experimentos, onde há baixo contraste de densidade eletrônica. Em contrapartida, estudos envolvendo materiais que possam afetar dramaticamente esse contraste também tornam-se interessantes, pois podem fornecer novos dados referentes à dinâmica de incorporação e liberação. Adaptações do modelo podem tornar factível a determinação quantitativa do material localizado dentro dos poros, o que por sua vez permitirá que formulações para uso clínico possam ser desenvolvidas de 
maneira sistemática e objetiva.

Como conclusão final, o potencial de aplicação dos materiais mesoporosos ordenados, em particular a sílica tipo SBA-15, com estrutura hexagonal bidimensional, não pode ser desprezado. Esse material, conforme percebe-se pela ampla literatura de trabalhos científicos disponível, vem recebendo muita atenção como um poderoso veículo para a proteção e o transporte de fármacos dos mais diversos tipos, bem como agente seletor de alvos para a liberação mais efetiva desses compostos, levando a formulações mais sensíveis e efetivas para o tratamento de diversas doenças e levando a uma melhor qualidade de vida para o ser humano. 


\section{Curvas obtidas no LNLS}

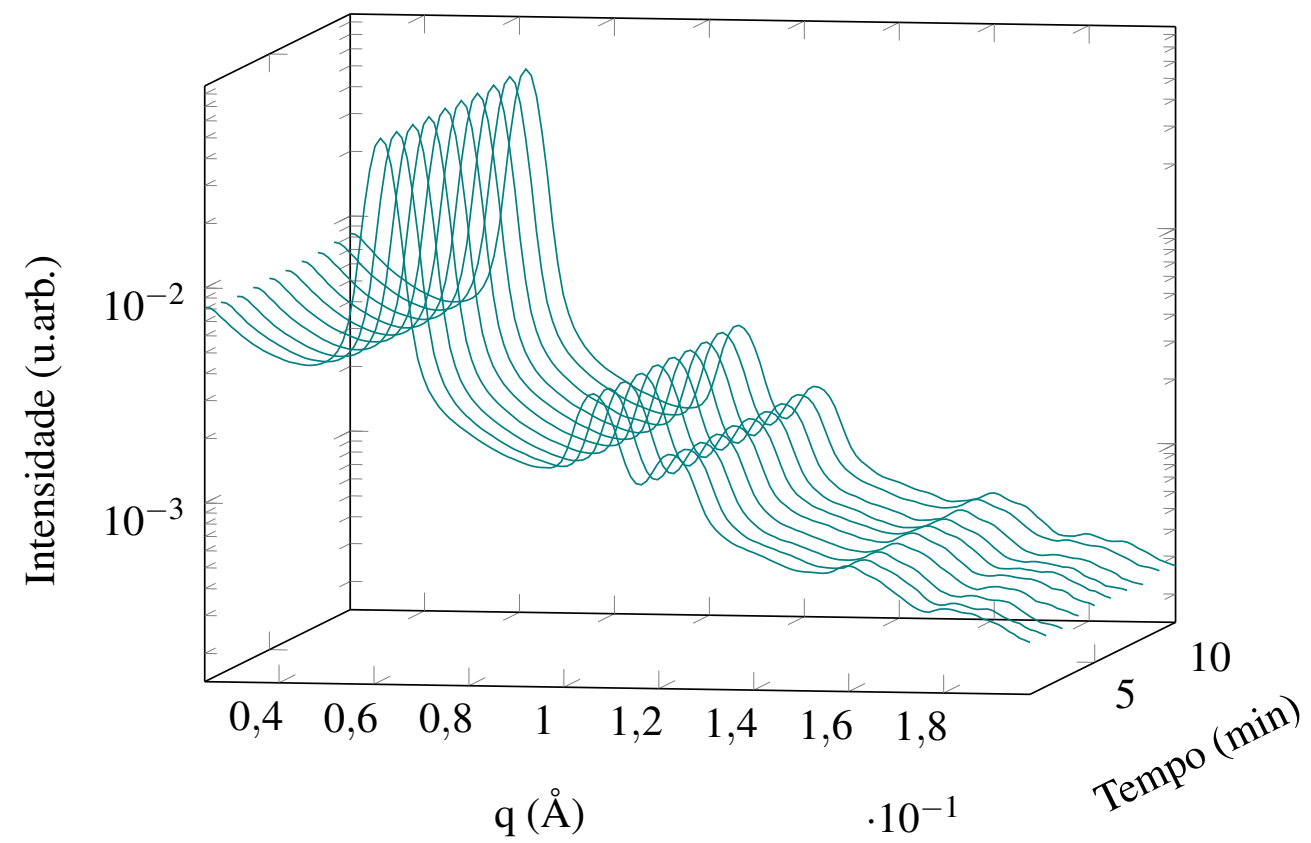

Figura A.1: Curvas de SAXS do experimento de incorporação de insulina em SBA-15 (subseção ??). 


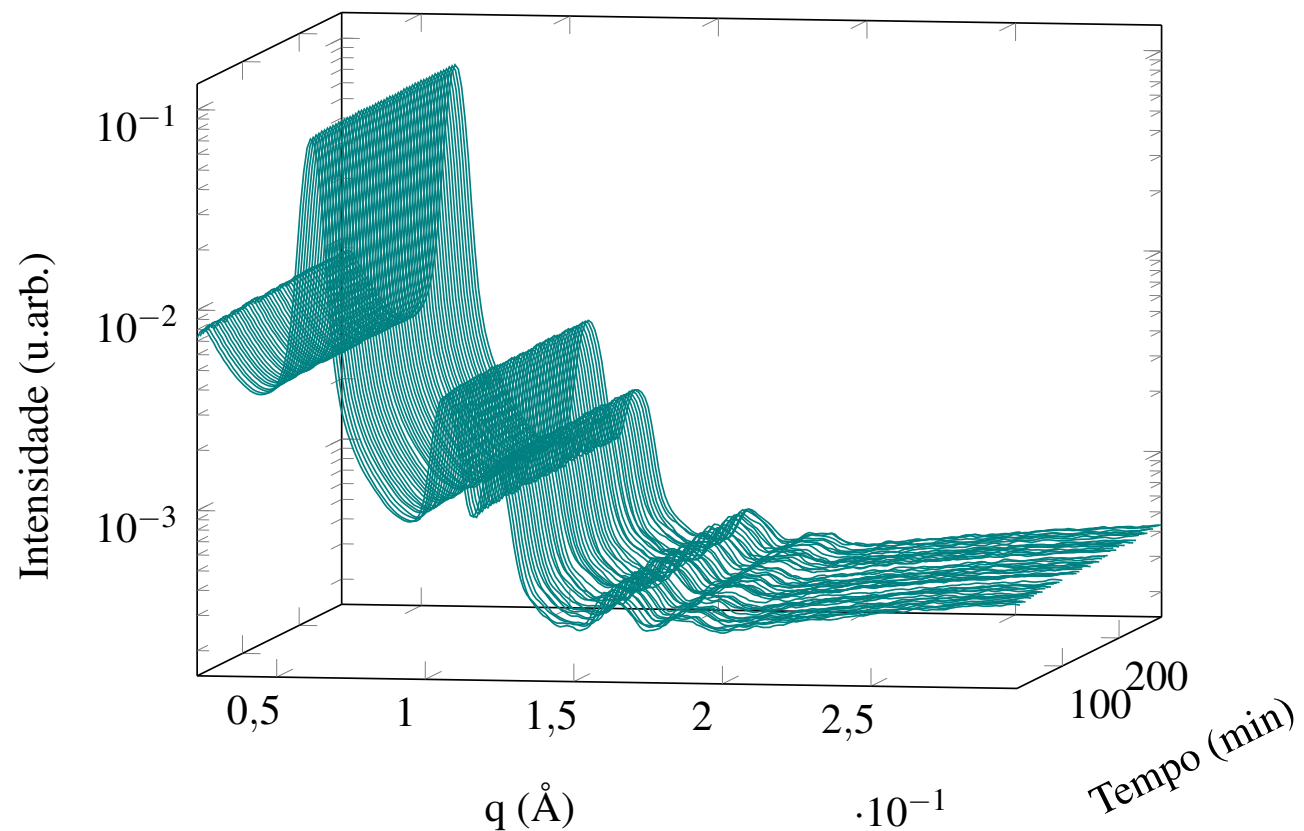

Figura A.2: Curvas de SAXS do experimento de liberação de insulina em suco gástrico (subseção 5.5.3).

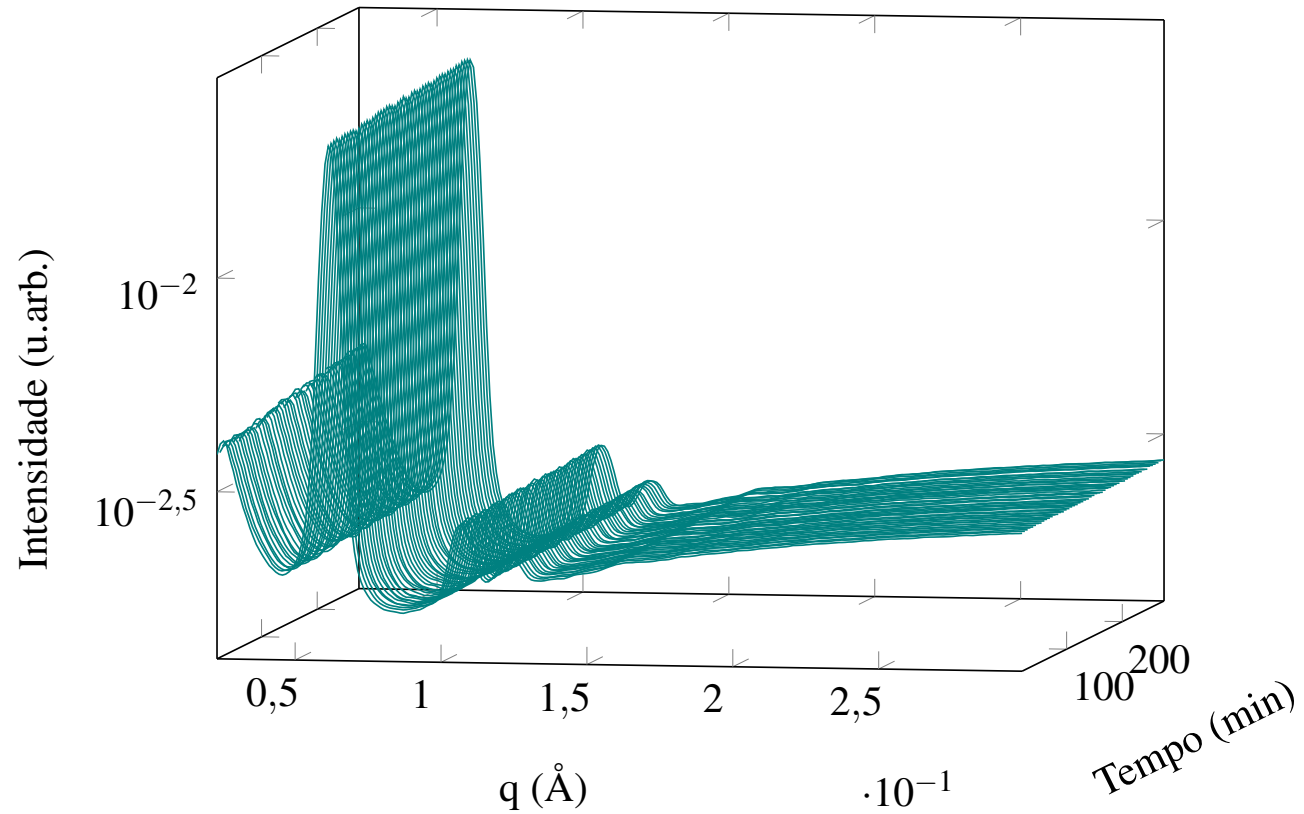

Figura A.3: Curvas de SAXS do experimento de liberação de insulina em suco gástrico (subseção 5.5.3). 


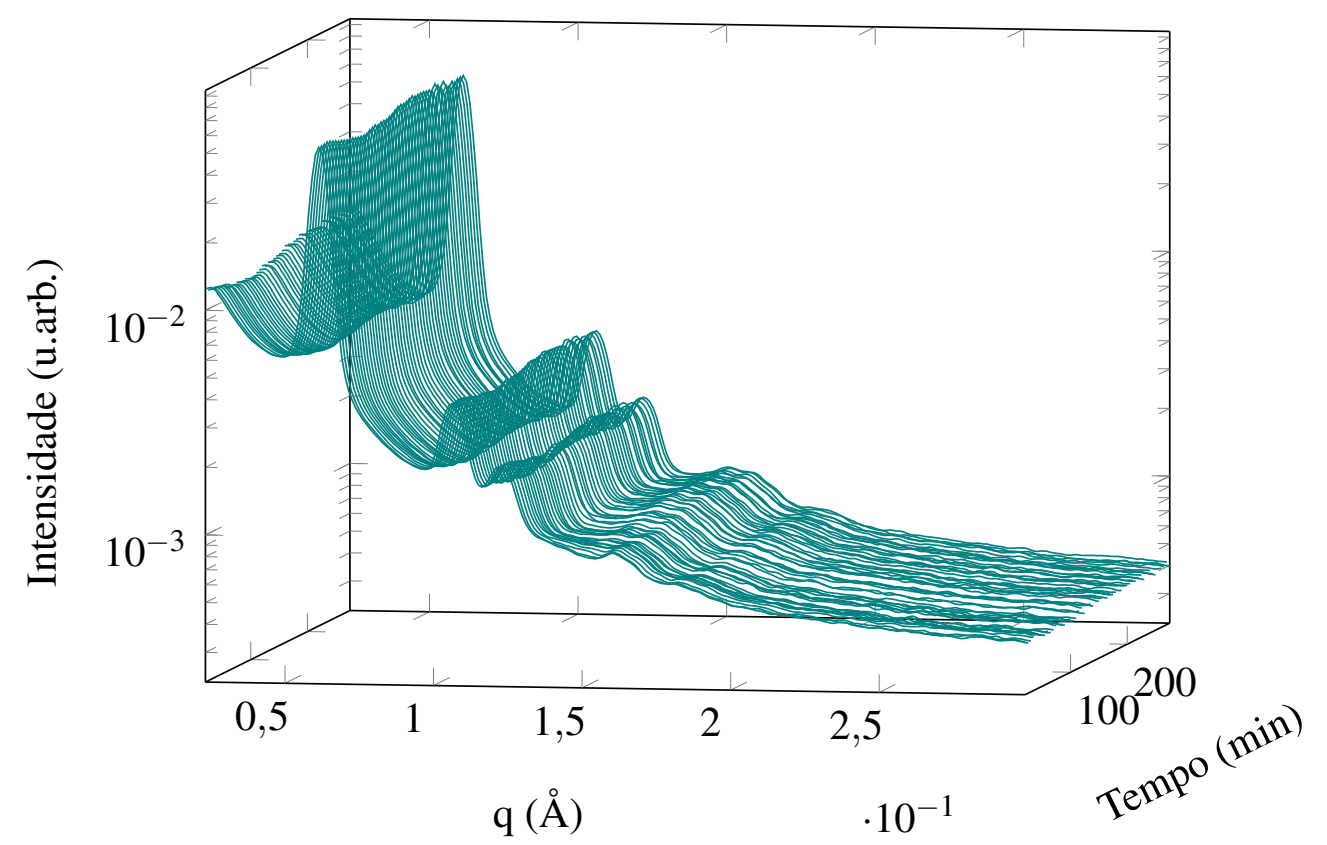

Figura A.4: Curvas de SAXS do experimento de liberação de insulina (amostra sem Eudragit) em suco intestinal (subseção 5.5.3).

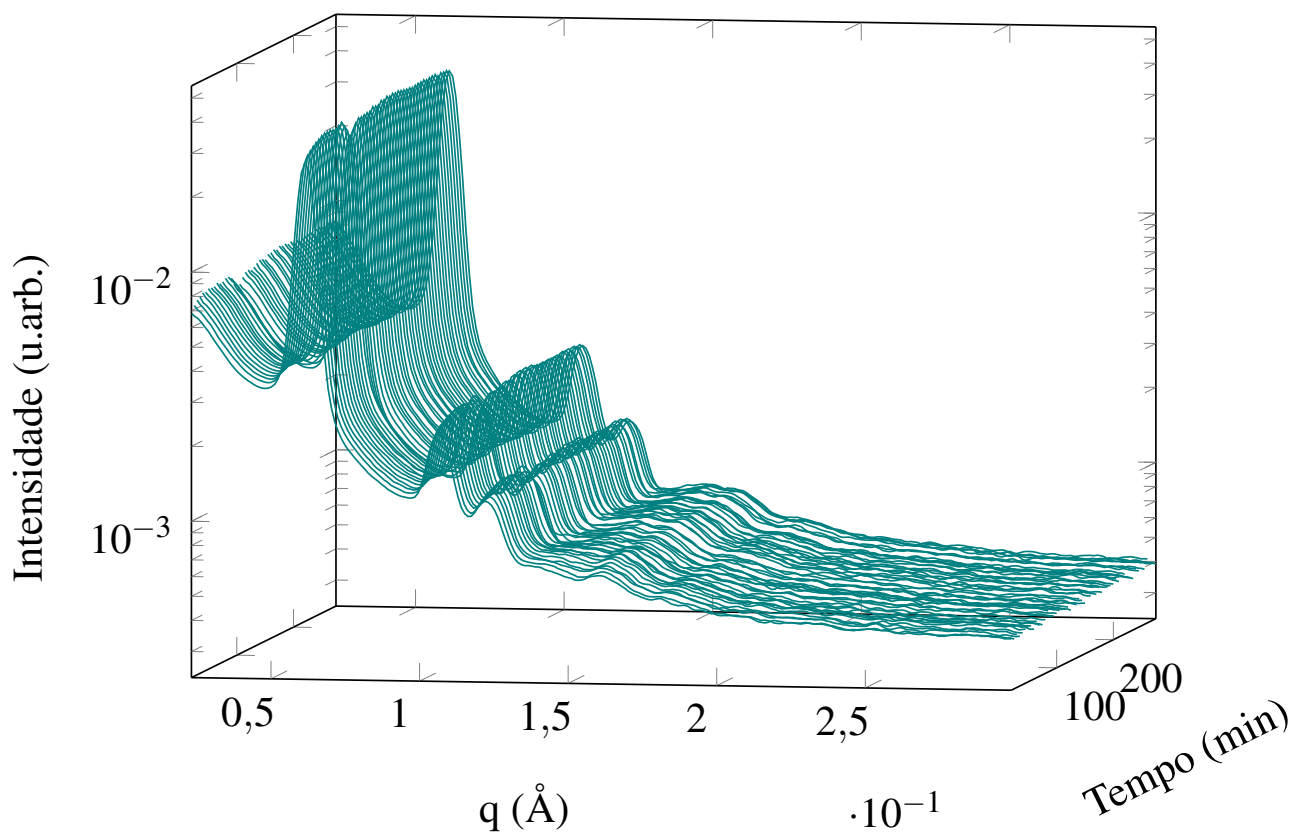

Figura A.5: Curvas de SAXS do experimento de liberação de insulina (amostra com Eudragit) em suco intestinal (subseção 5.5.3). 


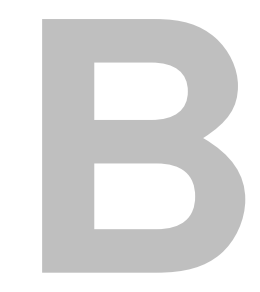

\section{Raios X}

Raios X é o nome normalmente dado à radiação eletromagnética cujo comprimento de onda esteja na faixa de $0,01 \mathrm{~nm}$ a $10 \mathrm{~nm}$, sendo superiores em energia aos raios ultra-violeta e inferiores à radiação gama. Foram descobertos em 1895 por Röntgen e encontraram aplicação quase imediata na área médica, devido à sua capacidade de identificar estruturas ósseas.

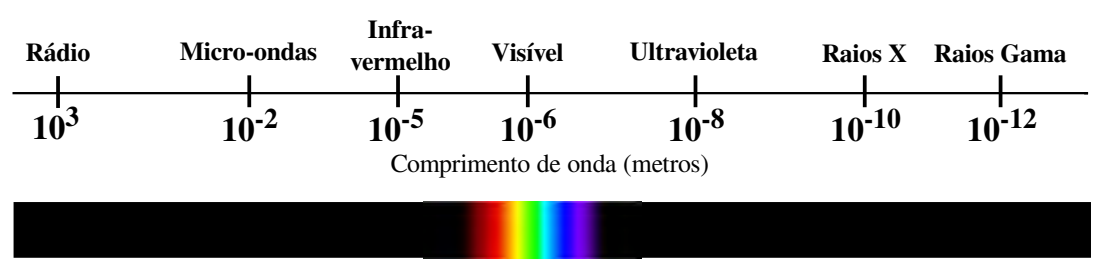

Figura B.1: Espectro eletromagnético.

Atualmente, apesar dos riscos à saúde apresentados por esse tipo de radiação (particularmente o fato de ser carcinogênica), diversas técnicas fazem uso de raios $\mathrm{X}$ para diagnóstico e tratamento. Além de radiografias, faz-se uso de raios $\mathrm{X}$ em exames de tomografia computadorizada (em que uma imagem interna do corpo é reconstruída a partir das informações de absorção de radiação) e fluoroscopia (em que uma substância de contraste é introduzida de modo a expor em tempo real os movimentos das estruturas internas de um paciente). A técnica terapêutica mais comum envolvendo raios $\mathrm{X}$ é a radioterapia, em que uma região do corpo é bombardeada com radiação numa tentativa de controlar ou matar as células de 
tumores malignos.

Do ponto de vista físico, somente em 1912 foi observada a difração de raios X por von Laue ${ }^{[64]}$, sendo confirmada assim a sua natureza ondulatória e, portanto, a sua classificação como radiação eletromagnética. Em 1915 W. L. Bragg publicou a Lei de Bragg (eq. 2.24), estabelecendo uma relação entre as distâncias interplanares em um cristal e o padrão de interferência gerado por esse cristal. A partir de então a cristalografia de forma geral passou por um período de rápido e profícuo desenvolvimento, tornando-se a área da ciência com o maior número de prêmios Nobel até hoje.

O desenvolvimento da técnica permitiu que também fossem caracterizadas as estruturas atômicas de compostos biológicos, como a penicilina e a mioglobina. Também foi através da cristalografia que Watson e Crick descobriram a estrutura de dupla-hélice do DNA ${ }^{[65]}$.

\section{B.1 Interação dos raios $X$ com a matéria}

Fundamentalmente a interação dos raios $\mathrm{X}$ com a matéria é regida pela sua interação com a densidade eletrônica da amostra. Dessa forma, dado um feixe incidente e uma distribuição eletrônica, cada elétron se torna uma fonte de uma onda espalhada coerentemente*.

Seja um feixe de raios $\mathrm{X}$ de intensidade $I_{0}$, propagando-se ao longo do eixo $\overline{O X}$ (fig. B.2), com um vetor campo elétrico $\boldsymbol{E}_{0}$ incidente sobre um elétron livre e em repouso posicionado na origem $O$ do sistema de coordenadas. O campo elétrico no ponto $P$ à distância $r$ desse elétron, ocasionado pela sua oscilação, será dado por $^{[35]}$

$$
\boldsymbol{E}=\left(\frac{\mu_{0}}{4 \pi} \frac{e}{c} \operatorname{sen} \phi\right) \boldsymbol{\gamma}
$$

onde $\boldsymbol{\gamma}=\boldsymbol{E}_{0} e / m_{e}$ é a aceleração do elétron causada por $\boldsymbol{E}_{0}$ e $\phi$ é o ângulo entre $\overline{O P}$ e $\boldsymbol{\gamma}$. No ponto $P$ haverá então uma radiação incidente de mesma freqüência da radiação da onda incidente original e cuja amplitude é dada por

${ }^{*}$ Embora haja também espalhamento não-coerente este pode ser ignorado uma vez que apenas ângulos pequenos serão considerados aqui ${ }^{[41]}$. 


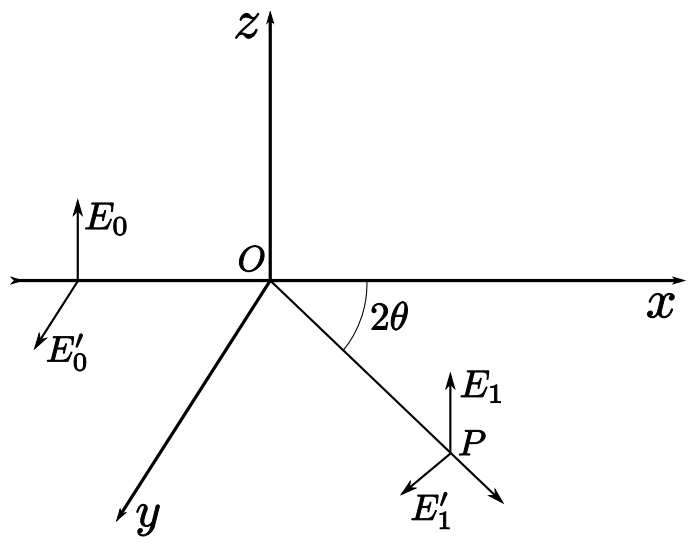

Figura B.2: Espalhamento de raios $X$ por um elétron. O ângulo $2 \theta$ está no plano determinado pelos segmentos $\overline{O P}$ e $\overline{O X}$.

$$
E=\frac{\mu_{0}}{4 \pi} \frac{e^{2}}{m_{e}} E_{0} \frac{\operatorname{sen} \phi}{r}
$$

Tomando proveito da simetria azimutal do sistema em torno do eixo $\overline{O X}$ podemos supor, para facilitar o cálculo, que o ponto $P$ está no plano $\overline{O X Y}$. Além disso decompomos o campo elétrico incidente em suas componentes perpendicular e paralela à direção de incidência. Assim, para a componente perpendicular, temos $\operatorname{sen} \phi=0$ e, para a componente paralela, $\operatorname{sen} \phi=\cos 2 \theta$. As expressões para os campos elétricos no ponto $P$ se tornam

$$
E_{\perp}=r_{e} \frac{E_{0}}{r} \quad E_{\|}=r_{e} \frac{E_{0}}{r} \cos 2 \theta
$$

onde $r_{e}=\left(\mu_{0} / 4 \pi\right)\left(e^{2} / m_{e}\right)$ é o raio clássico do elétron. A razão entre a intensidade espalhada em $P$ e a intensidade incidente em $O$ é igual à razão entre as amplitudes dos campos elétricos nesses pontos ao quadrado. Portanto o fluxo de energia que atravessa uma unidade de área a uma distância $r$ da origem será dado por

$$
I_{\perp}=I_{o} \frac{r_{e}^{2}}{r^{2}} \quad I_{\|}=I_{o} \frac{r_{e}^{2}}{r^{2}} \cos ^{2} 2 \theta
$$

Dividindo pelo ângulo sólido $1 / r^{2}$ e somando $I_{\perp}$ e $I_{\|}$chegamos à expressão para a seção de choque de espalhamento: 


$$
\frac{\mathrm{d} \sigma}{\mathrm{d} \Omega}=\frac{I_{e}}{I_{0}}=r_{e}^{2}\left(k_{\perp}+k_{\|} \cos ^{2} 2 \theta\right)
$$

como o feixe não é polarizado $k_{\perp}=k_{\|}=1 / 2$ e portanto

$$
\frac{\mathrm{d} \sigma}{\mathrm{d} \Omega}=r_{e}^{2} \frac{1+\cos ^{2} 2 \theta}{2}
$$

A equação B.6 é a fórmula de Thomson, que permite calcular a energia espalhada por um elétron por unidade de ângulo sólido por segundo.

Outros fatores podem afetar o comportamento do feixe espalhado, tais como a polarização do feixe original, absorção de radiação e variações na posição dos elétrons devidas à vibração térmica. Para um tratamento mais detalhado, ver os textos de Cullity ${ }^{[34]}$ e Guinier ${ }^{[41]}$, além de Craievich ${ }^{[66]}$.

\section{B.2 Interferência}

O espalhamento coerente, baseado na equação de Thomson B.6, acima, é a base para a análise de materiais por espalhamento de raios $\mathrm{X}$ a baixo ângulo.

No caso do espalhamento coerente as amplitudes são somadas, tendo igual amplitude mas fase variável $\phi$, sendo convenientemente representadas por uma única onda espalhada $e^{i \phi}$.

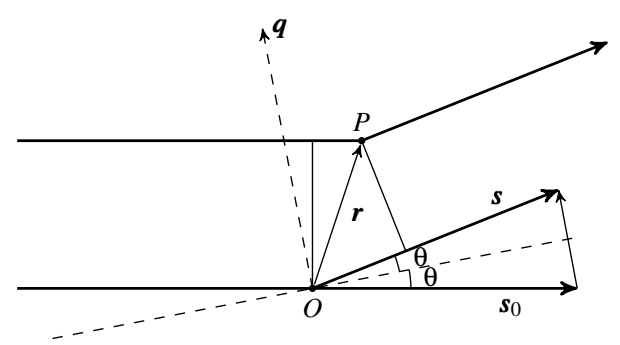

Figura B.3: Representação do espalhamento por um ponto P localizado numa posição $\boldsymbol{r}$.

A figura B.3 representa o espalhamento. $\boldsymbol{s}$ é a direção do raio espalhado e $\boldsymbol{s}_{0}$ a direção do raio incidente. Ambos esses vetores têm módulo 1 e a diferença entre eles, $\left(\boldsymbol{s}-\boldsymbol{s}_{0}\right)$, aponta na direção do espalhamento, dado o ângulo $\theta$. A diferença de fase entre a onda primária (incidente) e a secundária (espalhada) será $\phi=2 \pi x / \lambda$, onde $x$ é a diferença de caminho ótico entre as ondas espalhadas pela origem $\mathrm{O}$ 
e pelo ponto $\mathrm{P}$, dada por $-\boldsymbol{r} \cdot\left(\boldsymbol{s}-\boldsymbol{s}_{0}\right)$, isto é, pela projeção de $\boldsymbol{r}$ na direção do espalhamento. A fase se torna, então,

$$
\phi=-\frac{2 \pi}{\lambda} \boldsymbol{r}\left(\boldsymbol{s}-\boldsymbol{s}_{0}\right)
$$

A diferença $\boldsymbol{s}-\boldsymbol{s}_{0}$ tem módulo $2 \operatorname{sen} \theta$. Somando-se a isso o fato de que o produto escalar tem propriedade comutativa, essa equação se torna

$$
\phi=-q \cdot r
$$

com

$$
q=\frac{4 \pi}{\lambda} \operatorname{sen} \theta
$$

E a fase então fica sendo $e^{-i \boldsymbol{q} \cdot \boldsymbol{r}}$. Isso evidencia que só é relevante, em termos de difração, a componente do vetor $\boldsymbol{r}$ na direção do espalhamento; dessa forma um conjunto de pontos com a mesma componente nessa direção formará um plano (ou família de planos), para o qual pode-se então considerar uma "reflexão cristalográfica".

A amplitude resultante da interferência dos diversos centros espalhadores (elétrons) pode então ser obtida somando-se as diversas ondas secundárias. Evidentemente essa tarefa tem dimensão exageradamente grande; por isso é corrente fazer-se uso da densidade eletrônica, $\rho(\boldsymbol{r})$, de forma que uma unidade de volume $\mathrm{d} \boldsymbol{r}$ contenha um número $\rho(\boldsymbol{r}) \mathrm{d} \boldsymbol{r}$ de elétrons. Dessa forma, a intensidade será dada pela integral:

$$
A(\boldsymbol{q})=\int \rho(\boldsymbol{r}) e^{-i \boldsymbol{q} \cdot \boldsymbol{r}} \mathrm{d} \boldsymbol{r}
$$

Dessa forma, a distribuição de densidade eletrônica da amostra pode ser completamente determinada a partir da informação da amplitude espalhada, através da transformada inversa:

$$
\rho(\boldsymbol{r})=\frac{1}{(2 \pi)^{3}} \int A(\boldsymbol{q}) e^{-i \boldsymbol{q} \cdot \boldsymbol{r}} \mathrm{d} \boldsymbol{q}
$$




\section{Problema da Fase}

Em um experimento de espalhamento de raios X, entretanto, a forma da partícula é representada na intensidade espalhada pelo fator de forma $P(q)$, dado pela média espacial do produto de $A(\boldsymbol{q})$ pelo seu complexo conjugado, $A^{*}(\boldsymbol{q})$ :

$$
P(q)=\left\langle A(\boldsymbol{q}) A^{*}(\boldsymbol{q})\right\rangle_{\Omega}
$$

onde $\Omega$ é o ângulo sólido no espaço recíproco. Essa operação permite que somente o módulo de $A(\boldsymbol{q})$ seja determinado, uma vez que a informação sobre a fase é perdida na parte angular da integração. Sem essa informação não é possível determinar completamente a amplitude de espalhamento e a equação B.11 não pode ser resolvida. Este fenômeno é conhecido como o Problema da fase e é o grande obstáculo no caminho da análise de estruturas materiais através dos resultados de experimentos de espalhamento de raios $\mathrm{X}$. 


\section{Lista de Figuras}

2.1 Esquema de produção de raios $\mathrm{X}$ em tubo de $\mathrm{Cu} . \quad \ldots \ldots$

2.2 Exemplo de espectro contínuo e característico (fora de escala). . . 7

2.3 Função distribuição de distância para alguns formatos de partícula 13

2.4 Ilustração da Lei de Bragg. . . . . . . . . . . . . . . . . . . . . . 15

2.5 Poros durante a dessorção: (a) preenchido, (b) núcleo livre e camada adsorvida. . . . . . . . . . . . . . . . 22

3.1 Representação esquemática do contraste de densidade eletrônica radial do poro. . . . . . . . . . . . . . . . 26

3.2 Diagrama demonstrando a relação entre o perfil de densidade eletrônica radial (fig. 3.1 e a rede hexagonal bidimensional dos poros. 26

4.1 Estrutura do copolímero tribloco Pluronic ${ }^{\circledR} \mathrm{P} 123 \ldots \ldots$. . . . . . . 31

4.2 Estrutura da fonte de sílica (TEOS) . . . . . . . . . . . . . . 31

4.3 Esquema representando o processo de síntese da sílica mesoporosa SBA-15. . . . . . . . . . . . . . 32

4.4 Geometria experimental de um experimento de SAXS/SAXRD. . 35

4.5 Arranjo para medida de isotermas de adsorção. . . . . . . . . . . 38

5.1 Isoterma de adsorção de uma amostra de SBA-15 sintetizada para os estudos in-situ. . . . . . . . . . . . . . . . 41

5.2 Distribuição de tamanho de poros de uma amostra de SBA-15 sintetizada para os estudos in-situ. . . . . . . . . . . . . 42

5.3 Curva de SAXS de uma amostra de SBA-15 sintetizada para os estudos in-situ. . . . . . . . . . . . . . . . . . 43

5.4 Perfil de densidade eletrônica calculado a partir do ajuste da figura

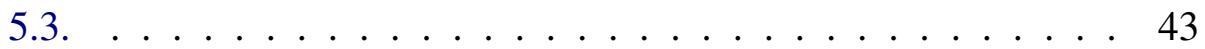

5.5 Imagens de SEM das amostras de SBA-15 preparada para os estudosin-situ. . . . . . . . . . . . . . . . . . . 44

5.6 Isoterma de adsorção de uma amostra de SBA-15 pura e com Eudragit. . . . . . . . . . . . . . . 45 
5.7 Distribuição de tamanho de poros de SBA-15 pura e com Eudragit. 46

5.8 Curva de SAXS de uma amostra de SBA-15 sintetizada para os estudos in-situ. . . . . . . . . . . . . . . . . . . . 47

5.9 Perfis de densidade eletrônica calculados a partir dos ajustes da

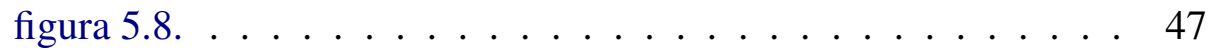

5.10 Curvas de SAXS de amostras de SBA-15 em água. . . . . . . . . 48

5.11 Curvas de SAXS de amostras de SBA-15 em PBS. . . . . . . . . 49

5.12 Região de Guinier das curvas de SAXS da figura 5.11. . . . . . . 50

5.13 Curvas de SAXS de amostras de SBA-15 em suco gástrico. . . . . 50

5.14 Curvas de SAXS de amostras de SBA-15 em suco intestinal. . . . 51

5.15 Curvas de SAXS de amostras de SBA-15 com BSA em PBS. . . . 52

5.16 Curvas de SAXS de amostras de SBA-15 com BSA em suco gástrico. 53

5.17 Curvas de SAXS de amostras de SBA-15 com BSA e Eudragit em suco gástrico. . . . . . . . . . . . . . . . . . . 54

5.18 Curvas de SAXS de amostras de SBA-15 com BSA em suco

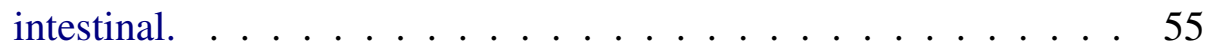

5.19 Curvas de SAXS de amostras de SBA-15 com BSA e Eudragit em suco intestinal. . . . . . . . . . . . . 55

5.20 Curva de SAXS de uma amostra de SBA-15 obtida na linha SAXS2. 57

5.21 Parâmetro de escala obtido dos ajustes das curvas experimentais de incorporação de insulina. . . . . . . . . . . . . . . 59

5.22 Parâmetro de escala obtido dos ajustes das curvas experimentais de incorporação de insulina. . . . . . . . . . . . . . . 60

5.23 Background constante obtido dos ajustes das curvas experimentais de incorporação de insulina. . . . . . . . . . . . . . . . 61

5.24 Parâmetro $c$ obtido dos ajustes das curvas experimentais de incorporação de insulina. . . . . . . . . . . . . . . . . . 61

5.25 Raio interno dos poros obtido dos ajustes das curvas experimentais de incorporação de insulina. . . . . . . . . . . . . . . 62

5.26 Dispersão relativa do tamanho dos poros obtida dos ajustes das curvas experimentais de incorporação de insulina. . . . . . . . . . 62

5.27 Raio externo dos ajustes das curvas experimentais de incorporação de insulina. . . . . . . . . . . . . . . 63

5.28 Parâmetro de escala do espalhamento a baixo $q$ obtido dos ajustes das curvas experimentais de incorporação de insulina. . . . . . . . 63

5.29 Parâmetro de escala obtido dos ajustes das curvas experimentais de liberação de insulina. . . . . . . . . . . . . . . . . . . . 64

5.30 Parâmetro de escala dos microporos obtido dos ajustes das curvas experimentais de liberação de insulina. . . . . . . . . . . . . 65

5.31 Parâmetro $c$ obtido dos ajustes das curvas experimentais de liberação de insulina. . . . . . . . . . . . . . . . . . . . . 66 
5.32 Background constante obtido dos ajustes das curvas experimentais de liberação de insulina. . . . . . . . . . . . . . . . . 67

5.33 Fator de escala para baixo $q$ obtido dos ajustes das curvas experimentais de liberação de insulina. . . . . . . . . . . . . 68

A.1 Curvas de SAXS do experimento de incorporação de insulina em SBA-15 (subseção ??). . . . . . . . . . . . . . . . . 74

A.2 Curvas de SAXS do experimento de liberação de insulina em suco gástrico (subseção 5.5.3) . . . . . . . . . . . . . . 75

A.3 Curvas de SAXS do experimento de liberação de insulina em suco gástrico (subseção 5.5.3) . . . . . . . . . . . . . . . 75

A.4 Curvas de SAXS do experimento de liberação de insulina (amostra sem Eudragit) em suco intestinal (subseção 5.5.3). . . . . . . . . . 76

A.5 Curvas de SAXS do experimento de liberação de insulina (amostra com Eudragit) em suco intestinal (subseção 5.5.3). . . . . . . . . 76

B.1 Espectro eletromagnético. . . . . . . . . . . . . . 77

B.2 Espalhamento de raios X por um elétron. . . . . . . . . . . . . 79

B.3 Representação do espalhamento por um ponto P localizado numa posição $\boldsymbol{r} . \ldots \ldots \ldots$. . . . . . . . . . . . 80 


\section{Lista de Tabelas}

2.1 Relação entre distância interplanar e o parâmetro de rede $a$ para as primeiras reflexões de uma rede hexagonal plana $(l=0)$.

3.1 Parâmetros utilizados na subrotina de ajuste e equivalência com os termos do modelo (seção 3.1). . . . . . . . . . . . . . . . . . 29

4.1 Proporções em massa empregadas na síntese da sílica SBA-15. . . 30

4.2 Quantidades utilizadas na preparação do PBS. . . . . . . . . . 32

5.1 Ajustes lineares feitos às curvas da fig. 5.32 . . . . . . . . . . . 66

5.2 Ajustes lineares feitos às curvas da fig. 5.33. O valor para a amostra S.I. c/ Eudragit foi calculado a partir do ponto $t=60 \mathrm{~min} . \quad$. 67 


\section{Referências Bibliográficas}

[1] OICM. The International System of Units (SI), 2006. vii

[2] Kresge, C., Leonowicz, M., Roth, W., et al. Ordered Mesoporous Molecularsieves Synthesized by a Liquid-Crystal Template Mechanism. Nature, 359(6397):710-712, 22 Oct 1992. 1

[3] Beck, J., Vartuli, J., Roth, W., et al. A New Family of Mesoporous Molecularsieves Prepared with Liquid-Crystal Templates. Journal of the American Chemical Society, 114(27):10834-10843, 30 Dec 1992. 1

[4] Sing, K., Everett, D., Haul, R., et al. Reporting Physisorption Data for Gas-Solid Systems with Special Reference to the Determination of SurfaceArea and Porosity (Recommendations 1984). Pure and Applied Chemistry, 57(4):603-619, 1985. 1, 20

[5] Zhao, D., Feng, J., Huo, Q., et al. Triblock Copolymer Syntheses of Mesoporous Silica with Periodic 50 to 300 angstrom Pores. Science, 279(5350):548552, 23 Jan 1998. 1, 2, 31

[6] Zhao, D., Huo, Q., Feng, J., et al. Nonionic Triblock and Star Diblock Copolymer and Oligomeric Surfactant Syntheses of Highly Ordered, Hydrothermally Stable, Mesoporous Silica Structures. Journal of the American Chemical Society, 120(24):6024-6036, 24 Jun 1998. 2

[7] Ciesla, U. e Schuth, F. Ordered Mesoporous Materials (review). Microporous and Mesoporous Materials, 27(2-3):131-149, Fev 1999. 2

[8] Feng, X., Fryxell, G., Wang, L., et al. Functionalized Monolayers on Ordered Mesoporous Supports. Science, 276(5314):923-926, 9 MAY 1997. 2

[9] Wu, C. e Bein, T. Conducting Carbon Wires in Ordered, Nanometer-sized Channels. Science, 266(5187):1013-1015, 11 NOV 1994. 2

[10] Wu, C. e Bein, T. Conducting Polyaniline Filaments in a Mesoporous Channel Host. Science, 264(5166):1757-1759, 17 JUN 1994. 2 
[11] Leon, R., Margolese, D., Stucky, G., et al. Nanocrystalline Ge Filaments in the Pores of a Mesosilicate. Physical Review B, 52(4):R2285-R2288, 15 JUL 1995. 2

[12] Diaz, J. e Balkus, K. Enzyme Immobilization in MCM-41 Molecular Sieve. Journal of Molecular Catalysis B - Enzymatic, 2(2-3):115-126, 4 DEC 1996. 2

[13] Lin, Y., Tsai, C., Huang, H., et al. Well-ordered Mesoporous Silica Nanoparticles as Cell Markers. Chemistry of Materials, 17(18):4570-4573, Sep 6 2005. 2

[14] Liu, Y., Xu, Q., Feng, X., et al. Immobilization of Hemoglobin on SBA-15 Applied to the Electrocatalytic Reduction of H2O2. Analytical and Bioanalytical Chemistry, 387(4):1553-1559, Feb 2007. 2

[15] O'Connor, A., Hokura, A., Kisler, J., et al. Amino Acid Adsorption onto Mesoporous Silica Molecular Sieves. Separation and Purification Technology, 48(2, Sp. Iss. SI):197-201, Mar 2006. 2

[16] Charnay, C., Begu, S., Tourne-Peteilh, C., et al. Inclusion of Ibuprofen in Mesoporous Templated Silica: Drug Loading and Release Property. European Journal of Pharmaceutics and Biopharmaceutics, 57(3):533-540, May 2004. 2

[17] Lu, J., Liong, M., Zink, J., et al. Mesoporous Silica Nanoparticles as a Delivery System for Hydrophobic Anticancer Drugs. Small, 3(8):1341-1346, Aug 2007. 2

[18] Slowing, I., Trewyn, B., Giri, S., et al. Mesoporous Silica Nanoparticles for Drug Delivery and Biosensing Applications. Advanced Functional Materials, 17(8):1225-1236, 21 May 2007. 2

[19] Fagundes, L. B., Sousa, T. G. F., Sousa, A., et al. SBA-15-collagen Hybrid Material for Drug Delivery Applications. Journal of Non-Crystalline Solids, 352(32-35):3496-3501, Sep 15 2006. 2

[20] Institute, N. C. Dictionary of Cancer Terms. http://www.cancer.gov/dictionary. 2

[21] Mercuri, L., Carvalho, L., Lima, F., et al. Ordered Mesoporous Silica SBA-15: A New Effective Adjuvant to Induce Antibody Response. Small, 2:254-256, 2006. 2, 69 
[22] Carvalho, L., Ruiz, R., Scaramuzzi, K., et al. Immunological parameters related to the adjuvant effect of the ordered mesoporous silica SBA-15. Vaccine, 28:7829-7836, 2010. 3

[23] Vivero-Escoto, J., Slowing, I., Trewyn, B., et al. Mesoporous Silica Nanoparticles for Intracellular Controlled Drug Delivery. Small, 6(18):1952-1967, 2010. 3

[24] Yu, H. e Zhai, Q.-Z. Mesoporous SBA-15 molecular sieve as a carrier for controlled release of nimodipine. Microporous and Mesoporous Materials, 123:298-305, 2009. 3

[25] Gao, F., Botella, P., Corma, A., et al. Monodispersed Mesoporous Silica Nanoparticles with Very Large Pores for Enhanced Adsorption and Release of DNA. Journal of Physical Chemistry, 113:1796-1804, 2009. 3

[26] Ajitha, S. e Sugunan, S. Tuning mesoporous molevular sieve SBA-15 for the immobilization of $\alpha$-amylase. Journal of Porous Materials, 17:341-349, 2010. 3

[27] Halamová, D., Badaničová, M., Zeleňák, V., et al. Naproxen drug delivery using periodic mesoporous silica SBA-15. Applied Surface Science, 256:64896494, 2010. 3

[28] Rosenholm, J., Meinander, A., Peuhu, E., et al. Targeting of Porous Hybrid Silica Nanoparticles fo Cancer Cells. ACS Nano, 3(1):197-206, 2009. 3

[29] Lu, J., Lion, M., Zink, J., et al. Biocompatibility, Biodistribution and DrugDelivery Efficiency of Mesoporous Silica Nanoparticles for Cancer Therapy in Animals. Small, 6(16):1794-1805, 2010. 3

[30] He, Q., Zhang, Z., Gao, F., et al. In vivo Biodistribution and Urinary Excretion of Mesoporous Silica Nanoparticles: Effects of Particle Size and PEGylation. Small, 7(2):271-280, 2011. 3

[31] Pacheco, O., Sant'Anna, O. A. B. E., Mercuri, L. P., et al. Immunogenic Complex Formed by Vaccinal Antigens Encapsulated by Nanostructured Mesoporous Silica, 2007. 3

[32] Guyton, A. C. e Hall, J. E. Tratado de Fisiologia Médica. Guanabara Koogan, Rio de Janeiro, 1997. ISBN 85-277-0395-5. 3

[33] Sundblom, A., Oliveira, C. L. P., Palmqvist, A. E. C., et al. Modeling in Situ Small-Angle X-ray Scattering Measurements Following the Formation of 
Mesostructured Silica. The Journal of Physical Chemistry C, 113(18):77067713, 2009. doi:10.1021/jp809798c. 3, 24, 25, 58

[34] Cullity, B. Elements of X-ray Diffraction. 2nd edição. Addison-Wesley, Reading, Massachusetts, 1978. ISBN 0-201-01174-3. 7, 80

[35] Jackson, J. Classical Electrodynamics. 3rd edição. John Wiley \& Sons, Berkeley, CA, 1999. ISBN 978-0-471-30932-1. 8, 78

[36] Margaritondo, G. Introduction to Synchrotron Radiation. Oxford University Press, Oxford, UK, 1988. ISBN 0-19-504524-6. 8

[37] Ewald, P. X-ray diffraction by finite and imperfect crystal lattices. Proceedings of the Physical Society, 52:167, 1940. 9

[38] Guinier, A. e Fournet, G. Small-Angle Scattering of X-Rays. John Wiley and Sons, New York, 1955. 9

[39] Debye, P. e Bueche, A. M. Scattering by an Inhomogeneous Solid. Journal of Applied Physics, 20(6):518-525, 1949. doi:10.1063/1.1698419. 11

[40] Mertens, H. e Svergun, D. Structural characterization of proteins and complexes using small-angle X-ray solution scattering. Journal of Structural Biology, 172:128-141, 2010. 12

[41] Guinier, A. X-Ray Diffraction in Crystals, Imperfect Crystals and Amorphous Bodies. Dover, New York, 1994. ISBN 0-486-68011-8. 13, 15, 36, 78, 80

[42] Bragg, W. The Diffraction of Short Electromagnetic Waves by a Crystal. Proceedings of the Cambridge Philosophical Society, 17:43-57, 1914. 16

[43] Pedersen, J., Posselt, D., e Mortensen, K. Analytical Treatment of the Resolution Function for Small-Angle Scattering. Journal of Applied Crystallography, 23:321-333, 1990. 19, 28

[44] Brunauer, S., Emmett, P., e Teller, E. Adsorption of Gases in Multimolecular Layers. Journal of the American Chemical Society, 60:309-319, 1938. 19

[45] Langmuir, I. The Constitution and Fundamental Properties of Solids and Liquids. Part I. Solids. Journal of the American Chemical Society, 38:222195, 1916. 19

[46] Lippens, B.C. and de Boer, J.H. Studies on pore systems in catalysts : V. The t method. Journal of Catalysis, 4(3):319 - 323, 1965. ISSN 0021-9517. doi:\{DOI:10.1016/0021-9517(65)90307-6\}. 20 
[47] Gregg, S. e Sing, K. Adsorption, Surface Area and Porosity. Academic Press, London, 1982. ISBN 978-0-123-00956-2. 21

[48] Jaroniec, M., Kruk, M., e Olivier, J. P. Standard Nitrogen Adsorption Data for Characterization of Nanoporous Silicas. Langmuir, 15(16):5410-5413, 1999. doi:10.1021/la990136e. 21

[49] Kruk, M., Jaroniec, M., e Sayari, A. Application of Large Pore MCM-41 Molecular Sieves To Improve Pore Size Analysis Using Nitrogen Adsorption Measurements. Langmuir, 13(23):6267-6273, 1997. doi:10.1021/la970776m. 23

[50] Pedersen, J. Analysis of small-angle scattering data from colloids and polymer solutions: modeling and least-squares fitting. Advances in Colloid Interface Science, 70:171-210, 1997. 25, 28

[51] Förster, S., Timmann, A., Konrad, M., et al. Scattering Curves of Ordered Mesoscopic Materials. The Journal of Physical Chemistry B, 109(4):13471360, 2005. doi:10.1021/jp0467494. PMID: 16851102. 25

[52] Mcnaught, A. D. e Wilkinson, A. IUPAC Compendium of Chemical Terminology. 2 edição. WileyBlackwel, agosto 2012. ISBN 978-0865426849. 27

[53] Pedersen, J. S. e Gerstenberg, M. C. Scattering Form Factor of Block Copolymer Micelles. Macromolecules, 29(4):1363-1365, 1996. doi: 10.1021/ma9512115. 28

[54] Pedersen, J. S. Form factors of block copolymer micelles with spherical, ellipsoidal and cylindrical cores. Journal of Applied Crystallography, 33(3 Part 1):637-640, Jun 2000. doi:10.1107/S0021889899012248. 28

[55] Debye, P. Molecular-weight Determination by Light Scattering. The Journal of Physical and Colloid Chemistry, 51(1):18-32, 1947. doi: 10.1021/j150451a002. 28

[56] Philip R. Bevington, D. K. R. Data reduction and error analysis for the physical sciences, volume 1. 3 edição. McGraw-Hill, Boston, 2003. 28

[57] Levenberg, K. A Method for the Solution of Certain Non-Linear Problems in Least Squares. Quarterly of Applied Mathematics, 3:164-168, 1944. 28

[58] Marquardt, D. W. An algorithm for least-squares estimation of nonlinear parameters. Journal of the Society for Industrial and Applied Mathematics, 11(2):431-441, 1963. 28 
[59] Matos, J., Mercuri, L., Kruk, M., et al. Toward the Synthesis of Extra-LargePore MCM-41 Analogues. Chemistry of Materials, 13:1726-1731, 2001. 30

[60] Whittingham, J., Edwards, D., Antson, A., et al. Interactions of Phenol and mCresol in the Insulin Hexamer, and Their Effect on the Association Properties of B28 Pro $\rightarrow$ Asp Insulin Analogues. Biochemistry, 37(33):11516-11523, 1998. doi:10.1021/bi980807s. PMID: 9708987. 32

[61] Norrman, M. and Hubálek, F. and Schluckebier, G. Structural characterization of insulin NPH formulations. European Journal of Pharmaceutical Sciences, 30(5):414-423, 2007. ISSN 0928-0987. doi:DOI:10.1016/j.ejps. 2007.01.003. 32

[62] Packianathan, C., Katen, S., Dann, I., C.E., et al. Conformational Changes in the Hepatitis B Virus Core Protein Are Consistent with a Role for Allostery in Virus Assembly. Journal of Virology, 84(3):1607-1615, 2010. doi:10.1128/ JVI.02033-09. 32

[63] Convention, U. S. P. The United States Pharmacopeia 32 The National Formulary 27. 2008. 33

[64] Friedrich, W., Knipping, P., e von Laue, M. Interferenz-Erscheinungen bei Röntgenstrahlen. Sitzungsberichte der Mathematisch-Physikalischen Classe der Königlich-Bayerischen Akademie der Wissenschaften zu Münche, 303322, 1912. 78

[65] Watson, J. e Crick, F. H. Molecular structure of nucleic acids; a structure for deoxyribose nucleic acid. Nature, 171:737,758, 1953. 78

[66] Craievich, A. F. Small-angle X-ray scattering by nanostructured materials - Handbook of Sol-Gel Science and Technology - Volume II: Materials characterization. Chapter 8. Kluwer Academic Publishers, 2005. 80 


\section{Índice Remissivo}

adsorção

equilíbrio de, 37

espaço livre, 37

isoterma de, 37

ajuste, 29, 66, 68

amplitude de espalhamento, 8

Bragg

Lei de, 16, 78

condensação capilar, 21

copolímero, 30, 45

Eudragit $^{\circledR}, 45$

correlação

função de, 11

densidade eletrônica, 9, 10, 81

distribuição de, 10, 81

distância interplanar, 17

rede hexagonal 2D, 17

distribuição de tamanho de poros, 21

espectro de emissão, 6

Eudragit $^{\circledR}, 45$

Evonik, 45

fármacos

incorporação, 32

liberação, 33

fator de estrutura, 17

fator de forma, 82

fontes de raios $\mathrm{X}$

síncrotron, 7

tubo, 5 função de correlação, 11

função distribuição de distâncias, 12

Invariante, 12

isoterma de adsorção, 37

isoterma de adsorção

BET, 19

linear

ajuste, 66, 68

LNLS, 36

materiais porosos

MCM-41, 1

SBA-15, 2

materiais porosos

aplicações, 2

classificação da IUPAC, 20

classificação da IUPAC, 1

SBA-15, 1, 15, 17, 21, 24, 30

síntese, 30

Miller

Índices de, 16

parâmetro de rede, 16

parâmetros de ajuste, 29

Patterson

espaço de, 10

função de, 10, 11

PBS

composição, 32

Pluronic P123, 2

preparação de amostras, 33

Problema da fase, 82 
síncrotron, 36

surfactante, 1

P123, 30

TEOS, 2

Thomson

espalhamento, 78

fórmula de, 80

vetor de onda, 8 